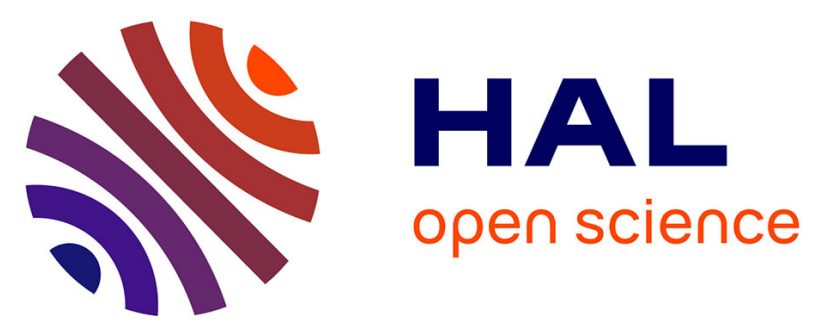

\title{
Une occupation de la fin du Dernier Maximum Glaciaire dans les Pyrénées: le Magdalénien inférieur de la grotte des Scilles (Lespugue, Haute-Garonne)
}

Mathieu Langlais, Jean-Marc Pétillon, Sophie A. de Beaune, Pierre Cattelain, François-Xavier Chauvière, Claire Letourneux, Carolyn Szmidt, Claire Bellier, Roelf Beukens, Francine David

\section{To cite this version:}

Mathieu Langlais, Jean-Marc Pétillon, Sophie A. de Beaune, Pierre Cattelain, François-Xavier Chauvière, et al.. Une occupation de la fin du Dernier Maximum Glaciaire dans les Pyrénées: le Magdalénien inférieur de la grotte des Scilles (Lespugue, Haute-Garonne). Bulletin de la Société préhistorique française, 2010, 107 (1), pp.5-51. halshs-00462077

\section{HAL Id: halshs-00462077 \\ https://shs.hal.science/halshs-00462077}

Submitted on 1 Jan 2013

HAL is a multi-disciplinary open access archive for the deposit and dissemination of scientific research documents, whether they are published or not. The documents may come from teaching and research institutions in France or abroad, or from public or private research centers.
L'archive ouverte pluridisciplinaire HAL, est destinée au dépôt et à la diffusion de documents scientifiques de niveau recherche, publiés ou non, émanant des établissements d'enseignement et de recherche français ou étrangers, des laboratoires publics ou privés. 
Mathieu LANGLAIS, Jean-Marc PÉTILLON, Sophie A. de BEAUNE,

Pierre CATTELAIN, François-Xavier CHAUVIÈRE,

Claire LETOURNEUX, Carolyn SZMIDT, Claire BELLIER, Roelf BEUKENS et Francine DAVID
Une occupation de la fin du Dernier Maximum glaciaire dans les Pyrénées : le Magdalénien inférieur de la grotte des Scilles (Lespugue, Haute-Garonne)

\begin{abstract}
Résumé
Les fouilles menées par R. et S. de Saint-Périer dans les années 1920 à la grotte des Scilles (Lespugue, Haute-Garonne) ont livré un ensemble de vestiges attribués au Magdalénien. L'étude de cette collection ancienne offre désormais la possibilité de préciser cette caractérisation à la lumière de travaux récents sur cette période. La présentation des différentes catégories de vestiges (industries lithique et osseuse, faune, parure, art mobilier et lampe) permet d'appréhender l'ensemble des registres d'activités documentés sur le site. En particulier, cet article présente les éléments typotechnologiques qui fournissent des arguments pour rattacher l'occupation de cette cavité au Magdalénien inférieur. Une date ${ }^{14} \mathrm{C}$ par SMA situe cette période autour de 16000 BP (19400 cal. BP) à la grotte des Scilles. La mise en évidence de ce premier jalon pyrénéen conduit ensuite les auteurs à discuter du peuplement magdalénien à la fin du Dernier Maximum glaciaire dans le Sud-Ouest de la France et le Nord de l'Espagne.
\end{abstract}

\begin{abstract}
The excavations by $R$. and $S$. de Saint-Périer at the Grotte des Scilles (Lespugue, Haute-Garonne, France) in 1923-1924 yielded archaeological material attributed to the Magdalenian. The re-examination of this old collection now allows a more precise characterization of it, in the light of recent research on this period. This article presents the different artefact types found (lithic and bone tools, faunal remains, personal ornaments, portable art items and one sandstone lamp) in order to consider all activities documented on the site. Particular attention is given to typological and technological data, the analyses of which point to a Lower Magdalenian chronological attribution. An SMA $14 C$ date shows that occupation of the Grotte des Scilles took place around 16000 BP (19400 cal. BP). The identification, for the first time, of a Lower Magdalenian presence in the Pyrenees raises new questions concerning Magdalenian occupation at the end of the Last Glacial Maximum in southwestern France and northern Spain.
\end{abstract}




\section{INTRODUCTION}

Le Magdalénien du versant nord des Pyrénées a été rendu célèbre par ses nombreuses grottes ornées et son industrie osseuse riche et variée. La genèse de cette culture paléolithique florissante reste cependant encore problématique. D'après les dates ${ }^{14} \mathrm{C}$ disponibles, l'émergence du Magdalénien moyen pyrénéen ne semble pas se placer avant le milieu du XV millénaire BP (Clottes, 1989), soit aux environs de 17500 cal. BP. Avant cela, dans la zone pyrénéenne, le Badegoulien serait présent à Enlène (Clottes, ibid.) et dans les Pyrénées occidentales (Merlet, 2005), mais il demeure mal connu et dépourvu de datations absolues. Quant au Solutréen, attesté dans une dizaine de gisements, les rares dates ${ }^{14} \mathrm{C}$ disponibles ne permettent pas de le faire perdurer plus tard que $18000 \mathrm{BP}$ environ (Foucher, 2007), soit vers 21000 cal. BP. Cette chronologie lacunaire laisse subsister un hiatus considérable - déjà souligné par J. Clottes (ibid.) - qui concerne en particulier les millénaires précédant immédiatement le début du Magdalénien moyen pyrénéen.

C'est dans ce contexte que nous avons entrepris le réexamen des vestiges de la couche $\mathrm{B}$ de la grotte des Scilles à Lespugue (Haute-Garonne). Un premier diagnostic de l'industrie lithique de cette couche avait en effet montré de nettes ressemblances avec plusieurs autres ensembles attribués à un Magdalénien inférieur stricto sensu, présents en France et dans le Nord de l'Espagne, datés de 17000 à $15000 \mathrm{BP}$ (soit autour de 20000-18000 cal. BP), mais jusqu'ici inconnus dans les Pyrénées (cf. infra). Ce premier indice nous a incités à effectuer une nouvelle étude collective et pluridisciplinaire de la totalité du matériel archéologique de cette couche, soit 740 vestiges (520 silex taillés, 3 autres pièces lithiques travaillées, 125 éléments de faune et 102 pièces d'industrie osseuse) conservés pour l'essentiel au musée d'Archéologie nationale (MAN) de Saint-Germain-en-Laye. Ce réexamen, qui n'avait jamais été entrepris depuis la publication princeps de Saint-Périer (1926) ${ }^{1}$, intégrait également un projet de datation radiocarbone.

Notre étude avait trois objectifs. Il s'agissait tout d'abord de vérifier l'attribution de la couche B de la grotte des Scilles au Magdalénien inférieur. Dans un deuxième temps, nous avons voulu documenter l'occupation de la couche B dans chacun de ses aspects : technotypologies lithique et osseuse, activités cynégétiques, activités symboliques. Enfin, les résultats obtenus ont permis de replacer le gisement dans son contexte régional et macrorégional.

\section{LE SITE}

\section{Situation et description}

Vingt-cinq kilomètres après avoir pris sa source dans le plateau de Lannemezan, la Save rencontre le massif calcaire de Lespugue-Montmaurin; elle y creuse une gorge étroite et encaissée, profonde d'une soixantaine de mètres, orientée sud-ouest/nord-est et débouchant abruptement sur une large vallée. La grotte des Scilles fait partie d'un ensemble de cavités de faible développement qui s'ouvrent sur les rives de cette gorge, en particulier sur la rive droite. Pour le secteur, il s'agit de l'occupation paléolithique située la plus en amont des gorges, approximativement à $750 \mathrm{~m}$ au sud-ouest des grottes des Rideaux et des Bœufs et à $1500 \mathrm{~m} \mathrm{du}$ débouché sur la vallée (fig. 1). D'accès facile, elle se situe à quelques mètres seulement au-dessus du niveau actuel de la Save. Peu profonde et largement ouverte, elle affecte la forme d' " une petite salle demi-circulaire qui mesure $5 \mathrm{~m}$ de largeur extérieure, sur une profondeur maximum de $4 \mathrm{~m}$; à l'intérieur, un prolongement

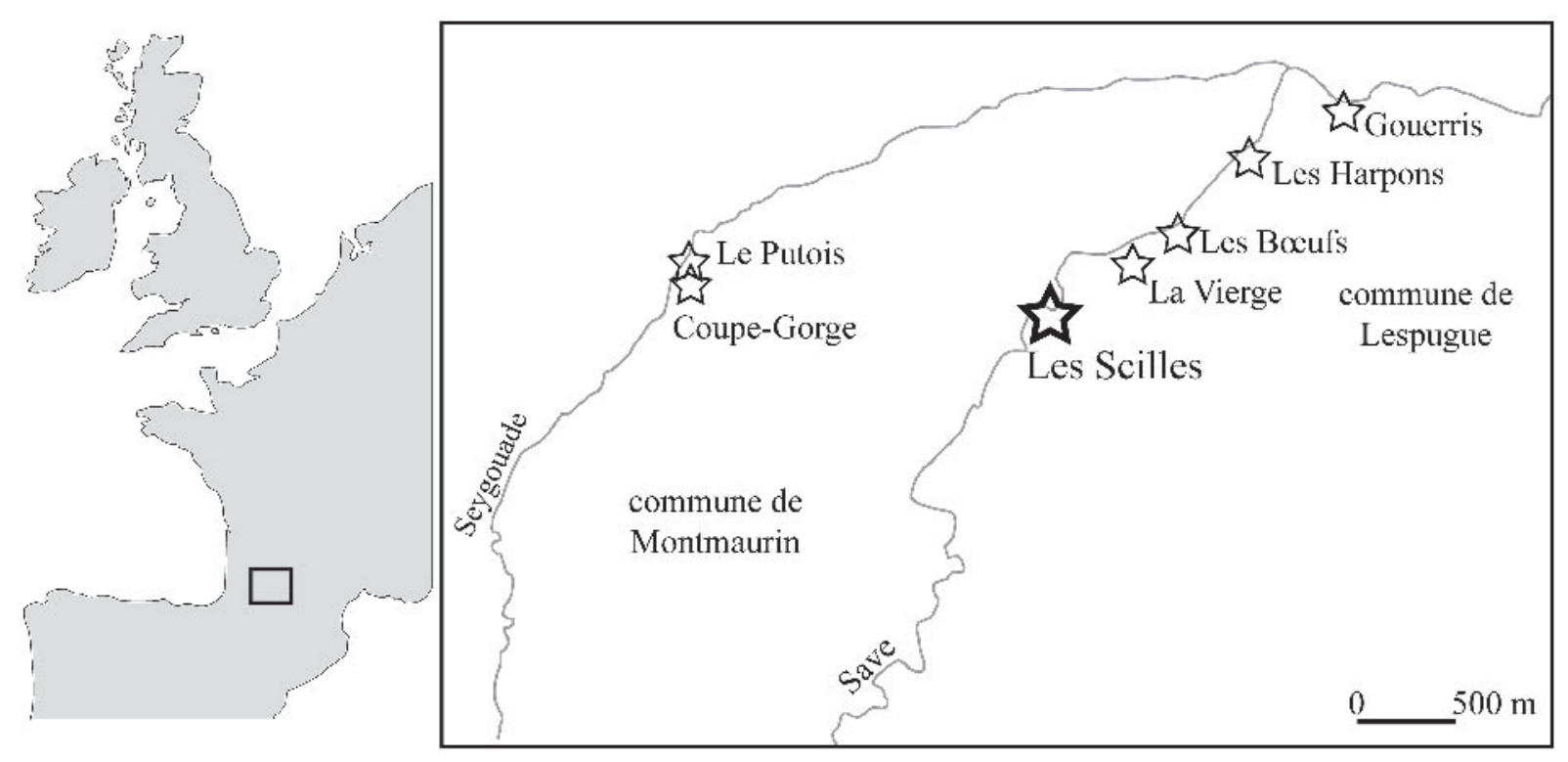

Fig. 1 - Localisation des sites attribués au Magdalénien dans les vallées de la Save et de la Seygouade (fond de carte d'après Simonnet, 1976, fig. 46, p. 118 ; DAO : M. L.). 


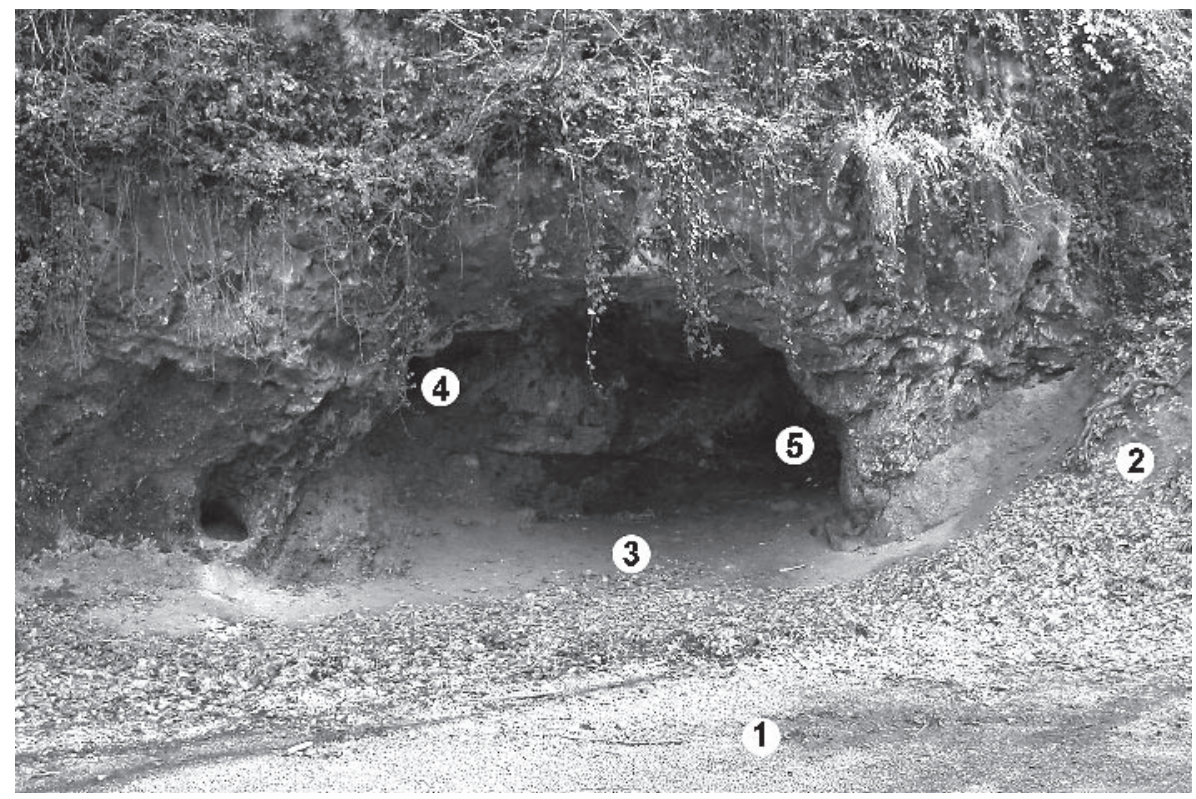

Fig. 2 - La grotte des Scilles en avril 2008. 1 : route goudronnée; $2:$ talus ; 3 : remblai (hauteur approximative de la couche B); 4 : entrée de la cheminée vers la salle supérieure; 5 : entrée du diverticule. Sauf mention contraire, les clichés sont de J.-M. P.

de la cavité rocheuse donne naissance à un diverticule qui s'étend [vers la droite sur] environ 3,5 m. À gauche, une cheminée donne accès, à $2 \mathrm{~m}$ de hauteur, à une salle supérieure, dépourvue de sol, [...] au plafond de laquelle une fissure indique une communication avec le plateau sus-jacent» (Saint-Périer, 1926, p. 15).

\section{Historique des fouilles}

La grotte des Scilles fut découverte par le comte René et la comtesse Suzanne de Saint-Périer dans le cadre des fouilles et prospections actives qu'ils menèrent dans les gorges de la Save à partir de 1911 : «Presque entièrement comblée avant nos fouilles, cette grotte n'était connue à Lespugue que d'un chasseur de renards qui s'était glissé à l'intérieur pour y tendre ses pièges. Nous avons donné à ce gisement le nom de grotte des Scilles à cause des nombreux Scilla liliohyacinthus L. qui croissaient près de son ouverture» (Saint-Périer, ibid.). La grotte fut intégralement fouillée en 1923-1924 et les résultats publiés en 1926 dans L'Anthropologie. Comme l'ensemble de la collection Saint-Périer, le matériel fut ensuite conservé au château de Morigny (Essonne), avant de rejoindre le MAN au début des années 1980, après le décès de Suzanne de Saint-Périer, veuve du comte. Une petite partie de la collection est cependant conservée dans d'autres musées : 15 pièces de la grotte des Scilles se trouvent ainsi au musée de Saint-Gaudens (Allard et Jarry, 1993) et 42 autres, jusqu'ici inédites, au musée de Montmaurin.

À notre connaissance, après les fouilles Saint-Périer, le site ne fit plus l'objet d'aucune opération archéologique et fut en partie remblayé à une date indéterminée : le niveau du sol se trouve aujourd'hui approximativement à la hauteur de la couche archéologique B. Ces travaux de comblement sont peut-être liés à l'élargissement d'une route qui passe aujourd'hui à moins de deux mètres devant le surplomb (fig. 2).

\section{Stratigraphie}

Le remplissage sédimentaire de la cavité s'étendait au maximum sur 5 à $6 \mathrm{~m}$ au-delà du surplomb rocheux, formant un talus épais d'environ $4 \mathrm{~m}$ (fig. 3). La description stratigraphique de Saint-Périer, la seule dont nous disposions (ibid., p. 17), distingue de la base au sommet les ensembles suivants :

- couche d'éboulis. Un niveau de $90 \mathrm{~cm}$ d'épaisseur, constitué «d'éboulis de la voûte», reposait directement sur le sol rocheux; il n'a fourni à Saint-Périer aucun vestige d'occupation humaine;

- couche sableuse. Il s'agit d'un «niveau de sable grossier à petits éléments roulés, mélangés d'éléments plus volumineux dont les arêtes sont émoussées ». Épaisse de 90 à $100 \mathrm{~cm}$, cette couche archéologiquement stérile est interprétée par R. de Saint-Périer comme un dépôt de la Save;

- couche B. Couche noire, épaisse de 35 à $40 \mathrm{~cm}$, qui «s'insinuait dans toutes les anfractuosités de la roche» et s'étendait jusqu'à $2 \mathrm{~m}$ en avant du surplomb;

- couche argileuse. Rouge, épaisse de 120 à 150 cm, elle est décrite comme homogène, bien que «mêlée de quelques galets de quartzite altéré » et présentant plusieurs poches de graviers à sa base. Selon SaintPérier, cette couche se serait déposée par ruissellement depuis le plateau, via la cheminée, la salle supérieure et la fissure mentionnées plus haut. À l'appui de cette idée, il note que les «galets de 


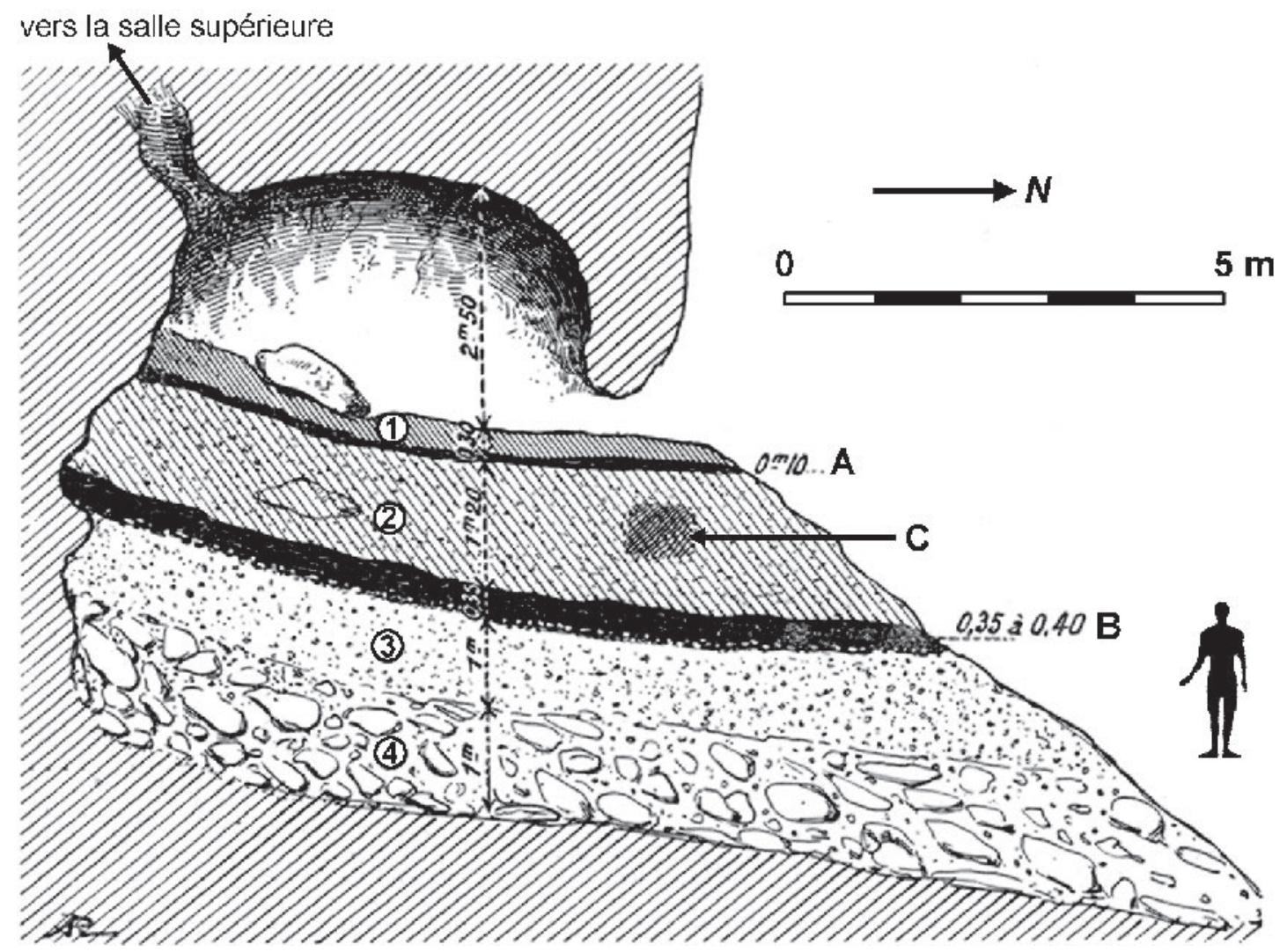

Fig. 3 - Coupe stratigraphique de la grotte des Scilles. 1 : terre végétale ; 2 : argile rouge; 3 : sable; 4 : éboulis. A : «foyer archéologique» supérieur; B : «foyer archéologique» inférieur ; C : structure de combustion ? D’après Saint-Périer, 1926, modifié (DAO : F.-X. C. et J.-M. P.).

quartzite altéré» présents dans la couche sont «abondants sur les plateaux supérieurs » (ibid., p. 15). Cette couche est archéologiquement stérile, si l'on excepte la présence d'une structure de combustion particulière (cf. ci-dessous);

- couche A. Couche noire, de 8 à $10 \mathrm{~cm}$ d'épaisseur, s'étendant sur toute la largeur de la grotte et jusqu'à $1 \mathrm{~m}$ au-delà du surplomb;

- terre végétale. 20 à $30 \mathrm{~cm}$ d'épaisseur.

\section{Les ensembles archéologiques}

\section{La couche B}

D'après les indications fournies par Saint-Périer, on peut estimer que cette couche a été fouillée sur une superficie de 20 à 30 mètres carrés. Elle a livré l'essentiel des vestiges archéologiques découverts dans la grotte. C'est sur le matériel de cette couche que porte la présente étude.

\section{Le «four polynésien»}

Au-dessus de la couche B, à l'intérieur de la «couche argileuse rouge», Saint-Périer mentionne la présence d'une «fosse mesurant $1 \mathrm{~m}$ de longueur sur $0,4 \mathrm{~m}$ de hauteur et 0,25 $\mathrm{m}$ de profondeur, creusée dans l'argile, limitée au-dessus et au-dessous par des pierres calcaires plates posées côte à côte. Au pourtour de cette cavité, l'argile était rubéfiée comme sous l'action d'un feu intense $[. .$.$] . La fosse contenait des fragments$ osseux [calcinés] [...] d'animaux de la taille du cheval et du bœuf. Ces os étaient plongés dans une terre de foyer très noire mélangée de charbons et de cendres; elle ne contenait aucun [...] objet d'industrie» (SaintPérier, 1926, p. 17-18). L'auteur interprète cette structure comme un «four polynésien». Il ne précise pas si les vestiges en ont été prélevés à la fouille; mais nous n'avons en tout cas noté ni pierres chauffées ni ossements calcinés dans le matériel de la grotte des Scilles conservé au MAN ou ailleurs. Ne disposant donc d'aucun argument pour rediscuter de la nature de cet aménagement, nous nous contenterons de noter la présence d'une probable structure de combustion en creux, au-dessus de la couche B, sans matériel archéologique diagnostique.

\section{La couche A}

Saint-Périer indique que cette couche a livré en tout et pour tout «quelques fragments d'os indéterminables, brisés, dont certains ont été rongés par des hyènes » (vestiges apparemment pas conservés dans les collections actuelles), six pièces d'industrie lithique et deux 
pièces d'industrie en bois de Cervidé. La pauvreté de cet ensemble nous a conduits à l'exclure de l'étude. Précisons seulement que l'examen des quelques pièces de la couche A ne montre pas de rupture nette avec le matériel de la couche $\mathrm{B}$ sous-jacente; les deux pièces en bois de Cervidé, notamment, sont similaires à certains outils particuliers provenant de la couche B (cf. ci-dessous).

\section{Sélection du matériel}

Si la plupart des pièces que nous avons étudiées portent bien la mention «Scilles» ou «grotte des Scilles », nous avons également trouvé, rangés dans les mêmes boîtes, un certain nombre de vestiges non marqués : une quinzaine de pièces d'industrie osseuse, une quarantaine de restes de faune et une centaine de pièces lithiques. Nous avons pris le parti de les considérer comme provenant du même site, surtout après avoir repéré certains d'entre eux parmi les pièces figurées par Saint-Périer en 1926.

Les vestiges de la grotte des Scilles ne portent généralement pas l'indication de leur provenance stratigraphique. Saint-Périer ayant toutefois figuré la quasitotalité des pièces de la couche A (Saint-Périer, 1926, fig. 3 : il ne manque qu'un seul outil lithique), nous avons pu les isoler et les exclure de l'étude. Nous avons considéré toutes les autres pièces comme provenant de la couche $\mathrm{B}$.

\section{L'INDUSTRIE LITHIQUE (M. L.)}

Les vestiges en silex provenant des fouilles SaintPérier se répartissent en 483 pièces déposées au MAN, 33 au musée municipal de Montmaurin et $4^{2}$ à celui de Saint-Gaudens, soit un total de $\mathbf{5 2 0}$ restes. D'emblée, nous pouvons remarquer une sous-représentation de la fraction fine et des déchets de taille et une surreprésentation des outils, sans doute à mettre au compte des méthodes de fouilles et de tri de l'époque.

\section{Les matières premières}

La cartographie des affleurements de silex dans les Pyrénées est aujourd'hui globalement bien connue grâce à plusieurs travaux (Barragué et al., 2001; Bon et al., 1996; Foucher, 2007; Lacombe, 1998 et 2005; Méroc, 1947; Normand, 1986; Séronie-Vivien et al., 2006; Simonnet, 1981, 1996, 1998, 1999 et 2007a). Nous nous appuierons également sur la gîtologie des silex du Haut-Agenais et du Périgord (Morala, 1984;

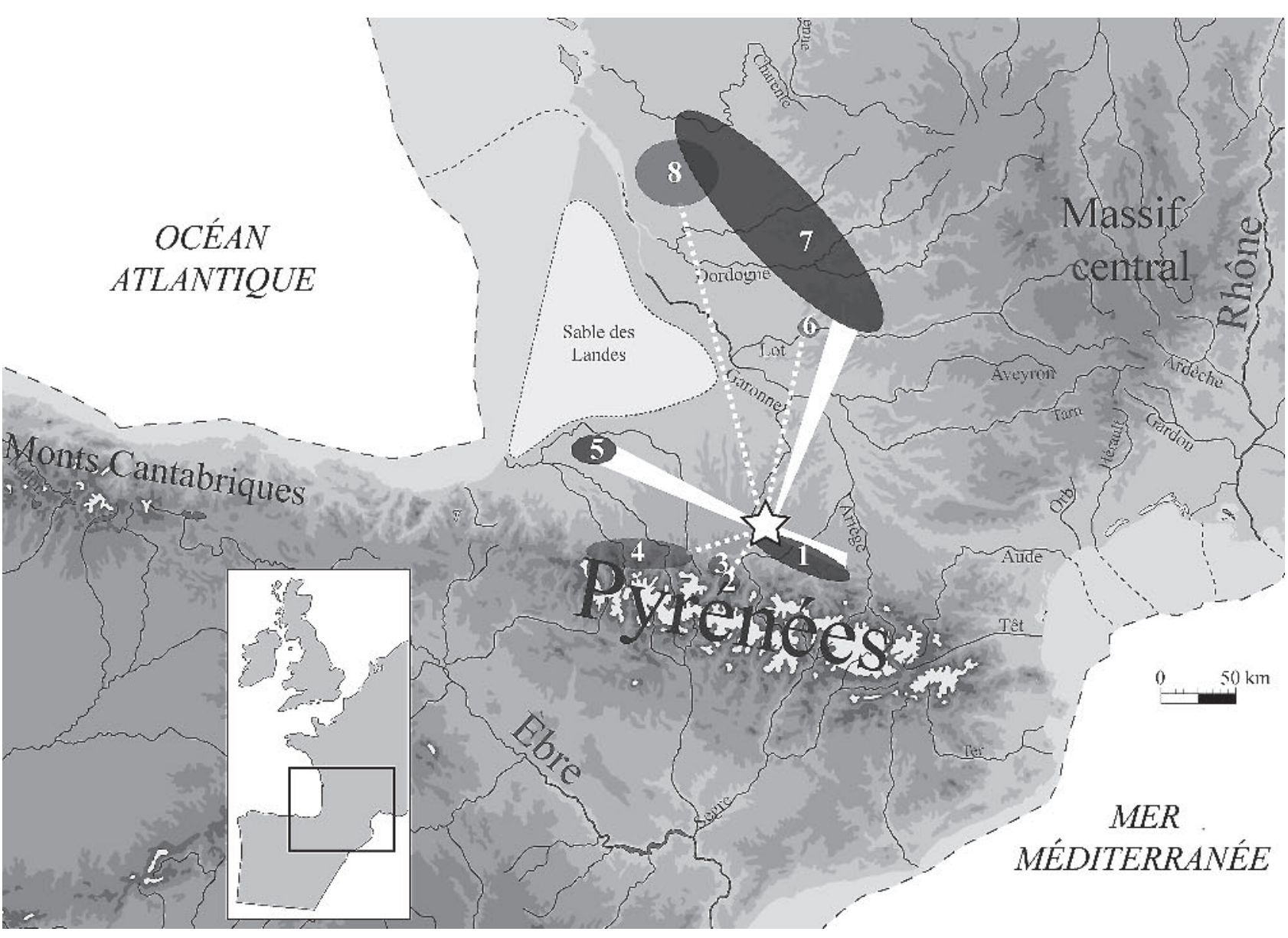

Fig. 4 - Localisation des sources de matières premières siliceuses exploitées aux Scilles. 1 : pré-Pyrénées; 2 : Paillon; 3 : Montsaunès; 4 : Flysch; 5 : Chalosse-gîtes d'Audignon; 6 : Fumélois; 7 : Sénonien gris-noir; 8 : «grain de mil». 
Séronie-Vivien et Séronie-Vivien, 1987; Turq, 2000), ainsi que de Saintonge (Simonnet, 2007b). En attendant qu'une étude archéopétrographique d'ensemble soit réalisée, nous présentons ici les premiers résultats. $\mathrm{La}$ grotte des Scilles se situe à proximité immédiate d'affleurements du silex tertiaire «bleu» des Petites Pyrénées (Simonnet, 1999) (fig. 4). Ce matériau est bien représenté à la fois au sein des outils, des armatures et des nucléus. Parmi les autres silex tertiaires, nous avons également noté la présence de variétés marron et grise dont la provenance est indéterminée. Au sein des silex marins déterminés, deux composantes principales se dégagent : des silex maastrichtiens de Chalosse - gîtes d'Audignon - et sénoniens du Périgord sont documentés par des outils et des armatures, mais également par quelques indices d'une importation de volumes à débiter. D'autres matériaux sont représentés sous la forme de quelques pièces : il s'agit du type «grain de mil» de Saintonge, du turonien type «fumélois » du Haut-Agenais, du flysch de MongaillardHibarette, du maastrichtien de Montsaunès et du Paillon. Le reste des silex marins, dont une variété jaspée, demeure de provenance indéterminée.

En termes géographiques, la présence de silex de provenances locale $(0-5 \mathrm{~km})$ et lointaine $(>50 \mathrm{~km})$, préférés aux matériaux régionaux $(5-50 \mathrm{~km})$, implique différentes stratégies d'anticipation des besoins. Des volumes à débiter et des outils ont été importés depuis la Chalosse (fig. 4). D'autre part, le silex de type «grain de mil», représenté par une chute de burin, semble avoir été introduit sous forme d'outil. Au sein des outils et des armatures, on note un équilibre entre les silex tertiaires locaux et secondaires allochtones. Toutefois, la sous-représentation des déchets de taille, liée aux méthodes de fouilles, rend difficile d'appréhender l'économie des matières premières sur ce site et limite les interprétations quantitatives.

\section{Description des supports}

Différents types de supports ont pu être distingués (tabl. 1). Les 168 lamelles et microlamelles se répartissent en 68 chutes de burin, 61 armatures, 29 pièces brutes, 7 outils et 3 ébauches de lamelles à dos, soit un taux de transformation de $42 \%$. Il s'agit majoritairement de supports de plein débitage de section triangulaire à trapézoïdale. Les 147 lames correspondent à 137 outils et 10 supports bruts, soit un taux de transformation exceptionnellement élevé de 93,2\% (tri à la fouille?). Au sein des 110 éclats, nous avons distingué, d'une part des déchets de débitages laminaire et lamellaire, et d'autre part des produits de première intention.

\begin{tabular}{|l|r|r|}
\hline \multicolumn{1}{|c|}{ Supports } & \multicolumn{1}{c|}{ Total } & \multicolumn{1}{c|}{$\%$} \\
\hline Lamelle & 168 & 32,31 \\
\hline Lame & 147 & 28,27 \\
\hline Éclat & 69 & 13,27 \\
\hline Fragment & 57 & 10,96 \\
\hline Éclat laminaire & 31 & 5,96 \\
\hline Rognon & 17 & 3,27 \\
\hline Fragment diaclasique & 16 & 3,08 \\
\hline Éclat lamellaire & 10 & 1,92 \\
\hline Esquille & 5 & 0,96 \\
\hline Total & $\mathbf{5 2 0}$ & 100 \\
\hline
\end{tabular}

Tabl. 1 - Les supports en silex.

\begin{tabular}{|l|r|r|r|r|r|r|r|}
\hline \multicolumn{1}{|c|}{ Types/supports } & Lame & Lamelle & Fragment & Éclat & $\begin{array}{r}\text { Éclat } \\
\text { laminaire }\end{array}$ & Total & \multicolumn{1}{c|}{$\%$} \\
\hline Burin et fgt. & 72 & 1 & 16 & 17 & 10 & $\mathbf{1 1 6}$ & 40,8 \\
\hline Grattoir et fgt. & 16 & & 8 & 1 & 1 & $\mathbf{2 6}$ & 9,2 \\
\hline Lame retouchée & 18 & & & & 2 & $\mathbf{2 0}$ & 7 \\
\hline Pièce esquillée et fgt. & 2 & & 8 & 2 & & $\mathbf{1 2}$ & 4,2 \\
\hline Microperçoir & & 6 & 1 & 1 & & $\mathbf{8}$ & 2,8 \\
\hline Lame tronquée & 7 & & & & & $\mathbf{7}$ & 2,5 \\
\hline Couteau & 3 & & & & 3 & $\mathbf{6}$ & 2,1 \\
\hline Grattoir-burin & 9 & & & & & $\mathbf{9}$ & 3,2 \\
\hline Perçoir & 1 & & 2 & 1 & & $\mathbf{4}$ & 1,4 \\
\hline Éclat retouché & & & 2 & 1 & & $\mathbf{3}$ & 1,1 \\
\hline Lame appointée & 3 & & & & & $\mathbf{3}$ & 1,1 \\
\hline Bec & & & 1 & 1 & & $\mathbf{2}$ & 0,7 \\
\hline Burin-bec & 3 & & & & $\mathbf{3}$ & 1,1 \\
\hline Burin-lame tronquée & 2 & & & & & $\mathbf{2}$ & 0,7 \\
\hline Grattoir-bec & 1 & & & & & $\mathbf{1}$ & 0,4 \\
\hline Pièce tronquée & & & 1 & & & $\mathbf{1}$ & 0,4 \\
\hline \multicolumn{1}{|c|}{ Total outils } & $\mathbf{1 3 7}$ & $\mathbf{7}$ & $\mathbf{3 9}$ & $\mathbf{2 4}$ & $\mathbf{1 6}$ & $\mathbf{2 2 3}$ & $\mathbf{7 8 , 5}$ \\
\hline \multicolumn{1}{|c|}{$\%$} & 61,4 & 3,1 & 17,5 & 10,8 & 7,2 & 100 & \\
\hline LD marginal & & 57 & & & & $\mathbf{5 7}$ & 20,1 \\
\hline LD simple & & 4 & & & & $\mathbf{4}$ & 1,4 \\
\hline \multicolumn{1}{|c|}{ Total armatures } & $\mathbf{0}$ & $\mathbf{6 1}$ & $\mathbf{0}$ & $\mathbf{0}$ & $\mathbf{0}$ & $\mathbf{6 1}$ & $\mathbf{2 1 , 5}$ \\
\hline Total équipements & $\mathbf{1 3 7}$ & $\mathbf{6 8}$ & $\mathbf{3 9}$ & $\mathbf{2 4}$ & $\mathbf{1 6}$ & $\mathbf{2 8 4}$ & $\mathbf{1 0 0}$ \\
\hline
\end{tabular}

Tabl. 2 - L'équipement lithique et les supports d'outils (fgt : fragment, LD : lamelle à dos, en grisé : outils d'extrémité). 

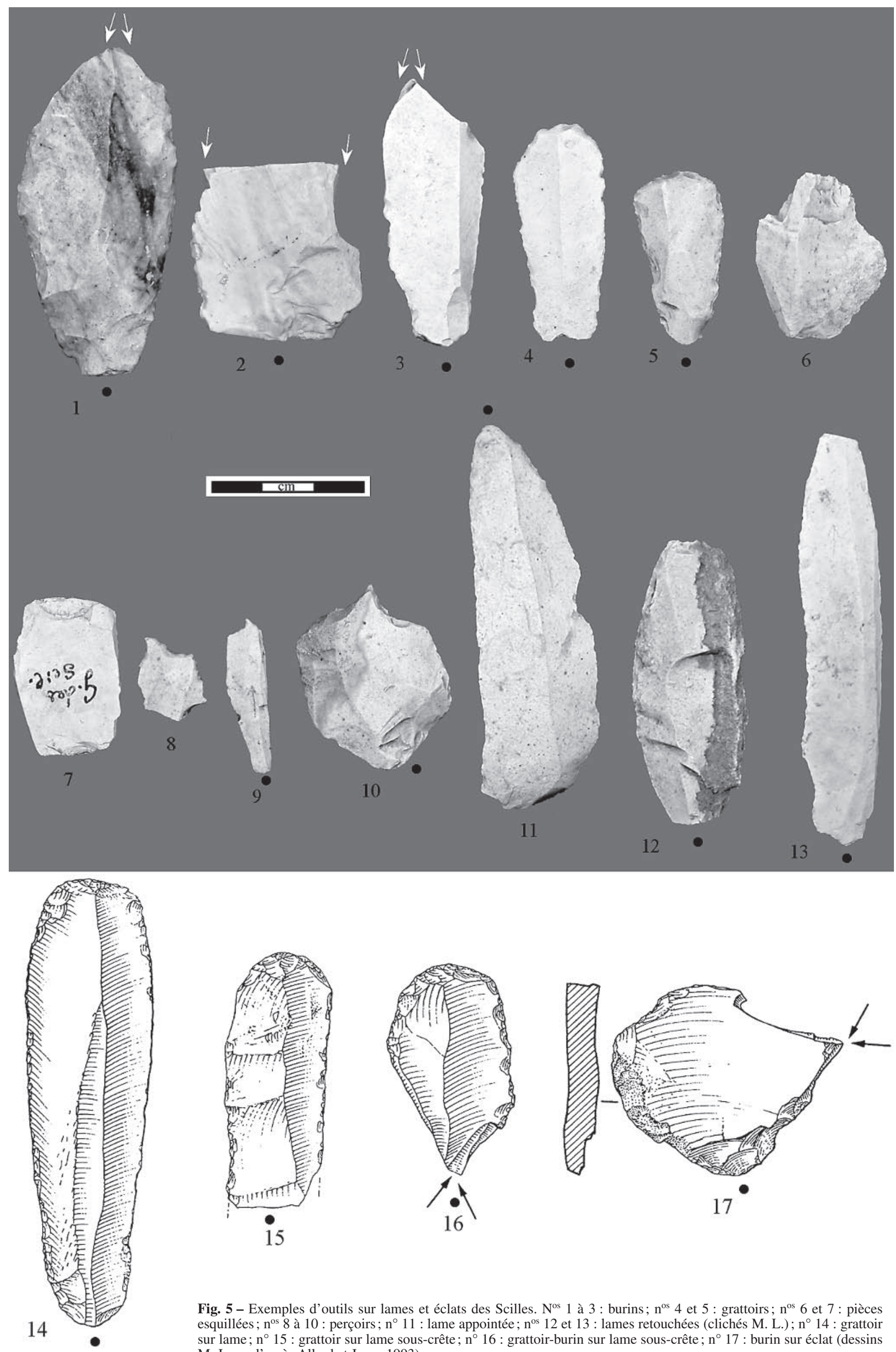

Fig. 5 - Exemples d'outils sur lames et éclats des Scilles. $N^{\text {os }} 1$ à $3:$ burins; $\mathrm{n}^{\text {os }} 4$ et $5:$ grattoirs; $\mathrm{n}^{\text {os }} 6$ et $7:$ pièces esquillées; $\mathrm{n}^{\text {os }} 8$ à 10 : perçoirs; $\mathrm{n}^{\circ} 11:$ lame appointée; $\mathrm{n}^{\text {os }} 12$ et $13:$ lames retouchées (clichés M. L.); $\mathrm{n}^{\circ} 14$ : grattoir sur lame; $\mathrm{n}^{\circ} 15$ : grattoir sur lame sous-crête; $\mathrm{n}^{\circ} 16$ : grattoir-burin sur lame sous-crête; $\mathrm{n}^{\circ} 17$ : burin sur éclat (dessins M. Jarry, d'après Allard et Jarry, 1993). 
Ces derniers correspondent à des supports épais exploités comme nucléus à lamelles et microlamelles $(\mathrm{N}=29)$. L'autre composante est constituée d'éclats, d'éclats laminaires et lamellaires, de deux tablettes et de quatre éclats corticaux de mise en forme. Ces pièces comprennent 40 outils, 37 pièces brutes et 4 nucléus à lamelles. Parmi les 73 fragments (supports non laminaires sans talon), on peut remarquer la présence de 16 fragments diaclasiques en silex tertiaire local, transformés en nucléus. Pour le reste, il s'agit de 39 outils, 5 nucléus et 13 pièces brutes. Les autres types de supports sont des rognons exploités en nucléus $(\mathrm{N}=15)$ ou en percuteur $(\mathrm{N}=2)$ et (seulement) 5 esquilles.

\section{L'outillage domestique et les débitages laminaires}

Les outils $(\mathrm{N}=223)$ sont réalisés sur lame $(61,4 \%)$, sur des supports allongés (fragments, éclats laminaires, lamelles) ou sur des éclats (tabl. 2). Du point de vue typologique, les outils «d'extrémité » dominent largement $(87 \%)$ avec, pour une grande part, différents sous-types de burin (fig. 5) : 75 dièdres (dont 2 fragments et 7 doubles), 19 sur cassure (dont deux fragments), 19 sur troncature (dont 3 doubles) et 3 multiples mixtes. Certains burins $(\mathrm{N}=5)$ ont été utilisés en percussion posée (esquillement de l'extrémité opposée au biseau). Le second type d'outil correspond au groupe des grattoirs, sur lames retouchées ou sur des fragments. Parmi les outils multiples, on peut également noter la présence de grattoirs-burins, de burinsbecs, de grattoirs-becs et de burins-lames tronquées (fig. 5). Plusieurs pièces esquillées, des microperçoirs (sur lamelles), perçoirs et becs, lames appointées ou tronquées complètent cet ensemble (tabl. 2).

Concernant les outils «latéraux» (13\%), plusieurs lames et éclats laminaires à retouches latérales, totales ou partielles et plus ou moins profondes, sont associés à quelques couteaux (lame à retouche marginale souvent discontinue) et à des éclats retouchés (fig. 5).

Les éclats transformés en outils proviennent de déchets des productions lamino-lamellaires et, sans doute, pour une autre part, des débitages d'éclats-supports de nucléus à lamelles. Ils présentent pour l'essentiel des talons lisses et montrent de nets indices d'une percussion à la pierre en retrait de la corniche. Les lames et lamelles (pour les microperçoirs) correspondent à des supports de première intention, issus de débitages autonomes.

L'examen des talons des lames (tabl. 3) permet de documenter deux types de préparation du plan de frappe : un facettage, permettant de surcreuser autour du point d'impact, ou une simple abrasion de la corniche. La sous-représentation des déchets techniques, en partie liée à un tri lors de la fouille, ne permet pas de caractériser un schéma opératoire laminaire précis. On peut néanmoins distinguer une composante élaborée et un ensemble de supports allongés moins normés. Dans le premier cas, il s'agit d'un débitage de type «semi-tournant»; le cintrage latéral de la table est unipolaire et plus rarement bipolaire. L'entretien des convexités peut également s'opérer depuis des crêtes postérieures et antérieures, comme le montrent des

\begin{tabular}{|l|c|c|c|c|}
\hline \multicolumn{1}{|c|}{ Lames } & Brutes & $\begin{array}{c}\text { Outils } \\
\text { «d'extrémité » }\end{array}$ & $\begin{array}{c}\text { Outils } \\
\text { «latéraux » }\end{array}$ & Total \\
\hline Facetté & 1 & 11 & 7 & $\mathbf{1 9}$ \\
\hline Lisse abrasé & 2 & 13 & 3 & $\mathbf{1 8}$ \\
\hline Autres & & 3 & 2 & $\mathbf{5}$ \\
\hline Total & $\mathbf{3}$ & $\mathbf{2 7}$ & $\mathbf{1 2}$ & $\mathbf{4 2}$ \\
\hline Présence de lèvre & 2 & 18 & 5 & $\mathbf{2 5}$ \\
\hline
\end{tabular}

Tabl. 3 - Types de talons des lames brutes ou transformées en outils.

\begin{tabular}{|l|c|c|c|c|}
\hline \multicolumn{1}{|c|}{ Lames } & Brutes & $\begin{array}{c}\text { Outils } \\
\text { «d'extrémité » }\end{array}$ & $\begin{array}{c}\text { Outils } \\
\text { “latéraux » }\end{array}$ & Total \\
\hline Pierre & 2 & 4 & 3 & $\mathbf{9}$ \\
\hline Tendre & 1 & 7 & 1 & $\mathbf{9}$ \\
\hline Tendre organique & 2 & 20 & 8 & $\mathbf{3 0}$ \\
\hline \multicolumn{1}{|c|}{ Total } & $\mathbf{5}$ & $\mathbf{3 1}$ & $\mathbf{1 2}$ & $\mathbf{4 8}$ \\
\hline
\end{tabular}

Tabl. 4 - Types de percuteurs pour les lames brutes ou transformées en outils.

lames à néocrête $(\mathrm{N}=4)$ et des lames sous-crête $(\mathrm{N}=9)$. La régularité des nervures indique une bonne récurrence du débitage de supports normés, extraits au percuteur tendre organique (tabl. 4). Cette composante laminaire soignée est documentée en silex marins allochtones et en tertiaire local (plus rare). Des supports moins réguliers présentent des talons lisses et des stigmates d'une percussion minérale ou tendre indéterminée (tabl. 4). Une part importante de ces pièces correspond à des lames de second choix intégrées au débitage laminaire. Toutefois, l'hypothèse d'une production secondaire, moins investie techniquement, demeure envisageable. Ainsi, la présence d'un unique nucléus à lames en silex tertiaire local témoigne d'une faible préparation du volume pour certains débitages laminaires.

Les longueurs des lames et lamelles entières montrent un pic entre 20 et $30 \mathrm{~mm}$ correspondant aux lamelles à dos (cf. infra). La question de la sousreprésentation des pièces entre 10 et $20 \mathrm{~mm}$ demeure suspendue aux conditions de ramassage (absence de tamisage). Concernant les lames, le trop faible nombre de pièces entières (plus grandes autour de $90 \mathrm{~mm}$ ) et une forte transformation en outils «d'extrémité» rendent difficile d'envisager ou non un continuum lamino-lamellaire.

\section{Les microlithes et les productions lamellaires/microlamellaires}

Les lamelles à dos constituent le second objectif économique des débitages. Tandis que de rares lamelles à dos simples $(\mathrm{N}=4)$ témoignent d'une seconde composante marginale, l'essentiel des microlithes correspond à un morphotype spécifique. Il s'agit de supports lamellaires à microlamellaires de profil rectiligne à tors. Dans ce dernier cas, il s'agit d'une torsion dextrogyre, de type «contra-horaire» (Pelegrin et O'Farrell, 2005). Une même formule est appliquée pour la réalisation de ces pièces (fig. 6 et 7). Nous pouvons remarquer que la transformation modifie peu le support initial, luimême fortement prédéterminé. 
- le dos, systématiquement latéralisé sur le bord dextre, est réalisé selon une retouche directe marginale (fig. 6a). L'examen microscopique des bords abattus met en évidence l'emploi d'une pierre pour façonner ces dos, comme en témoignent des corniches et des gibbosités émoussées (J. Pelegrin, comm. pers.);

- le bord opposé au dos porte fréquemment un bordage proximal direct (fig. 6b) et mésial direct ou inverse (fig. 6c), permettant de conformer un tranchant

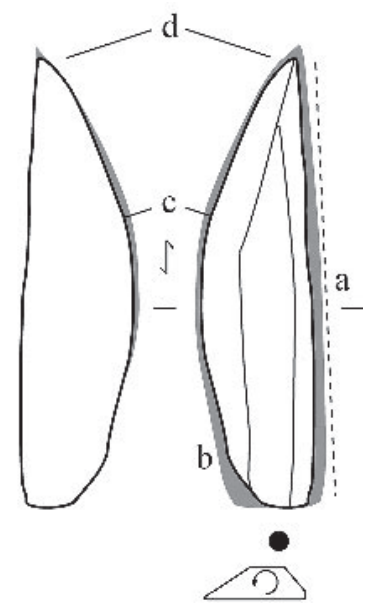

Fig. 6 - Schéma de fabrication des lamelles à dos marginal (en grisé : support initial). convexe. Certains exemplaires présentent un appointage de l'extrémité distale (fig. 6d).

Les pièces entières ou subentières (microcassure distale) montrent un pic des longueurs entre 20 et $30 \mathrm{~mm}$ (fig. 8). De plus, l'ensemble des lamelles à dos marginal présente un gabarit stable entre 5 et $7 \mathrm{~mm}$ de large pour $2 \mathrm{~mm}$ d'épaisseur (fig. 9). La présence de 3 microlamelles à dos marginal et l'examen des derniers négatifs réussis sur les nucléus témoignent d'un objectif microlamellaire. Ces éléments entiers, autour de 10-15 mm de long, et a fortiori les fragments n'ont pas été vus ou ramassés lors de la fouille. Ainsi, la forte standardisation des lamelles à dos marginal $(25 \times 6$ x $2 \mathrm{~mm}$ en moyenne) est à relativiser par le biais de la sélection de la part du fouilleur. La question est alors de savoir dans quelle mesure nous avons affaire à un morphotype (dos dextre, bord opposé convexe, appointage) produit selon une réduction «linéaire» des volumes ou dans une autre mesure, si lamelles et microlamelles correspondent à deux concepts opératoires distincts.

L'examen des talons des lamelles $(\mathrm{N}=59)$ montre l'exploitation d'un plan de frappe lisse dont la corniche est soigneusement abrasée. Quelques supports $(\mathrm{N}=8)$ possèdent des stigmates diagnostiques d'un percuteur tendre organique. On peut remarquer la présence de deux lamelles sous-crête (postérieure) et deux néocrêtes à pan revers (indice d'un débitage «sur tranche» d'éclat). Plusieurs pièces présentent une convergence
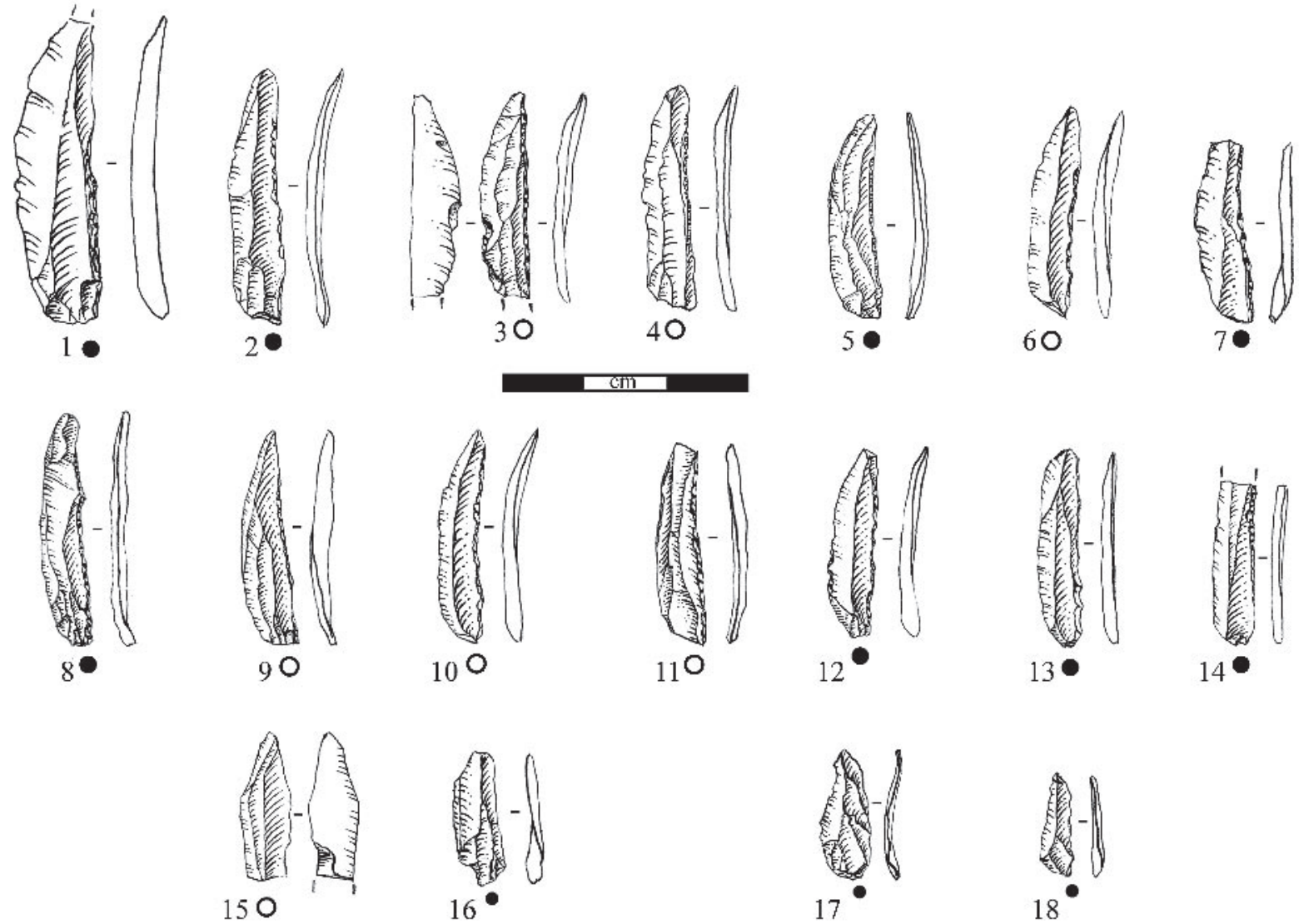

Fig. 7 - Exemples de lamelles à dos dextre marginal (dessins D. Molez). 


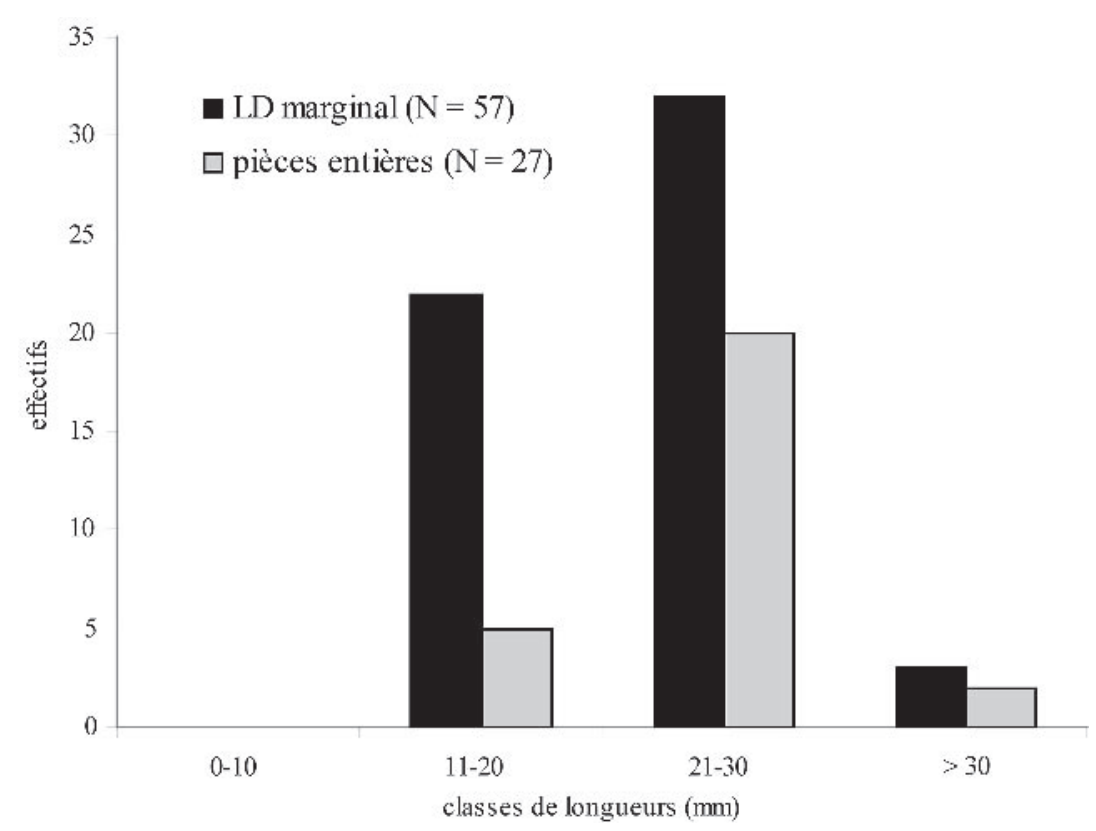

Fig. 8 - Histogramme des longueurs des lamelles et microlamelles à dos marginal entières et subentières.

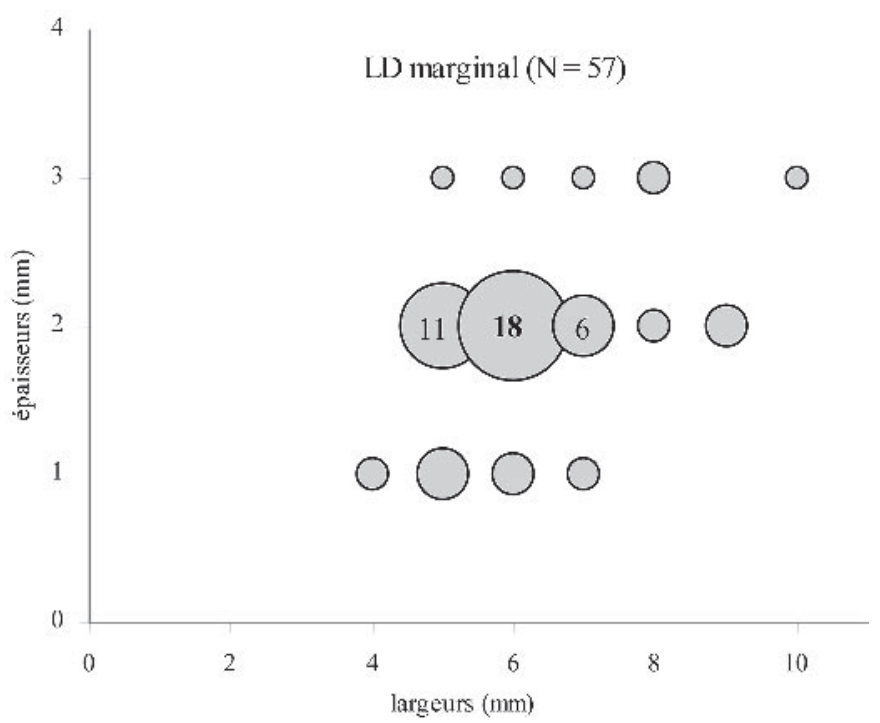

Fig. 9 - Gabarits des lamelles à dos marginal.

distale des nervures. Les débitages lamellaires, mis en œuvre sur place, sont documentés par des supports bruts et retouchés, des déchets techniques et surtout plusieurs nucléus $(\mathrm{N}=69)$ (fig. 10 à 12).

L'essentiel des nucléus sont réalisés sur éclats $(\mathrm{N}=33)$ et fragments $(\mathrm{N}=21)$, parmi lesquels on peut remarquer la présence d'une tablette de ravivage et de deux enlèvements de flanc provenant d'une production laminaire effectuée in situ en silex tertiaire et en Chalosse (fig. 10). À côté de quelques déchets de taille, $85 \%$ des éclat-nucléus proviennent d'un débitage unipolaire à la pierre de supports épais relativement normalisés. De nombreux fragments en silex local portent une surface de diaclase $(\mathrm{N}=16)$ qui a été mise à profit comme plan de frappe ou flanc du nucléus. Des rognons $(\mathrm{N}=15)$ ont également été importés.

L'analyse des 69 nucléus a permis de caractériser plusieurs modalités opératoires (tabl. 5). Près de la moitié correspondent à une modalité sur éclat épais, dans laquelle le plan de frappe (lisse abrasé) est installé sur la face inférieure du support et la surface microlamellaire exploite frontalement l'épaisseur de l'éclat. Ces pièces ont été considérées par le fouilleur comme des outils et comptabilisées comme "grattoirs pyramidaux, carénés et nucléiformes » (Saint-Périer, 1926, p. 23; Allard et Jarry, 1993, p. 69). Depuis quelques dizaines d'années (cf. Le Brun-Ricalens, 2005), leur réorientation technologique comme des nucléus à lamelles et microlamelles nous a conduit à proposer une terminologie plus neutre, fondée sur la localisation de la table (sur front) et son orientation (enlèvements directs, sur la face dorsale) (Ducasse et Langlais, 2007; Langlais, 2007a). Les nucléus «sur front dorsal» $(\mathrm{N}=33)$ ont produit des supports lamellaires et microlamellaires à partir d'une surface de débitage bien cintrée (fig. 11). Cette convexité est obtenue par des éclats unipolaires fronto-latéraux (à la jonction tableflanc) et des éclats lamellaires latéraux. En phase finale, on peut remarquer sur plusieurs pièces que le front microlamellaire est déjeté à droite par rapport à l'axe de l'éclat (vu depuis le plan de frappe). Si la plupart des nucléus sont abandonnés au stade microlamellaire, au moins six pièces montrent également un objectif de grandes lamelles.

Le second type de débitage lamellaire est mis en œuvre principalement sur des rognons et quelques éclats ou fragment diaclasiques. Il s'agit d'une production unipolaire dont la table est encadrée par des flancs qui convergent vers la base du nucléus. Cette 


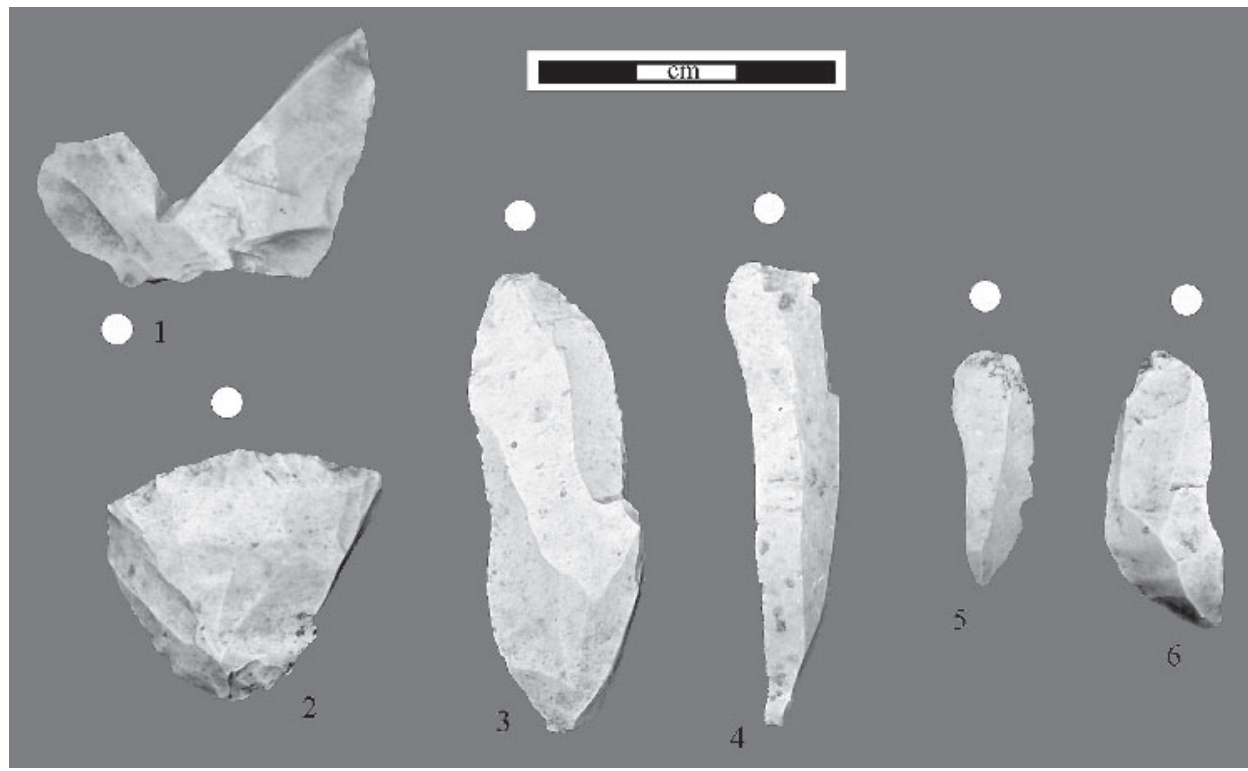

Fig. 10 - Exemples de déchets du débitage lamellaire. $\mathrm{N}^{\circ} 1:$ tablette $; \mathrm{n}^{\circ} 2$ : éclat fronto-latéral; $\mathrm{n}^{\text {os }} 3$ et 4 : éclats lamellaires; ${ }^{\text {os }} 5$ et 6 : éclats microlamellaires (clichés M. L.).

architecture pyramidale permet d'obtenir des supports naturellement pointus (fig. $12, \mathrm{n}^{\text {os }} 1$ et 2 ). L'entretien des convexités est effectué par des enlèvements latéraux outrepassants et parfois par l'installation d'une crête arrière. Ces nucléus unipolaires pyramidaux $(\mathrm{N}=16)$ produisent des lamelles de profil rectiligne à tors. Pour ces derniers, il s'agit de supports extraits à la jonction table-flanc gauche, «fuyant» en partie distale dans un sens contra-horaire. Les plans de frappe montrent des négatifs de ravivages frontaux à centripètes, qui témoignent de l'exploitation «enveloppante» du volume. Dans certains cas, un plan de frappe opposé est ouvert pour nettoyer des accidents (réfléchissements) survenus au centre de la table, notamment.

Les deux modalités suivantes possèdent des architectures «prismatiques » caractérisées par deux flancs parallèles à l'axe de débitage. Dans certains cas, la production demeure unipolaire $(\mathrm{N}=6)$, tandis que d'autres nucléus présentent deux plans de frappe «opposés-décalés » $(\mathrm{N}=5)$. Ces deux types de débitage sont mis en œuvre afin de réaliser des supports lamellaires de profil rectiligne à tors (surtout pour la modalité «opposé-décalé»).

D'autres modalités sont attestées sous la forme de quelques exemplaires (tabl. 5). Il s'agit de débitages «sur tranche» d'éclats, d'un nucléus «sur tranche» à préparation latérale (type encoche) et de deux éclats allongés exploités «sur front ventral déjeté » (Langlais, 2007a). Dans ce dernier cas (fig. 12, n 3), le plan de frappe est installé sur un méplat latéral de la face supérieure de l'éclat (bord gauche) et l'extrémité est exploitée dans l'épaisseur sur une table déjetée vers le bord droit (vue face supérieure). Enfin, deux nucléus «mixtes» associent sur un même volume deux modalités différentes avec une table installée «sur tranche» (fig. 12, $\mathrm{n}^{\circ} 4 \mathrm{a}$ ) opposée à une exploitation «sur front dorsal» (fig. 12, n 4b). Certains volumes présentent des négatifs à la fois de lamelles et de microlamelles, ce qui pose la question d'une production intégrée des deux types de supports. Toutefois, cette hypothèse demeure difficile à argumenter dans l'état des données. En termes de tendance et en gardant à l'esprit l'éventuel biais d'un tri à la fouille, nous distinguerons deux modalités principales :

- sur éclat, type «sur front dorsal», pour des microlamelles axiales (courbes à rectilignes) ou torses (percussion déjetée) et occasionnellement, des lamelles puis microlamelles;

- sur bloc, type enveloppant pyramidal ou prismatique pour des lamelles rectilignes à torses, se réduisant parfois en débitages microlamellaires.

En définitive, l'ensemble lithique de la grotte des Scilles témoigne de deux intentions économiques principales : des lames normalisées et soignées dévolues aux outils (surtout burins) et des lamelles-microlamelles transformées en pièces à dos particulières. Des éclats épais, produits de manière autonome (un seul nucléus à éclats) ou récupérés parmi les déchets du débitage laminaire, sont exploités comme nucléus à lamelles. Une part importante du débitage laminaire et lamellaire a nécessité une anticipation des besoins matérialisée par un apport de volumes de bonne aptitude depuis la Chalosse et le Périgord. Quelques pièces témoignent de relations (directes ou indirectes) avec la Saintonge et le Haut-Agenais. D'autre part, l'essentiel des productions microlamellaires est réalisée à partir de silex locaux. Au sein des microlithes, les lamelles et microlamelles à dos marginal constituent un morphotype original dans les Pyrénées. Plusieurs comparaisons macrorégionales permettront de discuter d'une attribution chronoculturelle au Magdalénien inférieur pour la série des Scilles (cf. infra). 


\section{L'INDUSTRIE \\ EN BOIS DE CERVIDÉ (J.-M. P.)}

L'industrie en bois de Cervidé de la couche B de la grotte des Scilles comprend $\mathbf{7 9}$ pièces (tabl. 6). Ce nombre tient compte des raccords entre pièces fragmentaires, raccords que nous avons systématiquement recherchés, prolongeant un travail entamé par Dominique Buisson au début des années 1990.

Pour la couche B, Saint-Périer mentionnait la présence de 78 baguettes et objets sur baguette en bois de Cervidé (Saint-Périer, 1926, p. 26 et 29). Notre série en comprend 68 , voire 72 si on ne tient pas compte des

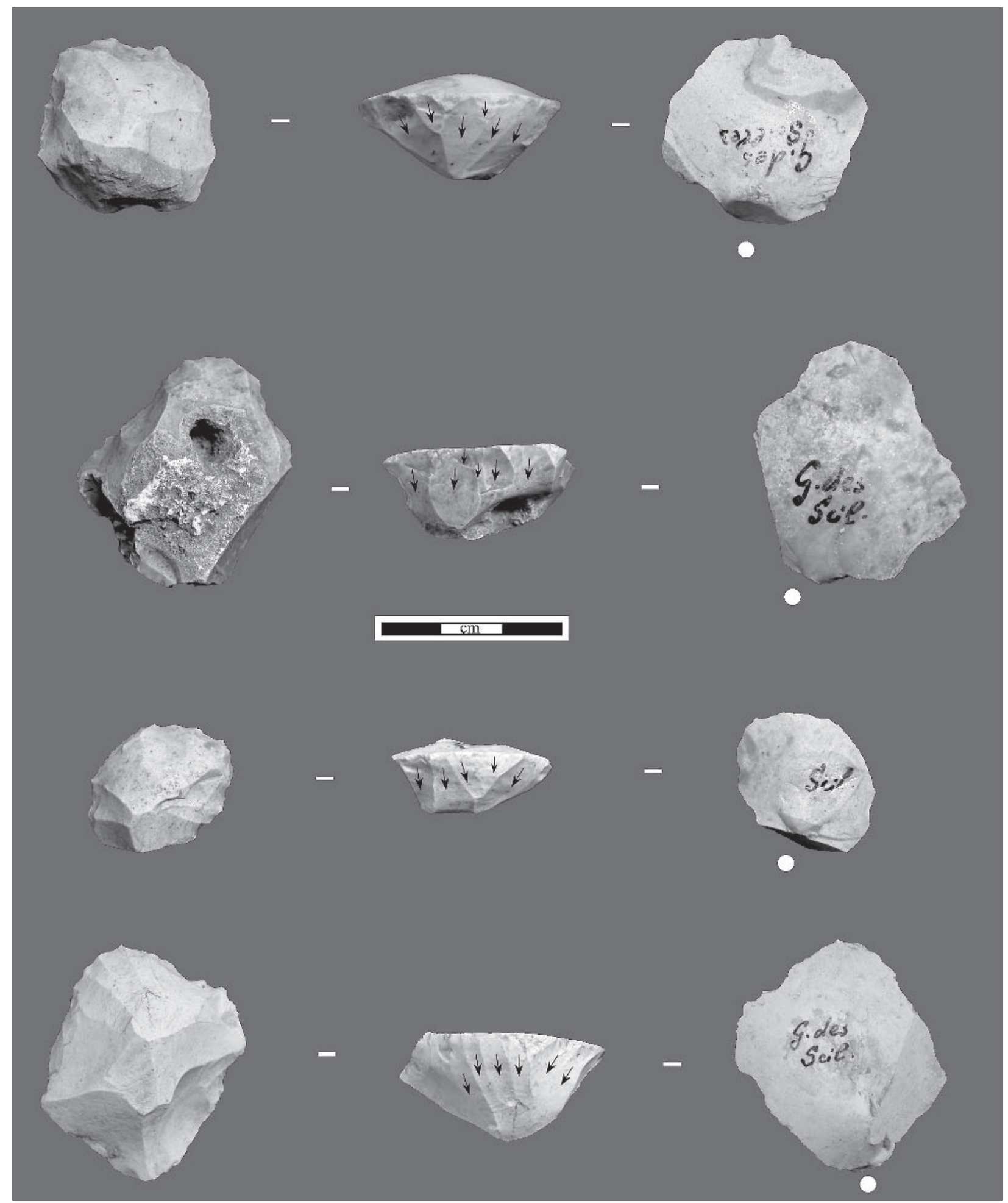

Fig. 11 - Exemples de nucléus à microlamelles de type «sur front dorsal» (cliché J.-M. P., DAO M. L.). 

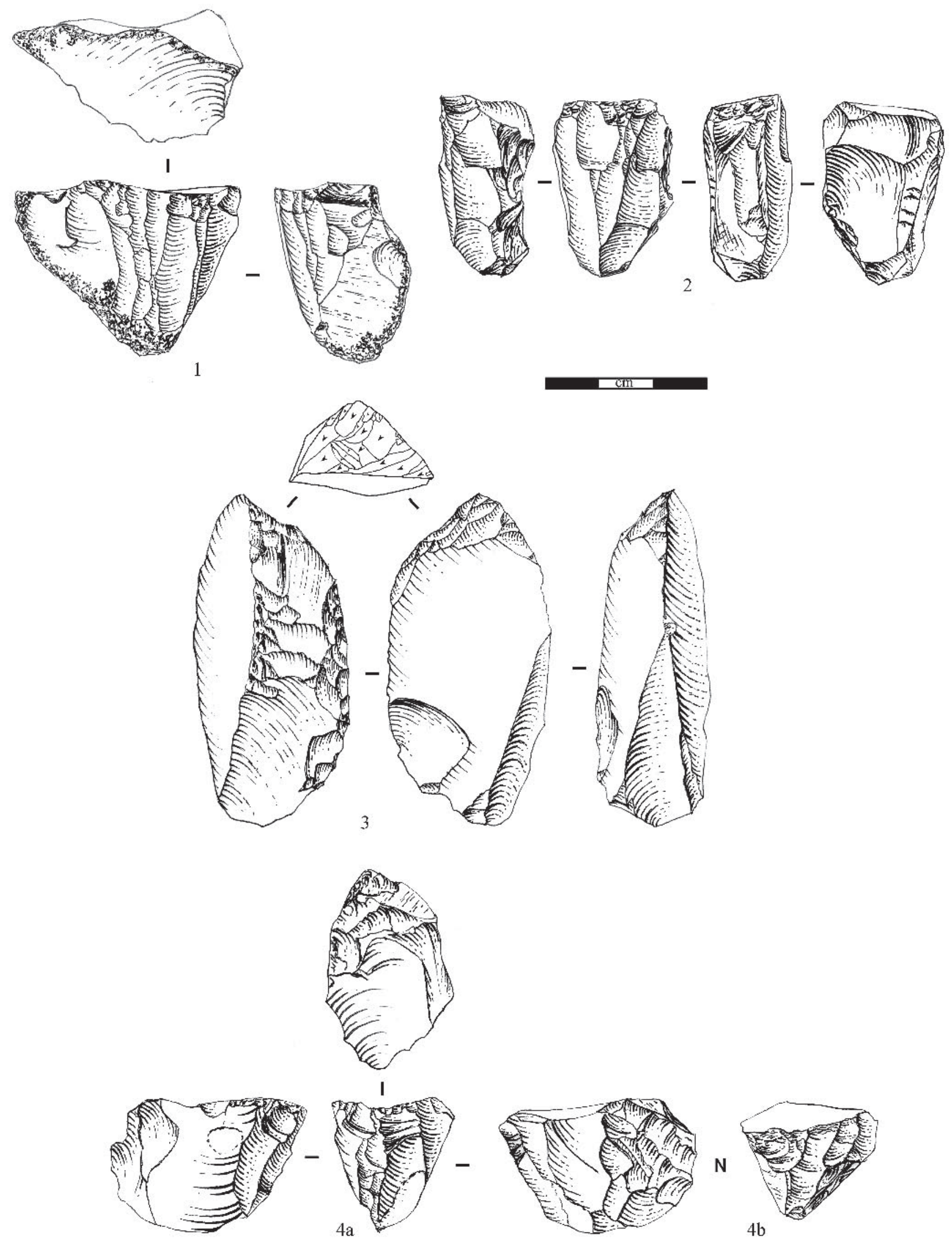

Fig. 12 - Exemples de nucléus à lamelles. $\mathrm{N}^{\circ \mathrm{s}} 1$ et $2:$ pyramidal $; \mathrm{n}^{\circ} 3:$ sur front ventral déjeté; $\mathrm{n}^{\circ} 4:$ mixte; $\mathrm{a}:$ sur tranche; $\mathrm{b}:$ sur front dorsal (dessins D. Molez). 


\begin{tabular}{|c|c|c|c|c|c|}
\hline Modalité/objectifs & Mld & Ld & Mixte & Indét. & Total \\
\hline «Sur front dorsal» & 27 & 2 & 4 & - & 33 \\
\hline Unipolaire pyramidal & 3 & 12 & 1 & - & 16 \\
\hline Unipolaire prismatique & - & 4 & 2 & - & 6 \\
\hline Prismatique «opposé-décalé» & - & 4 & 1 & - & 5 \\
\hline "Sur tranche» & 2 & 1 & - & - & 3 \\
\hline «Sur front ventral déjeté» & 2 & - & - & - & 2 \\
\hline «Mixte» & 1 & - & 1 & - & 2 \\
\hline «Sur tranche» à encoche & - & - & - & 1 & 1 \\
\hline Indéterminé & - & - & - & 1 & 1 \\
\hline Total & 35 & 23 & 9 & 2 & 69 \\
\hline
\end{tabular}

Tabl. 5 - Modalités de débitage et objectifs lamellaires (Mld : microlamelle à dos; Ld : lamelle à dos; indet : indéterminé).

\begin{tabular}{|c|c|c|}
\hline \multirow{2}{*}{\multicolumn{2}{|c|}{ Fragments sans traces techniques }} & Effectif \\
\hline & & 6 \\
\hline \multirow{2}{*}{ Déchets de débitage } & déchets de débitage transversal & 2 \\
\hline & déchets de débitage longitudinal & 3 \\
\hline \multirow{3}{*}{ Baguettes } & baguettes brutes de débitage & 4 \\
\hline & baguette régularisée & 1 \\
\hline & déchets de sectionnement de baguette & 22 \\
\hline \multirow{4}{*}{ Objets finis sur baguette } & indéterminés & 2 \\
\hline & pseudo-baguettes demi-rondes & 3 \\
\hline & outils intermédiaires & 7 \\
\hline & pointes de projectile & 29 \\
\hline \multicolumn{2}{|l|}{ Total } & 79 \\
\hline
\end{tabular}

Tabl. 6 - L'industrie en bois de Renne.

raccords entre fragments. Il ne semble donc pas y avoir eu de pertes importantes de matériel depuis la fouille une demi-douzaine de pièces au maximum. Les huit pièces figurées par Saint-Périer ont toutes été retrouvées.

À quelques exceptions près, les pièces en bois de Cervidé de la grotte des Scilles sont mal conservées : la fragmentation post-dépositionnelle est intense et beaucoup de pièces sont affectées par une desquamation ayant entraîné la destruction des traces techniques sur tout ou partie de la surface de l'objet. Saint-Périer notait déjà que «beaucoup [de sagaies] sont très fragmentées anciennement» et que «les instruments en os et en bois de Renne sont, pour la plupart, mal conservés, à cause de l'humidité de la couche archéologique. Au niveau et en avant du surplomb, notamment, beaucoup de pièces étaient si altérées qu'elles n'ont pu être recueillies » (Saint-Périer, 1926, p. 24-26). En dehors de ces pièces trop altérées pour être prélevées, la récolte du matériel lors de la fouille semble avoir été assez systématique, si l'on en juge par la présence de fragments même de petites dimensions et/ou mal conservés.

Tous les fragments de bois non façonnés, les déchets de débitage et les supports bruts - soit 15 pièces - sont en bois de Renne; nous n'avons relevé aucun témoignage de l'utilisation du bois de Cerf. L'attribution spécifique des éléments façonnés est plus délicate, mais $42 \%$ d'entre eux (27/64) présentent un tissu compact épais d'au moins $7 \mathrm{~mm}$, ordre de grandeur qui évoque le bois de Renne et non le bois de Cerf (Averbouh, 2000, p. 93; Bouchud, 1974; Goutas, 2004, p. 63). Il nous semble donc raisonnable de considérer que l'ensemble de l'industrie en bois de Cervidé de la grotte des Scilles a été réalisé sur bois de Renne.

\section{Les activités de débitage pratiquées sur place}

\section{Absence de débitage par éclatement}

La série comprend quatre fragments de perche non façonnés, de contour allongé (longueurs de 77 à $113 \mathrm{~mm}$, largeurs de 13 à $26 \mathrm{~mm}$ ). Ces pièces ne présentent que des pans de fracture bruts, mais ne portent aucune trace diagnostique de débitage par éclatement (languette de rupture par flexion, bulbe ou encoche de percussion, trace d'insertion d'outil intermédiaire indiquant un débitage par fendage, etc.) (Allain et al., 1974; Liolios, 1999; Rigaud, 2004...). Les pans de fracture qu'elles présentent pourraient, pour la plupart, résulter d'une fragmentation postdépositionnelle. Par ailleurs, l'un des fragments provient d'un bois de petit module, incompatible avec les supports utilisés pour la production des objets finis (cf. ci-dessous). La série de la grotte des Scilles ne livre donc aucun élément indiquant la présence d'un schéma de débitage du bois de Renne par éclatement ${ }^{3}$. 


\section{Débitage transversal}

Un fragment de base de bois de chute de module moyen ou gros présente des traces de sectionnement transversal par entaillage et flexion, à environ $40 \mathrm{~mm}$ au-dessus de la meule (fig. 13, $\mathrm{n}^{\circ}$ 2). Un tronçon de perche $\mathrm{A}+\mathrm{B}$ de bois de module moyen présente également des traces de sectionnement transversal aux deux extrémités : l'extrémité distale (limite perche B/ perche $\mathrm{C}$ ) a été sectionnée par entaillage périphérique et flexion, tandis que l'extrémité proximale (au niveau de la perche A) a été sectionnée par un rainurage périphérique dégageant une gorge régulière (fig. 13, $\left.\mathrm{n}^{\circ} 1\right)$.
Le module des deux pièces, le type de traces et leur emplacement sont compatibles avec un schéma opératoire de fabrication de bâton percé (il est d'ailleurs théoriquement possible que les deux pièces proviennent du même bois). Cette attribution n'est cependant proposée qu'à titre hypothétique : le rattachement de ces pièces à un schéma opératoire précis reste délicat.

\section{Débitage longitudinal}

La série comprend deux bases de bois de gros module; le premier est un bois de chute, le second est vraisemblablement un bois de massacre qui a été séparé

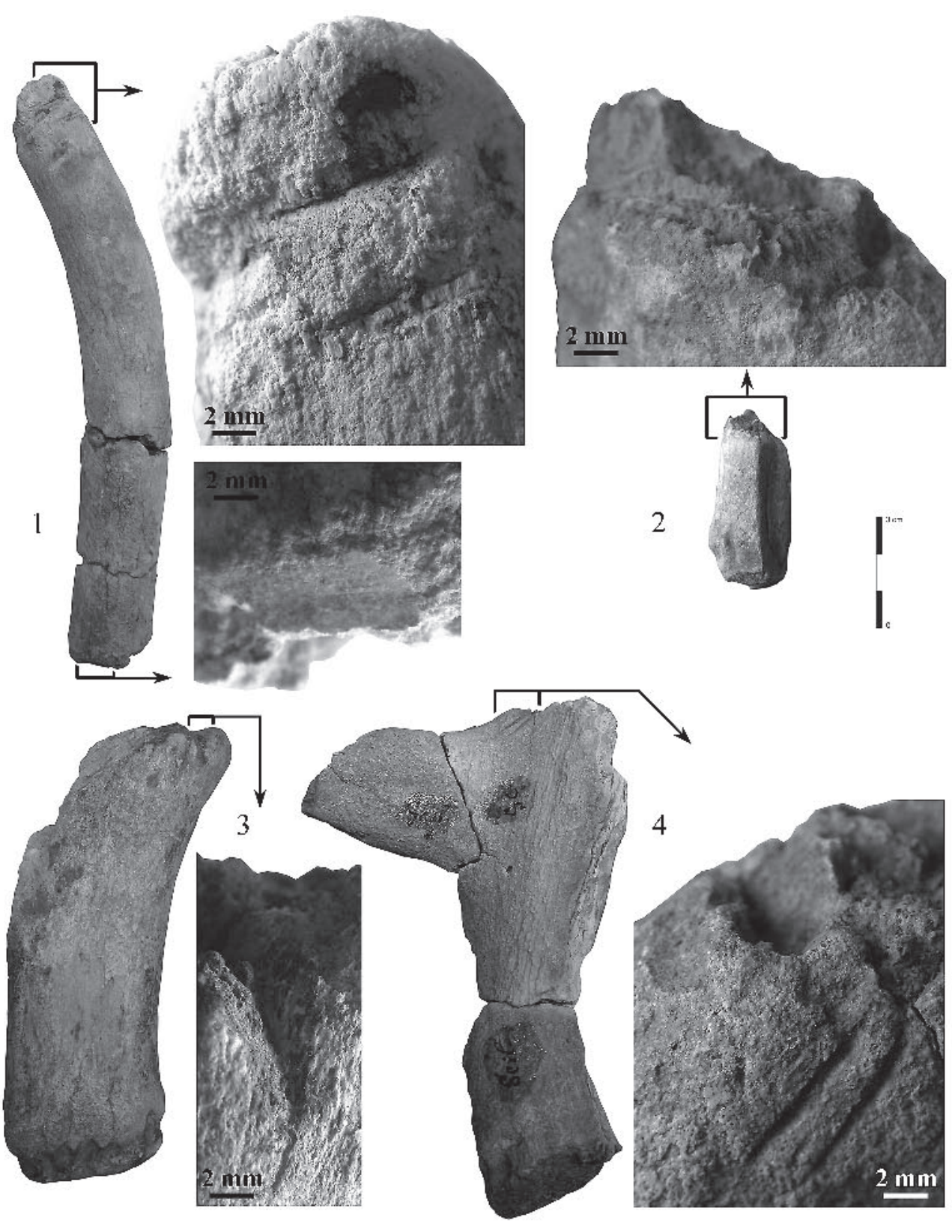

Fig. 13 - Déchets de débitage en bois de Renne, avec détail des stigmates techniques. $N^{\circ} 1:$ tronçon de perche avec sectionnement par entaillage (en haut) et sectionnement par rainurage transversal (en bas); $\mathrm{n}^{\circ} 2$ : fragment de base de bois de chute avec sectionnement par entaillage; $\mathrm{n}^{\circ} 3$ : base de bois de chute avec amorce de rainure longitudinale $\mathrm{n}^{\circ} 4$ : base de bois (bois de massacre proche de la chute ?) avec amorce de rainure longitudinale et languette d'arrachement. 
du crâne alors qu'il était proche de sa chute. Chacune de ces pièces présente, à la hauteur de l'andouiller de glace, une amorce de rainure indiquant une exploitation de la perche A par rainurage longitudinal (fig. 13, $\mathrm{n}^{\text {os }} 3$ et 4). Une troisième pièce - un petit fragment de déchet de débitage indéterminé, portant encore un pan de rainure longitudinale - est également compatible avec cette modalité de débitage.

L'emplacement et l'orientation des rainures incitent à considérer ces deux parties basilaires comme des déchets de production de baguettes par double rainurage parallèle, par analogie avec les déchets similaires connus au Paléolithique supérieur. Dans un cas, la rainure est d'ailleurs associée à un pan de fracture en dents de scie situé sur la face antérieure du bois, qui pourrait indiquer le détachement de l'extrémité d'une baguette d'environ $14 \times 12 \mathrm{~mm}$ de section. Quoique plausible, l'attribution de ces deux pièces ne peut cependant être affirmée de façon catégorique car ces objets sont mal conservés et une seule amorce de rainure est préservée sur chacun d'eux.

La production de baguettes par double rainurage parallèle est en revanche attestée de façon certaine par quatre fragments de baguettes brutes de débitage montrant encore des pans de rainure sur les deux bords (fig. 14). De section ovale ou subquadrangulaire, larges de 12 à $23 \mathrm{~mm}$ et présentant un tissu compact épais de 6 à $8 \mathrm{~mm}$, ces fragments témoignent de la recherche de baguettes de calibre assez important, prises sur bois de gros module. Ce module est compatible avec celui des deux déchets sur partie basilaire, mais nous ne pouvons pas affirmer que les quatre fragments proviennent de baguettes produites sur place. Nous ne disposons par ailleurs d'aucun élément pour estimer la productivité des débitages (longueur et nombre de baguettes produites à partir d'un seul bois).

\section{Synthèse}

Dans le matériel de la grotte des Scilles, les activités de débitage du bois de Renne ne sont représentées que par cinq déchets, qui indiquent l'introduction sur le site d'au moins trois bois (un bois de chute de gros module, un bois de chute de module moyen ou gros et un bois de gros module, sans doute de massacre). Deux de ces cinq déchets pourraient peut-être témoigner de la production sur place d'un ou deux bâtons percés, sur bois de module moyen et/ou gros. Les trois autres déchets montrent que la perche de deux bois de gros module a été exploitée par rainurage longitudinal, vraisemblablement pour la production de baguettes extraites par double rainurage parallèle.

\section{L'équipement}

Les 38 objets finis en bois de Cervidé provenant de la couche B de la grotte des Scilles sont tous des objets sur baguette façonnés par raclage. Excepté deux pièces typologiquement indéterminées, ils se répartissent en trois catégories.

\section{Pseudo-baguettes demi-rondes}

Deux pièces fragmentaires et un objet entier se caractérisent par une section planoconvexe très aplatie : leur indice d'aplatissement (rapport largeur/épaisseur) se situe entre 1,7 et 1,8 (soit 11-15 x 7-8 mm). Parmi ces pièces se trouvent probablement les «deux petits fragments » de la couche B que Saint-Périer considérait comme des baguettes demi-rondes (Saint-Périer, 1926, p. 26).

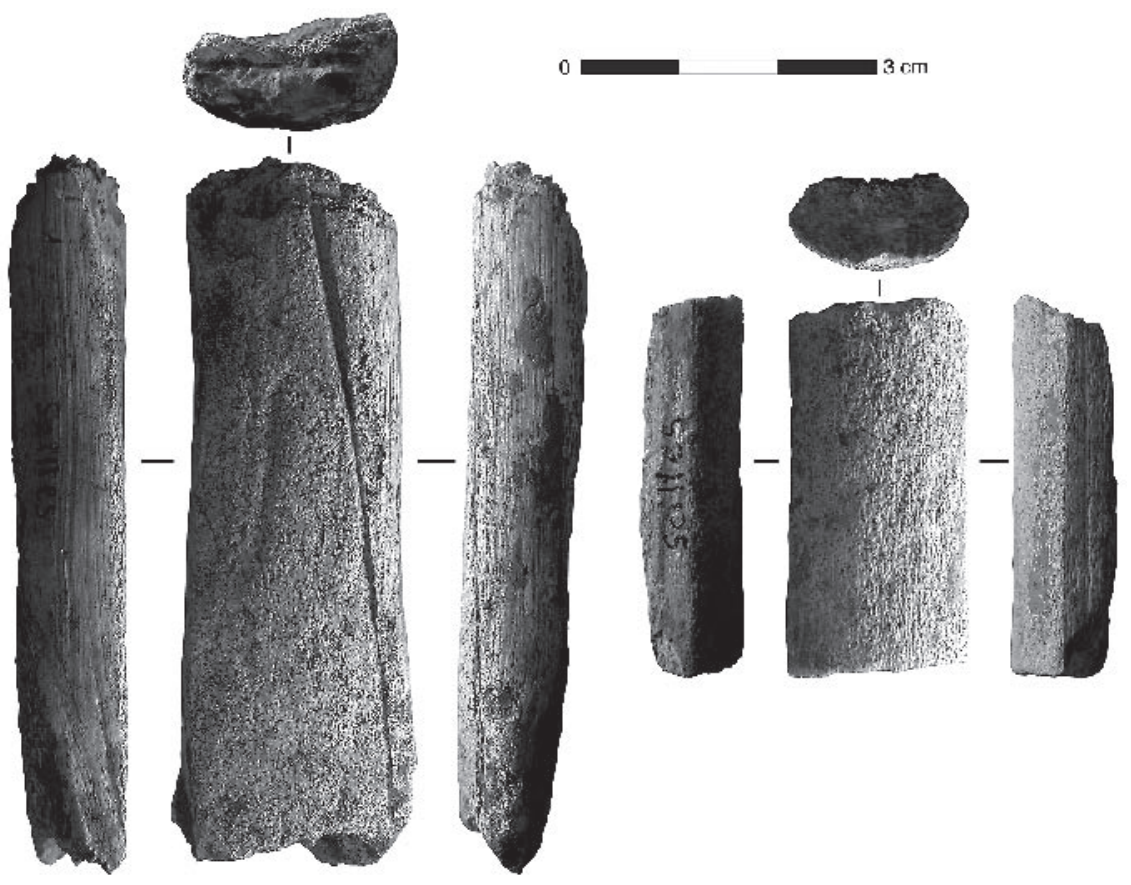

Fig. 14 - Fragments de baguettes en bois de Renne avec traces d'extraction par double rainurage. 
Plusieurs éléments nous conduisent cependant à rejeter cette attribution typologique. En effet, ces trois pièces (fig. 15) ne présentent aucun des aménagements de surface fréquemment rencontrés sur les baguettes demi-rondes pyrénéennes. Leur face inférieure (spongieuse) ne comporte aucune série d'incisions obliques, alternées ou en épi - aménagements relevés sur la face inférieure de $63 \%$ des baguettes demi-rondes d'Isturitz et d'Enlène (Feruglio, 1992) et sur $94 \%$ de celles de la Vache (Feruglio, 2003). La face supérieure des pièces de la grotte des Scilles est tout aussi sobre : deux pièces présentent une fine rainure longitudinale sur un ou deux bords (fig. 15, $\mathrm{n}^{\text {os }} 2$ et 3 ), mais aucune ne montre de rainure axiale striée, de relief axial, de décor géométrique, ni aucun des motifs décoratifs présents sur la majorité des baguettes demi-rondes des gisements des Pyrénées (Feruglio, ibid.).

Par ailleurs et surtout, les extrémités des pièces de la grotte des Scilles ne présentent aucune des morphologies connues pour les baguettes demi-rondes. Un des fragments présente une extrémité montrant un vestige de perforation circulaire (fig. $15, \mathrm{n}^{\circ} 2$ ) et le deuxième fragment présente une extrémité «spatuliforme » (large et amincie) (fig. $15, \mathrm{n}^{\circ} 3$ ). La pièce entière, longue de $138 \mathrm{~mm}$, présente une extrémité appointée déjetée vers le bord gauche, opposée à une extrémité mousse portant probablement des traces de percussion (fig. 15, $\mathrm{n}^{\circ}$ 1) (sa mauvaise conservation ne permet pas d'être catégorique). Les extrémités des baguettes demi-rondes, lorsqu'elles sont préservées, présentent au contraire des morphologies similaires à celles des armatures de projectile (pointe axiale, biseau facial ou latéral, fourche, etc.) (Feruglio, ibid.) - morphologies qui font ici défaut.

Rien ne rapproche donc ces trois pièces des «vraies» baguettes demi-rondes, en dehors de leur section planoconvexe. En particulier, aucun élément ne permet de supposer que les pièces de la grotte des Scilles aient fonctionné par paires, accolées dos à dos pour former des objets bivalves (Feruglio et Buisson, 1999; Rigaud, 2006). Par ailleurs, la morphologie de leurs extrémités évoque plus des outils de transformation (poinçons, lissoirs, outils intermédiaires?) que des armatures de projectile, qui sont la fonction la

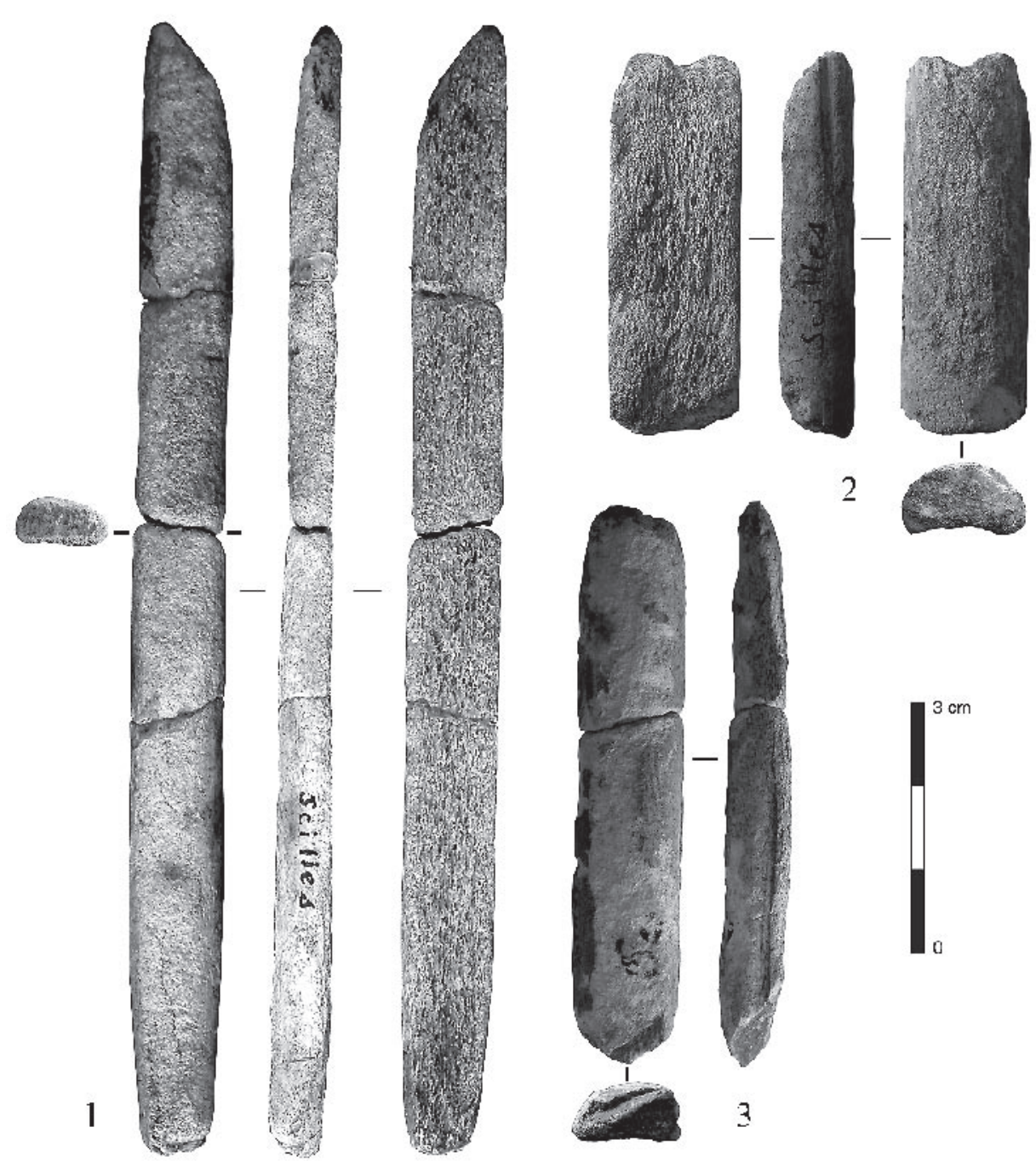

Fig. 15 - Outillage en bois de Renne : outils à section planoconvexe. $N^{\circ} 1$ : pièce entière; $n^{\circ} 2$ : fragment à extrémité perforée; $n^{\circ} 3$ : fragment à extrémité «spatuliforme». 

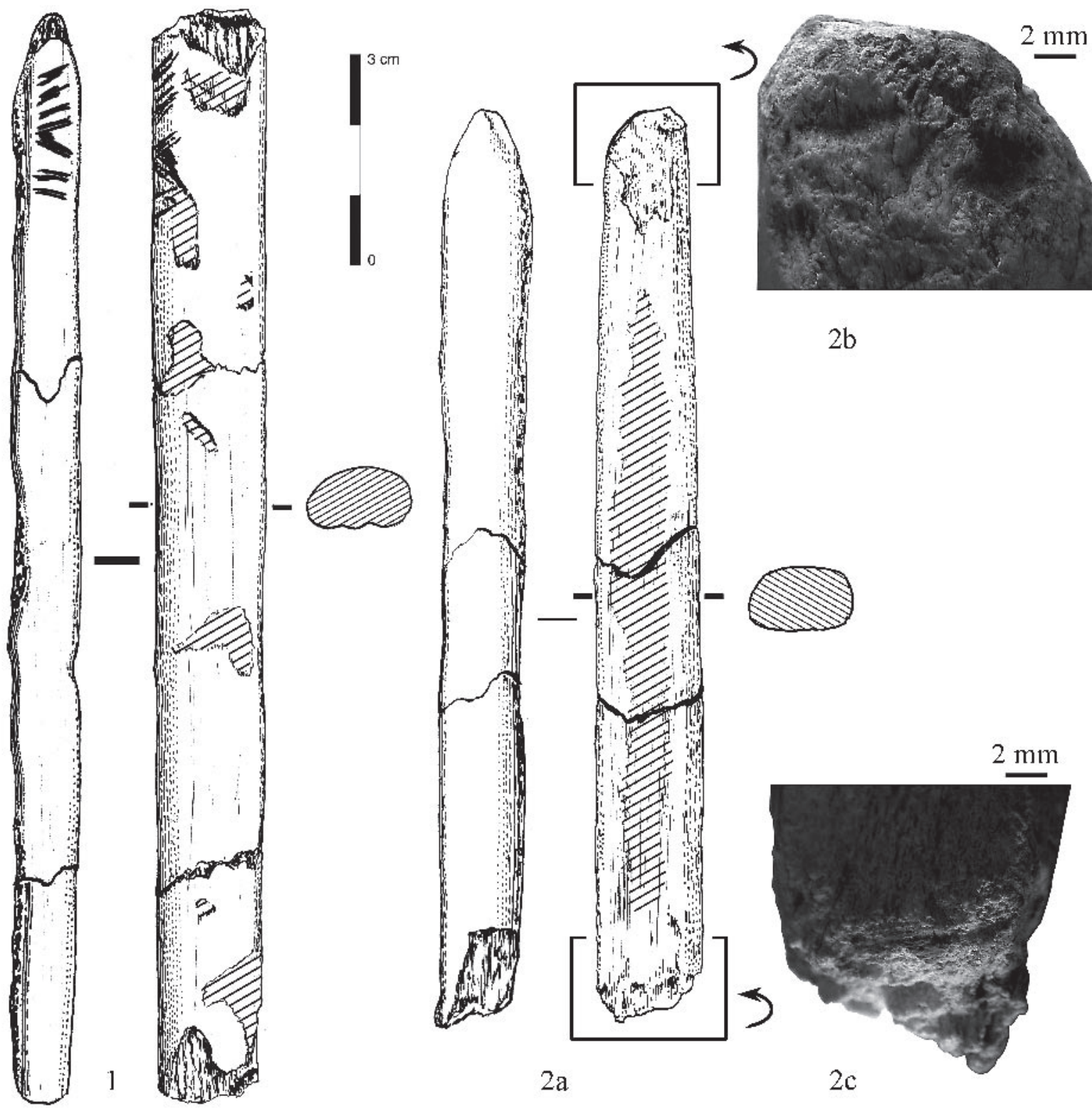

Fig. 16 - Outillage en bois de Renne : outils intermédiaires. $\mathrm{N}^{\text {os }} 1$ et $2 \mathrm{a}$ : pièces entières; $\mathrm{n}^{\circ} \mathrm{2b}$ : détail de la partie active (face inférieure); $\mathrm{n}^{\circ} 2 \mathrm{c}$ : détail du plan de frappe (face inférieure) montrant le repli des fibres et les traces de sciage transversal. Les zones hachurées sont des zones où la surface est mal conservée (dessins $\mathrm{D}$. Molez).

plus souvent retenue pour les baguettes demi-rondes (Rigaud, 2006). La ou les fonctions précises des objets de la grotte des Scilles demeurent cependant indéterminées; à notre connaissance, aucun objet identique n'a été signalé ailleurs.

En revanche, notons que ces trois pièces présentent une forte ressemblance avec les deux fragments d'objets en bois de Cervidé provenant de la couche A (SaintPérier, 1926, fig. 3 , n ${ }^{\text {os }} 6$ et 7). Ces derniers présentent la même section planoconvexe - Saint-Périer considérait d'ailleurs l'un d'entre eux comme une baguette demi-ronde - ainsi que les mêmes aménagements de surface (fines incisions sur les bords) et les mêmes types d'extrémités (pointe déjetée vers le bord gauche, extrémité mousse avec possibles traces de percussion).

\section{Outils intermédiaires}

Sept objets, dont trois entiers, présentent des traces d'utilisation comme outil intermédiaire. Ces objets à section planoconvexe sont relativement longs (les pièces entières mesurent entre 119 et $156 \mathrm{~mm}$ ) et de gros calibre : les largeurs s'échelonnent en général de 15 à $17 \mathrm{~mm}$ et les épaisseurs de 10 à $12 \mathrm{~mm}$. Leur extrémité proximale - ou plan de frappe - est droite, tandis que l'extrémité distale, préservée sur trois exemplaires, présente un court biseau sur la face inférieure (fig. 16).

L'épaisseur importante du tissu compact (de 5 à $11 \mathrm{~mm}$, moyenne $8 \mathrm{~mm}$ ) indique que ces objets ont été façonnés sur des baguettes issues de la perche de bois de Renne de gros module. Les traces d'extraction de 
ces baguettes ont été détruites par le façonnage des bords et de la face inférieure. L'extrémité proximale a été aménagée par sectionnement d'un support à l'origine plus long: sur trois pièces, le plan de frappe de l'outil se présente en effet sous la forme d'un pan de fracture par flexion en dents de scie, sur lequel les traces d'utilisation sont ensuite venues s'imprimer. Ce sectionnement peut également être effectué par un sciage transversal, dont la face inférieure de l'une des pièces porte encore les traces (fig. 16, $\mathrm{n}^{\circ} 2 \mathrm{c}$ ).

Seuls deux outils intermédiaires montrent des aménagements de surface : un fragment mésioproximal présente sur chaque bord une amorce de rainure longitudinale (interrompue par la fracture distale) et une pièce entière présente, sur la face supérieure, un décor élaboré qui sera décrit plus bas.

Ces outils montrent des traces macroscopiques d'utilisation tant sur l'extrémité proximale (tassement et repli des fibres, éclats de bord de plan de frappe) (fig. 16, $\mathrm{n}^{\circ}$ 2c) que sur l'extrémité distale (écrasement et esquillements) (fig. 16, $\mathrm{n}^{\circ} 2 \mathrm{~b}$ ). Cette combinaison laisse peu de doutes sur leur utilisation comme pièce intermédiaire pour le travail d'une matière dure par percussion lancée indirecte (Legrand, 2000).

\section{Pointes de projectile}

Avec 29 pièces, les pointes de projectile constituent la grande majorité de l'équipement en bois de Renne. Aucune n'est entière. Si 12 d'entre elles ne présentent que des fractures post-dépositionnelles, les 17 autres montrent au moins un stigmate compatible avec une utilisation comme pointe de projectile : fracture en languette ou écrasement (fig. 17, $\mathrm{n}^{\circ} 3$ ) (cf. Pétillon, 2006). Cette situation suggère que l'essentiel de la série est constitué de pièces endommagées à l'usage et rapportées sur le site après la chasse, à l'extrémité des hampes de projectile ou dans le corps de l'animal tué (Chadelle et al., 1991; Pétillon, 2006).

Les pointes de la grotte des Scilles sont de trois types (tabl. 7). Le premier type (fig. 17, $\mathrm{n}^{\text {os }} 1$ et 2 ) rassemble deux pointes à biseau simple qui présentent tous les caractères morphométriques des pointes de Lussac-Angles (Pinçon, 1988) :

- une longueur réduite : la première pointe, presque entière, mesure $62 \mathrm{~mm}$ et la seconde, réduite à un fragment mésial de $42 \mathrm{~mm}$, ne mesurait sans doute pas plus de $80 \mathrm{~mm}$ à l'origine;

- un biseau simple représentant près de la moitié de la longueur de la pièce : c'est le cas pour la pièce la plus complète et on peut raisonnablement supposer des proportions similaires pour le second objet;

- un calibre «moyen» par rapport aux autres types de pointes magdaléniennes : ici respectivement $10 \times 9 \mathrm{~mm}$ et $8 \times 8 \mathrm{~mm}$ à la limite entre le biseau et la partie mésiodistale;

- une section mésiodistale particulière : l'un des caractères spécifiques des pointes de Lussac-Angles est leur face supérieure plane, associé au fait que les bords forment souvent avec celle-ci un angle aigu; cette morphologie donne à la partie mésiodistale de la pointe une section planoconvexe, voire trapézoïdale ou subtriangulaire, et à l'extrémité distale une section allongée verticalement (i. e. plus épaisse que large) souvent décrite comme «tranchante» (Clottes, 1989, fig. 2, $\mathrm{n}^{\text {os }}$ 11-14; Delporte et Mons, 1988, fig. 5 ; Pinçon, 1988, p. 5). Ces caractères se retrouvent sur les deux pointes de la grotte des Scilles.

Les seules divergences concernent les aménagements de surface. Alors que les pointes de LussacAngles ont un biseau lisse dans $81 \%$ des cas (Pinçon, 1988), ici une des deux pièces présente un biseau strié. La faiblesse de notre échantillon limite cependant la portée de cette objection. En revanche, les pointes de Lussac-Angles portent systématiquement une rainure sur la face supérieure et souvent une autre sur la face inférieure (Pinçon, 1988) : or, si ces rainures sont bien présentes sur l'une de nos pièces, elles sont absentes de la seconde. Reste que, ce problème mis à part, la morphologie de cette dernière pointe est très proche de celles des pointes de Lussac-Angles, parenté qui avait déjà été soulignée par M. Allard et M. Jarry (1993, p. 67).

Le deuxième type de pointe est représenté par une pièce à base pleine, de très grandes dimensions, reconstituée à partir de trois fragments et restaurée au MAN (fig. 18). Façonnée sur un bois de gros module (compacta : $10 \mathrm{~mm}$ ), elle présente un calibre important (13 x $11 \mathrm{~mm}$ ) et une longueur de $297 \mathrm{~mm}$ : sans être totalement «hors norme», cette pièce figure parmi les plus longues pointes en bois de Renne paléolithiques connues (e. g. Bertrand, 1999, passim; Peyrony, $1950 \ldots)$. Sa section, circulaire en partie proximale, évolue vers une forme planoconvexe en partie mésiodistale. D'après leurs dimensions, la forme de leur section et l'épaisseur de leur tissu compact, deux fragments mésiaux et un proximal peuvent être rattachés au même type de pointe. Le fragment proximal présente sur la face supérieure trois rainures longitudinales, interrompues par une fracture d'impact (fig. 17, $\mathrm{n}^{\circ} 5$ ).

Le dernier type de pointe est représenté par un fragment mésioproximal ou mésiodistal long de $163 \mathrm{~mm}$ (fig. $17, \mathrm{n}^{\circ} 4$ ). Le contour et le profil de la pièce étant symétriques, il est difficile de distinguer les extrémités proximale et distale, d'autant que l'extrémité appointée, figurée par Saint-Périer (1926, fig. 6, n 3), est aujourd'hui perdue. La convergence des faces et bords indique toutefois clairement que les deux extrémités de l'objet se terminaient en pointe; la pièce entière devait mesurer entre 180 et $200 \mathrm{~mm}$. Il s'agit donc là encore d'une pointe à base pleine, la différence avec le type précédent résidant dans sa section ovalaire très aplatie (largeur et épaisseur maximales : 14 x $7 \mathrm{~mm}$ ). Peut-être faut-il y voir une adaptation à un module de bois plus réduit, le tissu compact ne dépassant pas $6 \mathrm{~mm}$ d'épaisseur. D'après leurs dimensions et la forme de leur section, quatre fragments mésiaux et deux distaux (ou proximaux) peuvent être rattachés au même type d'objet (fig. 17, $\mathrm{n}^{\circ}$ 6). Toutes ces pièces présentent 

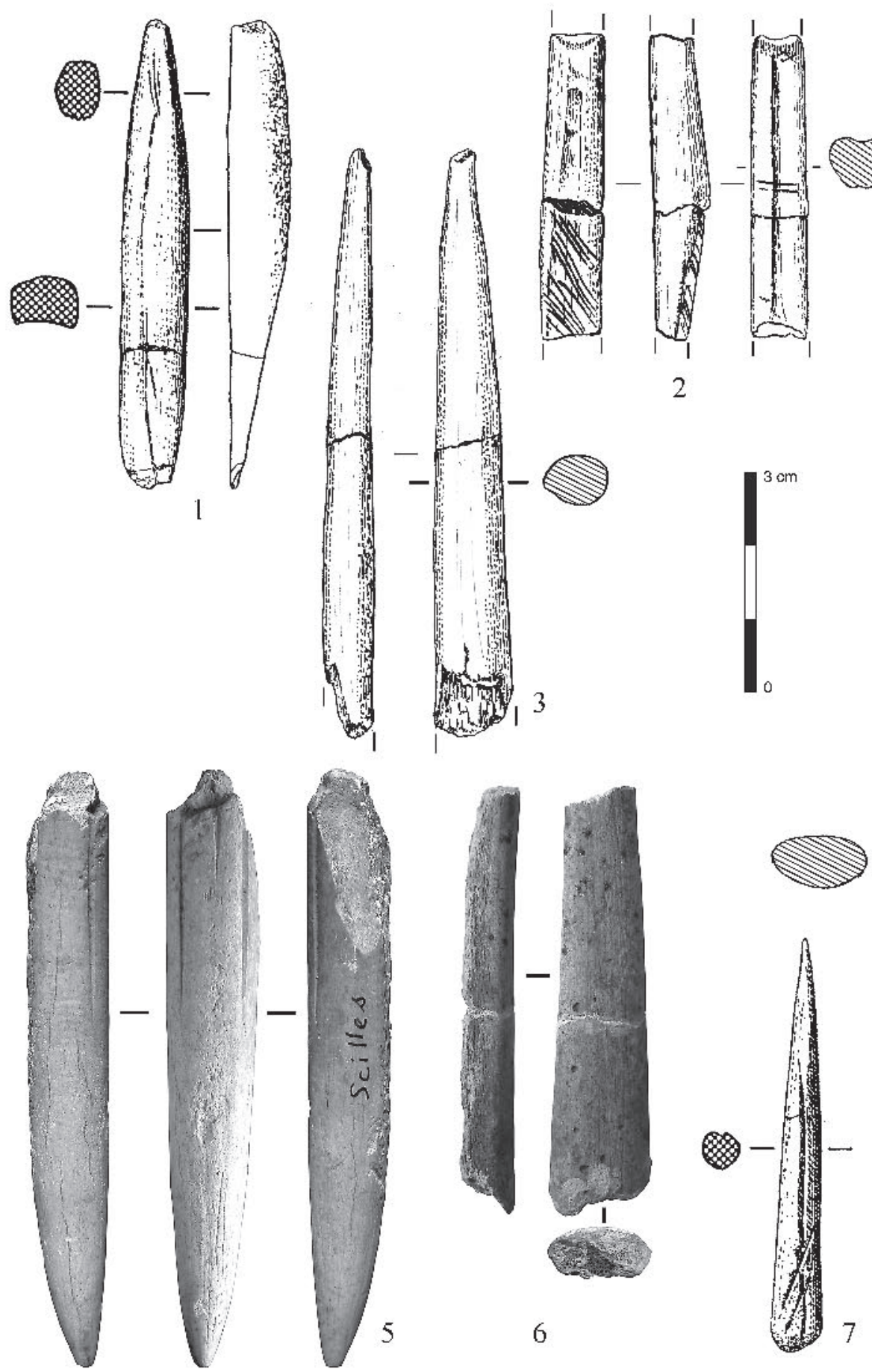

4
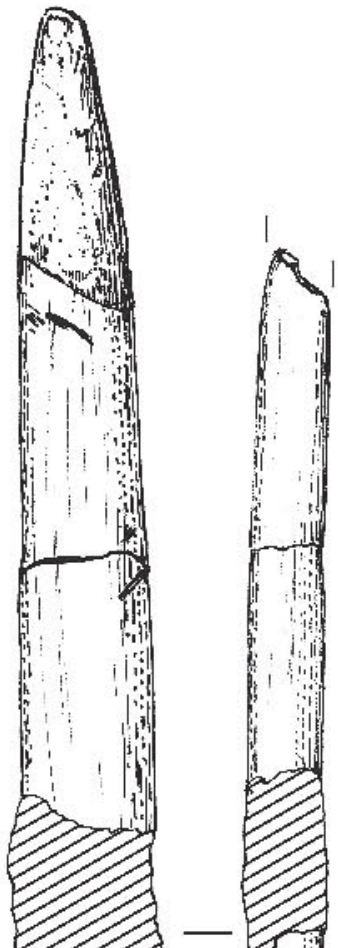

Fig. 17 - Pointes de projectile en bois de Renne. Nos 1 et 2 : pointes à biseau simple de type Lussac-Angles; $n^{\circ} 3:$ fragment mésial; $n^{\circ} 4:$ pointe à base pleine de section ovalaire (le fragment distal, figuré par Saint-Périer et reproduit ici, n’a pas été retrouvé); $\mathrm{n}^{\circ} 5:$ fragment mésioproximal de pointe à base pleine de section circulaire, avec trois rainures longitudinales; $\mathrm{n}^{\circ} 6$ : fragment mésial de pointe à section ovalaire; $\mathrm{n}^{\circ} 7:$ fragment mésiodistal de pointe avec rainure longitudinale ( $\mathrm{n}^{\text {os }} 1$ et $7:$ dessins M. Jarry, d'après Allard et Jarry, 1993; $\mathrm{n}^{\text {os }} 2$ à $4:$ dessins D. Molez)

\begin{tabular}{|c|c|c|c|c|c|c|}
\hline & $\begin{array}{c}\text { Quasi } \\
\text { entière }\end{array}$ & $\begin{array}{c}\text { Mésio- } \\
\text { proximaux }\end{array}$ & Mésiaux & $\begin{array}{c}\text { Més.-dist. } \\
\text { ou més.-prox. }\end{array}$ & Total \\
\hline \multicolumn{2}{|c|}{ Pointes à biseau simple (Lussac-Angles) } & 1 & & 1 & & 2 \\
\hline \multirow{2}{*}{ Pointes à base pleine } & à section circulaire & & 2 & 2 & & 4 \\
\hline & à section ovalaire & & & 4 & 3 & 7 \\
\hline \multicolumn{2}{|c|}{ Pointes de type indéterminé } & & & 9 & 7 & 16 \\
\hline \multicolumn{2}{|c|}{ Total } & 1 & 2 & 16 & 10 & 29 \\
\hline
\end{tabular}

Tabl. 7 - Typologie et état de fragmentation des pointes de projectile en bois de Renne. 


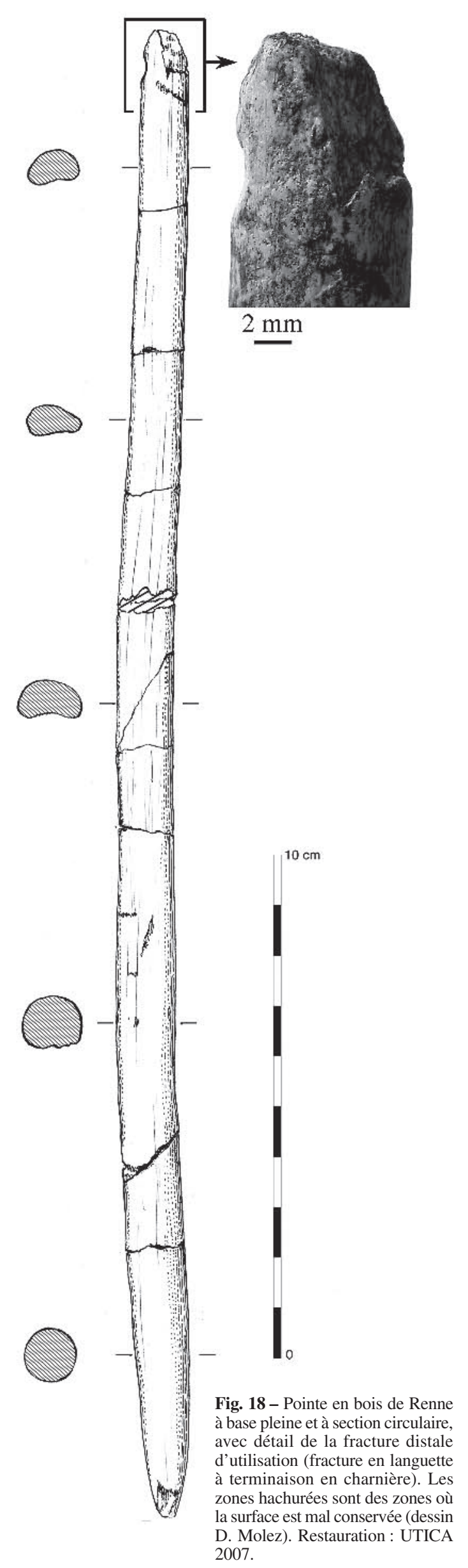

une section ovalaire aplatie (indice d'aplatissement situé entre 1,5 et 2 ) et semblent également façonnées sur des bois de module moyen (compacta: 4 à $6 \mathrm{~mm})$.

Enfin, 16 fragments mésiaux et distaux (ou proximaux), longs de 12 à 79 mm, n'ont pas pu être classés typologiquement mais s'inscrivent dans la variabilité morphométrique des deux dernières catégories de pointes. Aucun, en revanche, ne semble provenir d'une pointe de Lussac-Angles.

Sur l'ensemble des pointes, les aménagements de surface sont rares et discrets. En dehors de la pointe de Lussac-Angles (fig. 17, $\mathrm{n}^{\circ}$ 2) et du fragment mésioproximal à trois rainures (fig. $17, \mathrm{n}^{\circ} 5$ ), seuls trois fragments portent une fine rainure longitudinale sur la face supérieure ou sur un bord (fig. 17, $\mathrm{n}^{\circ} 7$ ). Près de $83 \%$ des pièces sont donc dépourvus de tout décor, rainures, etc.

\section{Synthèse}

L'outillage en bois de Renne de la couche B de la grotte des Scilles comprend trois outils à section planoconvexe, de fonction indéterminée, ainsi que sept outils intermédiaires de gros calibre façonnés sur bois de gros module. Les 29 autres objets finis sont tous des pointes de projectile. La panoplie d'armatures est dominée par des pointes à base pleine qui, d'après les plus longs fragments préservés, seraient d'une longueur importante: près de $20 \mathrm{~cm}$ pour l'une des pièces, plus de $30 \mathrm{~cm}$ pour l'autre. L'existence de deux types de pointes à base pleine (à section circulaire, à section ovalaire) pourrait être une adaptation à deux modules de bois différents (gros et moyen, respectivement). Les pointes à biseau simples, rares, sont représentées par deux pièces de type Lussac-Angles.

\section{Des supports aux objets finis : les déchets de sectionnement de baguette}

L'industrie en bois de Renne de la grotte des Scilles se singularise par une forte proportion d'éléments appointés sur baguette partageant les caractères suivants (fig. 19) :

- longueur réduite : en général de 25 à $60 \mathrm{~mm}$;

- calibre important : largeur en général de 11 à 16 mm, épaisseur de 8 à $12 \mathrm{~mm}$;

- fabrication sur bois de gros module : compacta épaisse de 6 à $10 \mathrm{~mm}$;

- section en général ovale ou planoconvexe;

- absence d'aménagements de surface;

- l'extrémité opposée à la pointe présente toujours une fracture par flexion, en languette ou en dents de scie.

Ces éléments, au nombre de 22, représentent $28 \%$ de l'industrie en bois de Renne. Il semble que SaintPérier les ait classés comme pointes à biseau simple, confondant le pan de fracture par flexion avec un biseau aménagé (Saint-Périer, 1926, p. 26); de là vient 


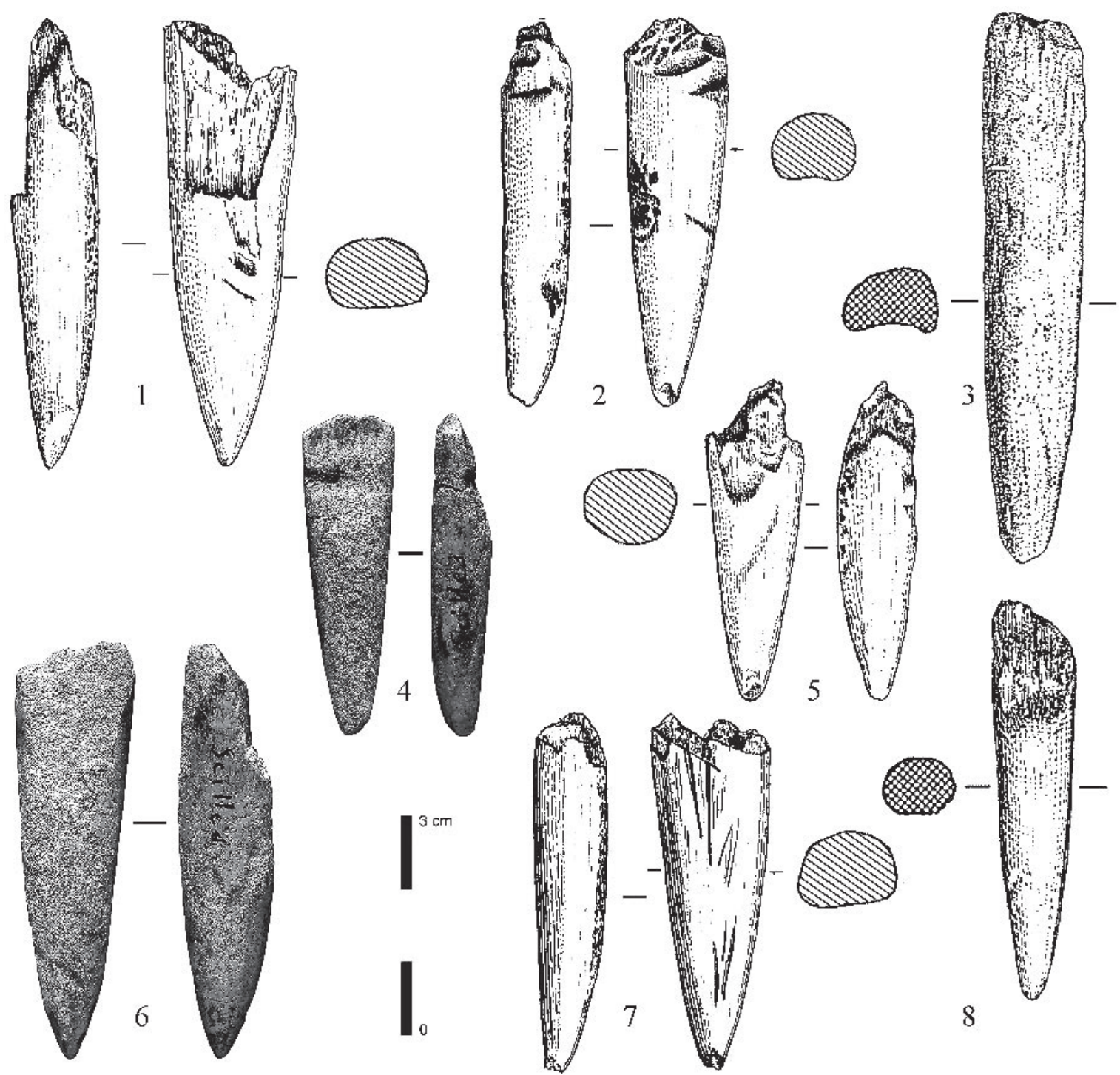

Fig. 19 - Déchets de sectionnement de baguettes en bois de Renne (dessins D. Molez, sauf $\mathrm{n}^{\text {os }} 3$ et 8 : dessins M. Jarry, d'après Allard et Jarry, 1993).

probablement sa remarque erronée selon laquelle la panoplie d'armatures osseuses de la grotte des Scilles serait dominée par «un type [de sagaie] archaïque à simple biseau » (Saint-Périer, ibid.). Nous avions déjà relevé une erreur similaire du même auteur dans le Magdalénien moyen de la salle de Saint-Martin d'Isturitz (Pétillon, 2004, p. 127, note 7).

Mais si ces pièces ne sont pas des pointes à biseau simple, que sont-elles? Deux arguments s'opposent à leur interprétation comme fragments distaux d'objets finis (pointes, outils intermédiaires) fracturés lors de l'utilisation :

- morphologie : la forme de l'extrémité appointée n'évoque pas celle de la partie active des outils intermédiaires (ceux-ci sont plutôt biseautés) ni des pointes de projectile (celles-ci sont moins trapues, plus acuminées). De fait, la morphologie de ces 22 pièces appointées ne correspond à aucun des objets finis de la grotte des Scilles;
- traces de sectionnement : dans 15 des 22 cas, la fracture par flexion a été précédée d'un entaillage, conduit en général sur la face supérieure et ayant manifestement pour but de guider la zone de fracture (fig. 19, $\mathrm{n}^{\text {os }} 2$, 4 et 5). Dans la majorité des cas, il est donc évident que la fracture ne résulte pas d'un accident d'utilisation mais bien d'un sectionnement délibéré.

Nous avons rapproché ces pièces d'une baguette de grandes dimensions $(216 \times 17 \times 12 \mathrm{~mm}$, compacta: $10 \mathrm{~mm}$ ), de section planoconvexe, dont les bords ont été régularisés par raclage mais dont la partie axiale de la face supérieure est restée brute (fig. 20). Les deux extrémités de cette pièce sont fracturées par flexion, mais les pans de fracture sont sur des plans différents, indiquant que les fractures ne se sont pas produites simultanément. Nous interprétons cette pièce, non comme un objet fini, mais comme un support-baguette régularisé (la rainure présente sur la face supérieure 
étant plus probablement un repentir de débitage qu'un aménagement de surface). De fait, son calibre correspond exactement à celui des outils intermédiaires de la série et est également compatible avec le module des baguettes utilisées pour la fabrication de certaines armatures - en particulier les pointes à base pleine de section circulaire.

Cette pièce présente une extrémité aux bords convergents : même si elle est amputée par la fracture, on peut voir qu'elle se terminait à l'origine en pointe. Cette morphologie n'est pas nécessairement acquise lors de la régularisation des bords, mais peut être liée au mode de débitage - le double rainurage convergent produit en effet des baguettes «naturellement» appointées, le principe étant d'amincir la baguette à ses extrémités afin d'en faciliter l'extraction. C'est cette interprétation qui nous semble ici la plus plausible.

Or, les 22 fragments appointés présentés ci-dessus s'inscrivent parfaitement dans la silhouette reconstituée de l'extrémité de cette baguette. Cette similitude morphométrique nous a conduit à rapprocher les deux catégories d'objets : nous proposons de voir dans les éléments appointés les résultats du sectionnement délibéré de l'extrémité de baguettes, préalablement extraites d'un bois de gros module par double rainurage convergent, puis régularisées sur les bords.

Presque aucun de ces éléments appointés ne porte de traces d'utilisation (un seul semble avoir été employé comme outil intermédiaire : utilisation opportuniste?). Il s'agit donc bien de déchets.

Pourquoi sectionner ainsi l'extrémité de baguettes? F.-X. Chauvière et A. Rigaud ont déjà évoqué un problème similaire, à propos des pièces dites «sagaies à base raccourcie » et de certaines baguettes demi-rondes (Chauvière et Rigaud, 2005; Rigaud, 2006) : ils ont montré que ces pièces, classiquement considérées comme des objets finis, sont plus probablement des déchets résultant d'un ajustement de la baguette au cours de la fabrication d'un objet (mise à longueur, mise à l'axe...). Cet ordre d'explication nous semble ici le plus vraisemblable. Sur la grande baguette de la grotte des Scilles, on constate d'ailleurs que l'extrémité aux bords convergents est déjetée par rapport à l'axe de la pièce, en contour comme en profil : si cette baguette avait été utilisée pour façonner un objet allongé type pointe de projectile - cette portion «déviante» aurait à l'évidence dû être supprimée (fig. 20).

Toute approche quantitative de l'industrie de la grotte des Scilles est périlleuse en raison de la mauvaise conservation des vestiges, qui introduit dans la série un biais évident. On peut cependant souligner que l'abondance des déchets sur baguette $(\mathrm{N}=22)$ contraste avec la relative rareté des déchets de débitage longitudinal (deux bois débités), suggérant qu'au moins une partie des baguettes n'ont pas été produites sur place mais ont été introduites telles quelles sous forme de «supports préparés», prêts à être façonnés en tel ou tel objet suivant les besoins. Le fait que, à une exception près, nous n'ayons pas retrouvé les baguettes mais seulement les déchets qui en sont issus indique que ces supports ont bien été utilisés sur le site pour la fabrication d'objets finis. Le corpus d'objets finis étant

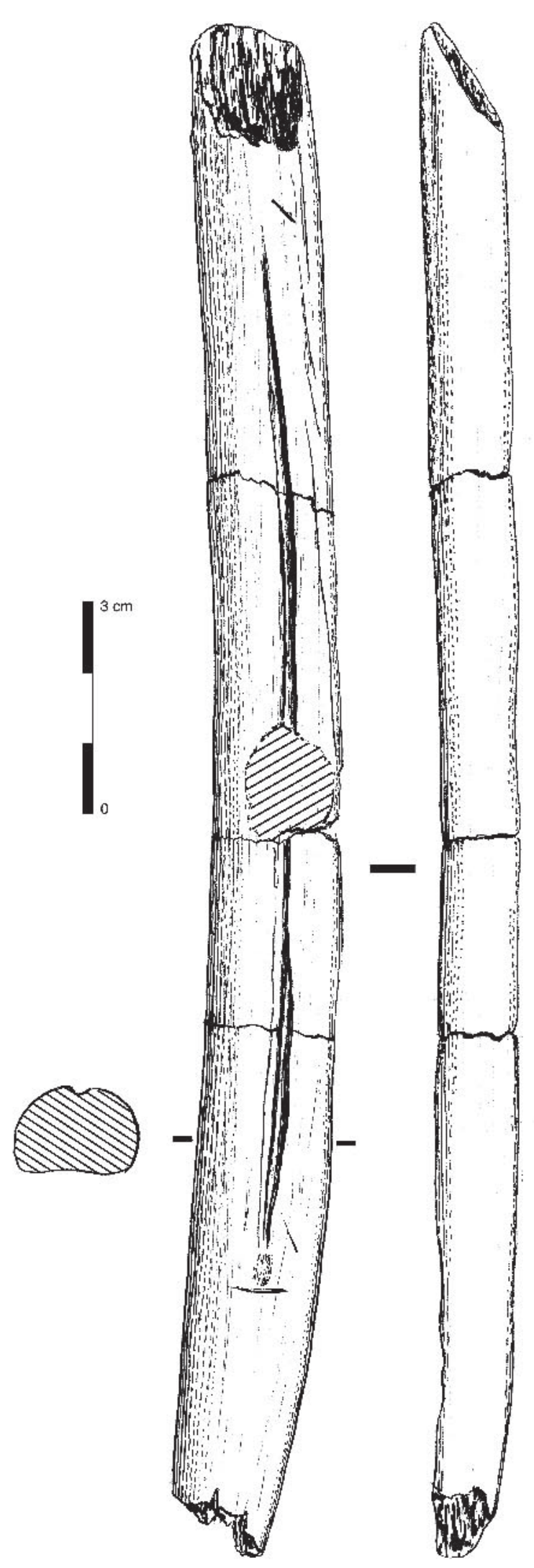

Fig. 20 - Baguette en bois de Renne. Les zones hachurées sont des zones où la surface est mal conservée (dessin D. Molez). 
constitué en grande partie de fragments d'armatures, dont une majorité est fracturée à l'usage, on peut penser que la destination de la majorité des baguettes était la fabrication d'armatures «de rechange». On ne peut cependant pas exclure que certaines aient servi à la fabrication d'outils intermédiaires - autre catégorie d'objets finis représentée dans l'industrie et au calibre similaire à celui des baguettes.

\section{Bilan : \\ principales tendances de l'économie du bois de Renne}

Si l'on résume les données qui précèdent, en écartant les modalités opératoires et les types d'objets les moins bien documentés, on obtient l'image simplifiée suivante.

L'équipement en bois de Renne retrouvé dans couche B de la grotte des Scilles est principalement constitué de fragments de pointes de projectile, dont la majorité, fracturée à l'usage, a très probablement été abandonnée sur place après le retour de la chasse. Ces pointes endommagées ont pu être en partie remplacées par une production locale : deux bois de gros module ont fait l'objet d'une exploitation de la perche par rainurage longitudinal, vraisemblablement pour la production de baguettes dont le module pourrait correspondre à celui de certaines pointes. En revanche, nous formulons l'hypothèse qu'une autre partie des pointes de rechange a été façonnée à partir de supports préparés : des baguettes de gros module, en partie régularisées, arrivées telles quelles sur le site. Les seuls vestiges de ces baguettes - outre une unique pièce de plus de $20 \mathrm{~cm}$ - sont leurs extrémités appointées, délibérément sectionnées et retrouvées en assez grande quantité.

\section{L'OUTILLAGE EN OS ET LA PARURE SUR MATIËRES DURES D'ORIGINE ANIMALE (F.-X. C.)}

Dans son article sur la grotte des Scilles, SaintPérier mentionne la découverte, dans le niveau $\mathrm{B}$, de neuf aiguilles à chas et d'une pendeloque en os qu'il interprète comme une figuration de phallus et qu'il décrit en détail (Saint-Périer, 1926). Il présente ensuite deux dents de Lion (carnassière et prémolaire) qu'il considère comme des éléments de parure au vu des rainures profondes qui entaillent leurs racines (op. cit., p. 27-28). Il ajoute à l'inventaire et figure trois coquilles qu'il attribue à Pectunculus sp., Cytherea (?) et Turritella sp. (op. cit., p. 27, fig. 7). Contrairement à l'industrie sur bois de Cervidé, ces 15 éléments n'ont pas été mobilisés par Saint-Périer (op. cit., p. 39-40) ni par d'autres auteurs à sa suite pour argumenter le calage chronologique de la couche B de la grotte des Scilles (Clottes, 1989; Simonnet, 1976).

D’une manière générale, les objets en os de la grotte des Scilles ne sont pas ceux sur lesquels on s'attarde lorsque l'on évoque ce gisement (Allard et Jarry, 1993; Taborin et Thiébault, 1994 ; Vialou, 2004). Le cas des deux dents de Lion est un peu différent. Celles-ci ont été régulièrement mises à contribution pour argumenter le rôle discret joué par ce taxon dans la parure magdalénienne (Barge-Mahieu et Taborin, 1991; Taborin, 1995 et 2004). Toutefois, elles ne sont pas toujours explicitement citées et, à l'heure actuelle, elles restent exceptionnelles à l'échelle du Paléolithique supérieur. Il en va tout autrement des coquillages des Scilles qu'Y. Taborin (1993) a inclus dans son travail sur la parure au Paléolithique. Au final, ce ne sont pas trois mais six coquilles de la couche B de la grotte des Scilles qui sont intégrées à la synthèse sur les groupes de la phase moyenne du Magdalénien pyrénéen. Nous verrons plus loin l'intérêt des déterminations spécifiques et des origines géographiques de ces éléments pour replacer les Scilles à l'échelle régionale.

Le récolement récent de la collection du MAN fait état de sept des 15 objets mentionnés par Saint-Périer dans son article princeps. Le déficit observé s'exerce au détriment des aiguilles à chas dont un seul des neuf exemplaires a été retrouvé (à moins que certains ne se trouvent désormais dans ce que nous avons interprété comme des ébauches ou des déchets de fabrication). Suite à l'examen orienté des restes fauniques, la série s'est enrichie d'objets sur os inédits, dont une matrice à aiguille et sept retouchoirs ou affûtoirs ${ }^{4}$ et deux pièces de type ciseau. Désormais, elle totalise 23 éléments (tabl. 8).

L'ancienneté des fouilles, l'absence de tamisage, le fait que l'ensemble du matériel organique repéré n'a pas été récolté - notamment celui qui, trop altéré, était localisé à l'entrée de la grotte (Saint-Périer, 1926, p. 24) - et les vicissitudes muséographiques font qu'il est impossible d'estimer la représentativité de la collection sur os, dent et coquille de la grotte des Scilles. L'interprétation des données en relation avec celles livrées par l'étude des restes fauniques, notamment, est délicate. C'est pourquoi nous avons centré notre propos sur l'interprétation technique et fonctionnelle des différents éléments de la série.

\begin{tabular}{|l|c|c|c|}
\hline Matière & Saint-Périer, 1926 & Taborin, 1993 & MAN 2007 \\
\hline Os & 10 & - & 15 \\
\hline Dent & 2 & - & 2 \\
\hline Coquille & 3 & 6 & 6 \\
\hline Total & $\mathbf{1 5}$ & - & $\mathbf{2 3}$ \\
\hline
\end{tabular}

Tabl. 8 - Inventaire des objets en os, dent et coquille de la couche B.

\begin{tabular}{|l|r|}
\hline Déchets de fabrication d'aiguilles et ébauche & 3 \\
\hline Aiguille à chas & 1 \\
\hline Ébauche de pointe & 1 \\
\hline Pièce intermédiaire (ciseau) & 2 \\
\hline Affûtoir & 7 \\
\hline Pendeloque & 1 \\
\hline Total & $\mathbf{1 5}$ \\
\hline
\end{tabular}

Tabl. 9 - États techniques des objets en os de la couche B. 


\section{Matières, états techniques et catégories fonctionnelles}

Au niveau du travail de l'os, l'article de Saint-Périer fait référence à la seule présence d'objets finis (les aiguilles à chas et la pendeloque phalloïde). Une lecture résolument technique du matériel d'étude permet aujourd'hui non seulement d'affiner la sériation de la collection en identifiant déchets de fabrication et ébauche, mais également d'élargir l'éventail fonctionnel de l'outillage avec la présentation de ciseaux et d'affûtoirs (tabl. 9).

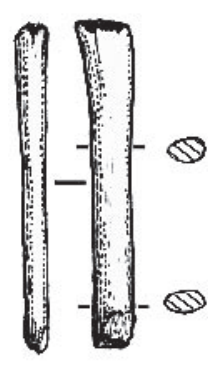

1

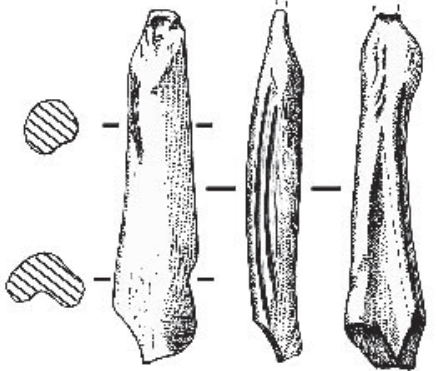

2
3
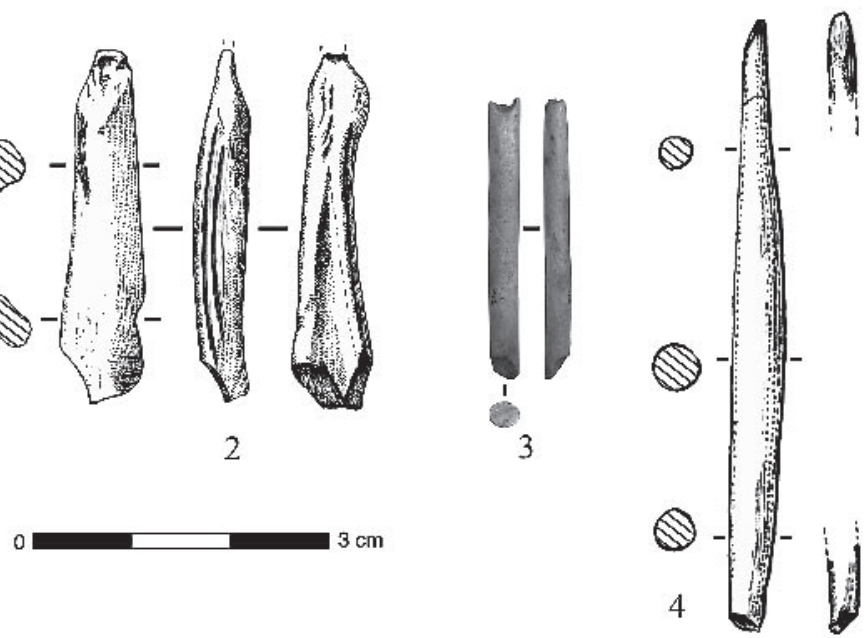

Fig. 21 - Aiguilles à chas. $\mathrm{N}^{\circ} 1$ : ébauche; $\mathrm{n}^{\circ} 2:$ déchet; $\mathrm{n}^{\circ} 3:$ objet fini et pointe en os $\left(\mathrm{n}^{\circ} 4\right)$.

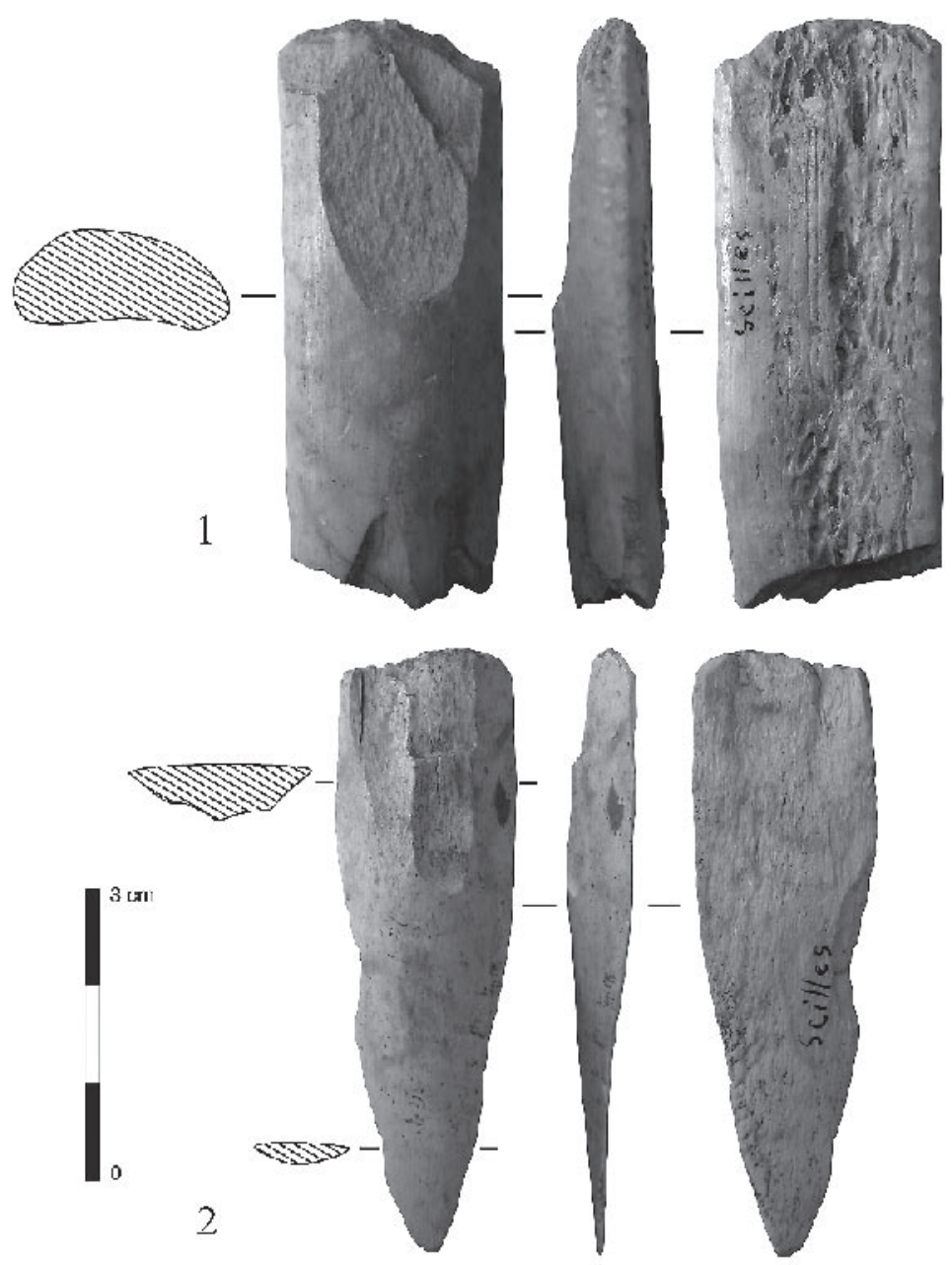

Fig. 22 - Ciseaux en os. $\mathrm{N}^{\circ} 1$ : fragment proximal; $\mathrm{n}^{\circ} 2$ : éclat d'utilisation. 
Nous interprétons comme une matrice à aiguilles à chas un métacarpe gauche de chamois duquel au moins une baguette rectiligne a été extraite par rainurage, tel ce fragment qui porte des traces de raclage sur la totalité de son volume et la marque d'un sectionnement transversal à son extrémité la moins large (fig. $21, \mathrm{n}^{\circ} 1$ ). Une troisième pièce, largement raclée au flanc de burin, peut être considérée comme un déchet de fabrication et serait consécutive à la régularisation de ces mêmes baguettes (fig. $21, \mathrm{n}^{\circ}$ 2). Le stade final de cette chaîne opératoire, commune à bien d'autres séries magdaléniennes, est illustré par un fragment d'aiguille cassé au niveau de la pointe et du chas (fig. $21, n^{\circ} 3$ ). Une seconde aiguille, entière, est figurée par Saint-Périer et fait partie des pièces aujourd'hui disparues (Saint-Périer, 1926, fig. 6, $\mathrm{n}^{\circ} 7$ ). Nous hésitons à voir dans un objet fusiforme une
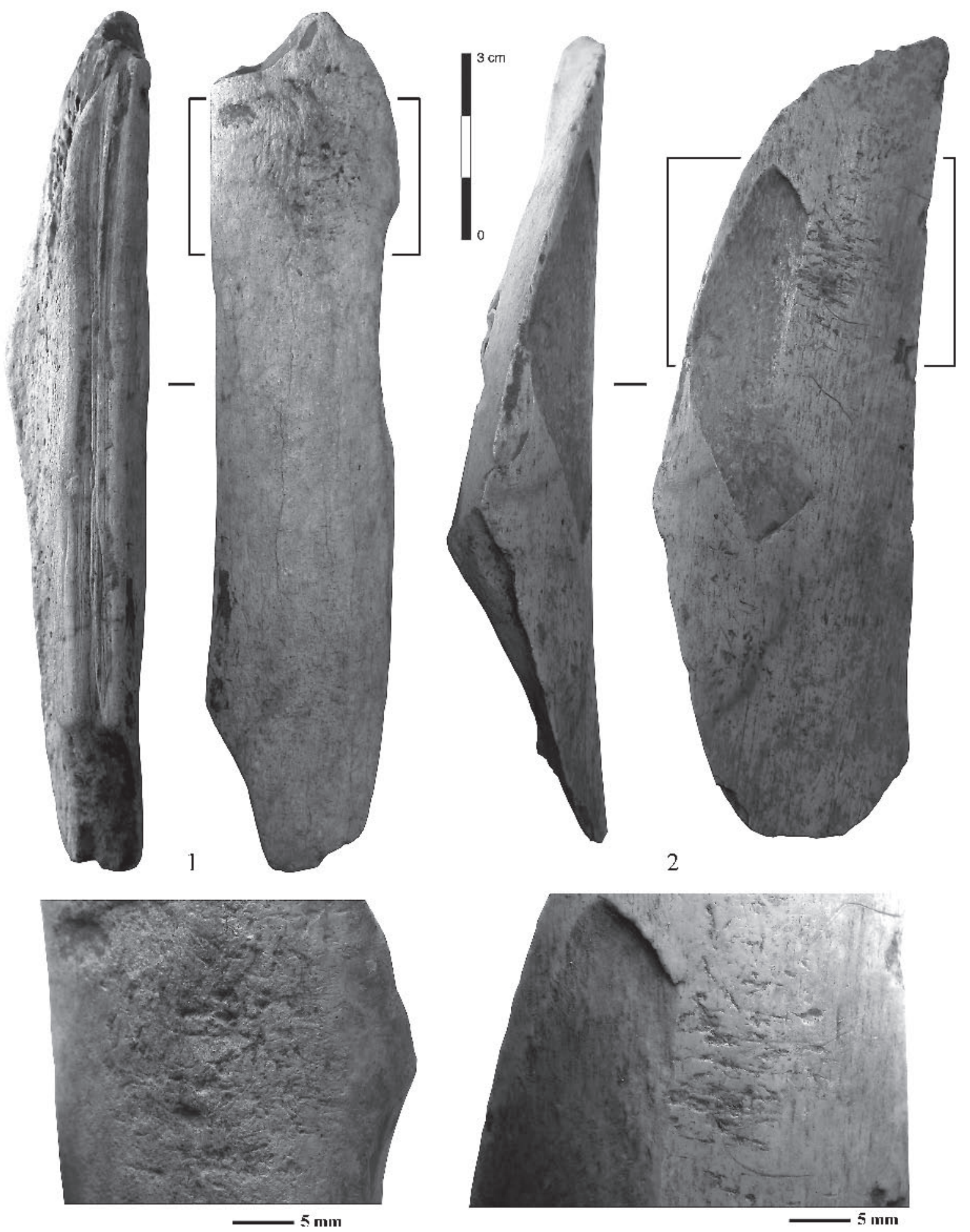

Fig. 23 - Affûtoirs en os. $\mathrm{N}^{\circ} 1$ : affûtoir double avec traces de rainurage; détail de l'une des plages d'utilisation; $\mathrm{n}^{\circ} 2$ : affûtoir simple; détail de la plage d'utilisation. 


\begin{tabular}{|l|l|c|c|c|c|}
\hline \multicolumn{1}{|c|}{ Espèce } & \multicolumn{1}{c|}{ Anatomie } & Longueur & Largeur & Épaisseur & $\begin{array}{c}\text { Épaisseur de } \\
\text { tissu compact }\end{array}$ \\
\hline Renne & tibia D & 98 & 22 & 13 & 7 \\
\hline Ongulé & diaphyse & 90 & 27 & 19 & 7 \\
\hline Ongulé 3/4 & diaphyse & 128 & 42 & 19 & 10 \\
\hline Ongulé 3/4 & diaphyse & 114 & 45 & 18 & 10 \\
\hline Ongulé 3/4 & diaphyse & 131 & 28 & 19 & 11 \\
\hline Cheval & tibia G & 153 & 44 & 21 & 14 \\
\hline Ongulé & diaphyse & 76 & 32 & 17 & 14 \\
\hline
\end{tabular}

Tabl. 10 - Dimensions des affûtoirs en os de la couche B (en mm).

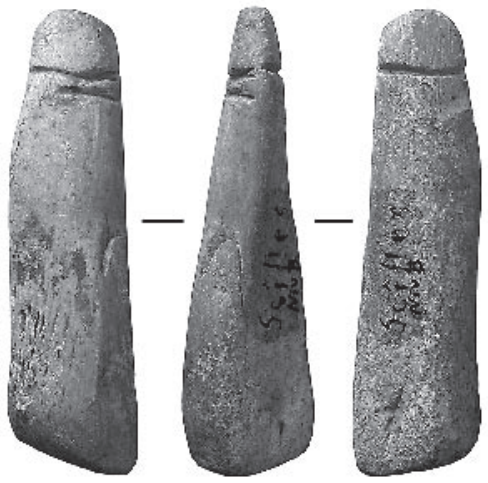

1

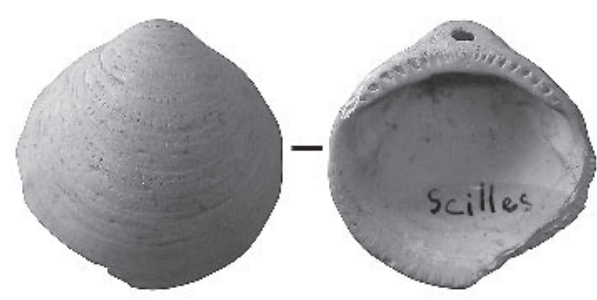

$4 \mathrm{a}$

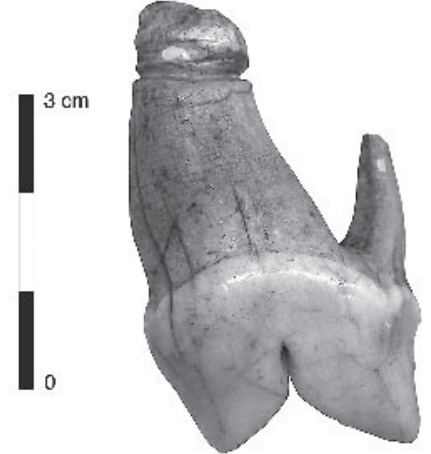

2

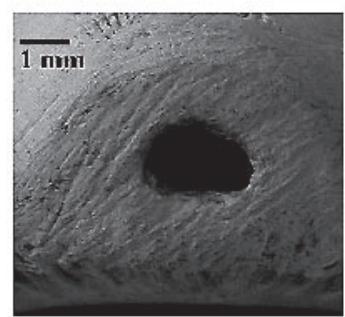

$4 \mathrm{~b}$

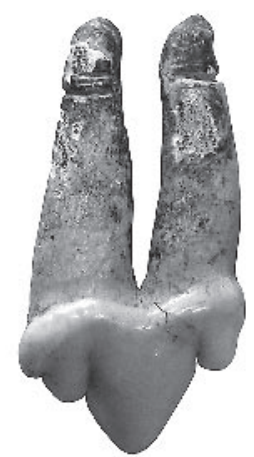

3

Fig. 24 - Éléments de parure. $\mathrm{N}^{\circ} 1$ : pendeloque en os $; \mathrm{n}^{\text {os }} 2$ et $3:$ dents de Lion aménagées $\left(\mathrm{n}^{\circ} 2: \mathrm{M} 1\right.$ inférieure droite; $\mathrm{n}^{\circ} 3: \mathrm{P} 4$ inférieure gauche), $\mathrm{n}^{\circ} 4 \mathrm{a}:$ Glycymeris glycymeris perforée $; \mathrm{n}^{\circ} 4 \mathrm{~b}:$ détail de la perforation par abrasion; $\mathrm{n}^{\text {os }} 5$ et $6:$ Turritella eryna perforées.

ébauche d'aiguille à chas car elle est trop épaisse (fig. 21, $\mathrm{n}^{\circ} 4$ ). Nous serions plus enclins à y déceler l'ébauche d'un objet bipointe et dépourvu de perforation.

Deux éléments portent des traces d'écrasement et des négatifs d'enlèvements consécutifs à un fonctionnement en pièces intermédiaires de type ciseau. L'un d'eux (62 x $23 \times 9 \mathrm{~mm})$ est interprété comme un fragment proximal (fig. 22, $\left.\mathrm{n}^{\circ} 1\right)$. L'autre $(64 \times 19 \times 6 \mathrm{~mm})$ est un éclat qui s'est détaché du corps de l'outil lors de son utilisation (fig. 22, $\mathrm{n}^{\circ} 2$ ). Pour le Paléolithique supérieur, de tels outils sont surtout réalisés sur bois de Cervidé, beaucoup plus rarement sur os. Ceux de la grotte des Scilles ont été façonnés par raclage à partir de volumes issus plutôt d'os longs de grands Ongulés et dont on ignore les modalités de débitage.

Sept fragments de diaphyses osseuses présentent les stigmates caractéristiques des affûtoirs dont le signalement, en contexte paléolithique supérieur, est directement soumis à une recherche ciblée parmi les ossements «bruts» (fig. 23) (Patou-Mathis dir., 2002).
À la grotte des Scilles, on dénombre quatre affûtoirs doubles - résultat d'une utilisation prolongée - et trois simples. Il s'agit de volumes allongés aux dimensions hétérogènes, de section planoconvexe et obtenus par percussion sur l'os (tabl. 10). L'un d'eux porte sur un bord des traces de rainurage qui correspondent à l'extraction de volumes rectilignes et qui sont antérieures à son utilisation en tant qu'affûtoir (fig. 23, $\mathrm{n}^{\circ} 1$ ). Au vu de l'épaisseur du tissu compact de l'os $(11 \mathrm{~mm})$, on pourrait interpréter ces traces comme celles d'un débitage destiné à l'obtention de volumes pour la fabrication de ciseaux tels que ceux décrits cidessus et non pas pour des aiguilles à chas.

Il convient d'ajouter à l'inventaire la pendeloque phalloïde déjà mentionnée (fig. $24, \mathrm{n}^{\circ} 1$ ). Cet objet probablement façonné à partir d'une diaphyse de grand Ongulé - est raclé et poli sur la totalité de son volume (48 x 13 x $11 \mathrm{~mm})$. Un sillon circulaire, localisé à son extrémité la plus étroite, a été réalisé au trait de silex et ne paraît pas très émoussé. Saint-Périer, qui l'a 


\begin{tabular}{|l|c|c|}
\cline { 2 - 3 } \multicolumn{1}{c|}{} & Complet & Fragmentaire \\
\hline Callista chione & 1 & - \\
\hline Glycymeris glycymeris & $1(\mathrm{P})$ & - \\
\hline Glycymeris sp. & - & 2 \\
\hline Turritella eryna & $2(\mathrm{P})$ & - \\
\hline Total & $\mathbf{4}$ & $\mathbf{2}$ \\
\hline
\end{tabular}

Tabl. 11 - Coquilles de la couche B (P : présence d'une perforation).

intégré dans une analyse comparative assez détaillée, a publié trois de ses faces et l'interprétait comme une figuration de phallus (op. cit., p. 27-28, fig. 7).

Comme nous l'avons déjà mentionné, les dents de grands Carnivores, et notamment celles de Lion, sont rares dans la parure du Paléolithique supérieur. Plus encore que les canines, les carnassières et les molaires n'ont été qu'exceptionnellement utilisées (Taborin, 1995). Les deux dents de la grotte des Scilles (P4 inférieure gauche et M1 inférieure droite) se distinguent du reste du corpus par le fait que leurs racines multiples portent non pas une perforation comme à Enlène, à Isturitz ou au Mas d'Azil, mais une gorge réalisée par sciage au trait de silex, à l'instar de la pendeloque en os décrite plus haut (fig. 24, $\mathrm{n}^{\text {os }} 2$ et 3 ). Ces deux dents proviennent-elles d'individu(s) chassé(s) ou ont-elles été récoltées sur une (des) carcasse(s) plus ou moins fossile(s)? Il est bien difficile de conclure quant au mode d'acquisition de ces deux éléments qui sont les seuls restes de la collection à être rapportés au Lion.

Six coquillages figurent actuellement à l'inventaire et sont comptabilisés comme objets de parure par Y. Taborin (1993, p. 445). Ils signent la présence de trois espèces (Turritella eryna, Callista chione et Glycymeris glycymeris). La fragmentation de deux coquilles empêche une attribution au-delà de l'espèce Glycymeris sp. (fig. 24, $\mathrm{n}^{\text {os }} 4,5$ et 6 ; tabl. 11).

Les deux tests de Turritella eryna ont été perforés à la base, peut-être par percussion. Le lieu de collecte de ce gastéropode miocène est à rechercher dans le SudOuest français (zones VI-Dax et VII-Salies de Béarn) plutôt qu'en Méditerranée (Taborin, op. cit., p. 87). Les coquillages miocènes en général et Turritella eryna en particulier sont présents dans d'autres gisements de la vallée de la Save : Lespugue/les Bœufs, Lespugue/les Harpons et Lespugue/les Rideaux (Taborin, op. cit., p. 476).

Callista chione et Glycymeris glycymeris sont des coquilles d'âge pliopléistocène. Leur origine renvoie plutôt vers les rivages de l'Atlantique car aucune espèce n'est strictement méditerranéenne (même si cette origine n'est toutefois pas à exclure a priori) (Taborin, op. cit., p. 392 et 401). L'exemplaire de Callista chione est une espèce rare dans les assemblages du Paléolithique supérieur qui est attestée dans le Magdalénien supérieur de la Vache (Ariège) et de la Crouzade (Aude). L'un des deux exemplaires de Glycymeris glycymeris découverts aux Scilles porte une perforation réalisée par abrasion au niveau du crochet. Ce taxon se retrouve dans les phases moyenne et supérieure du Magdalénien avec une belle régularité.

\section{Discussion}

Dans la couche B de la grotte des Scilles, l'os, la dent et la coquille ont été utilisés pour la confection d'objets de transformation (aiguilles à chas, ciseaux, affûtoirs) et de parure. C'est à des activités d'assemblage (aiguilles) et de fragmentation (ciseaux, affûtoirs) des matières d'œuvre que sont destinées les productions sur os. Aucun de ces éléments - à part, peut-être l'objet fusiforme bipointe - ne renvoie de manière explicite à la sphère des projectiles, à l'inverse de ceux réalisés sur bois de Cervidé.

Les modalités d'acquisition de chacun des matériaux sont probablement multiples et à mettre en liaison avec, d'une part, certaines des activités cynégétiques documentées par ailleurs (cf. infra) et, d'autre part, des activités de collecte (coquilles de la zone atlantique, les dents de Lion éventuellement) ou des échanges. Si les différentes catégories fonctionnelles relèvent parfois de mêmes gestes et actions techniques sur la matière, elles se différencient par la longueur des chaînes opératoires de fabrication reconstituées, les plus longues étant centrées sur les productions en os (aiguilles à chas, pendeloque et ciseaux). Le domaine de la parure est le seul à faire appel à des matériaux différents : perforations par percussion ou abrasion des coquilles et rainures de suspension aménagées sur les dents de félin et la pendeloque en os ont assuré la mise en fonction des objets (fig. 25).

La série des Scilles peut être comparée, sur la base des déterminations typologiques et des décomptes de René et Suzanne de Saint-Périer, avec celles issues de deux autres cavités des gorges de la Save fouillées par eux-mêmes : les grottes des Bœufs et des Harpons (Saint-Périer, 1912, 1920 et 1924) (tabl. 12). La grotte des Scilles s'individualise ainsi par l'absence de poinçons, de lissoirs et d'os décorés qui sont, en revanche, présents aux Harpons ou aux Bœufs dans des proportions que l'imprécision des effectifs ne permet pas d'évaluer. À l'inverse, seul le niveau B des Scilles a fourni des ciseaux et des affûtoirs. Les quantités de pendeloques sur dents et coquilles semblent équivalentes, même si des différences existent dans la nature des éléments anatomiques et des espèces déterminées (carnassière et prémolaire de Lion aux Scilles, incisives et canines d'Herbivore et de petit Carnivore aux Bœufs et aux Harpons).

On peut rechercher la raison de ces différences en invoquant d'emblée les décalages chronologiques qui existent entre les ensembles archéologiques de ces trois grottes. En effet, si le niveau B des Scilles est plus ancien que celui des Bœufs et que les niveaux A, B et $\mathrm{C}$ des Harpons (phases ancienne et moyenne du Magdalénien), il est plus récent que le niveau $\mathrm{D}$ de ce dernier gisement (Solutréen). La diversité des activités, perceptibles au travers des différentes catégories d'objets représentées, a pu également induire les variations observées dans l'outillage. Enfin, on ne peut négliger l'impact des conditions de conservation de la matière osseuse (assez mauvaise aux Scilles) et les modalités de constitution des séries (sélection dès la fouille de certaines catégories fonctionnelles, dispersion des 


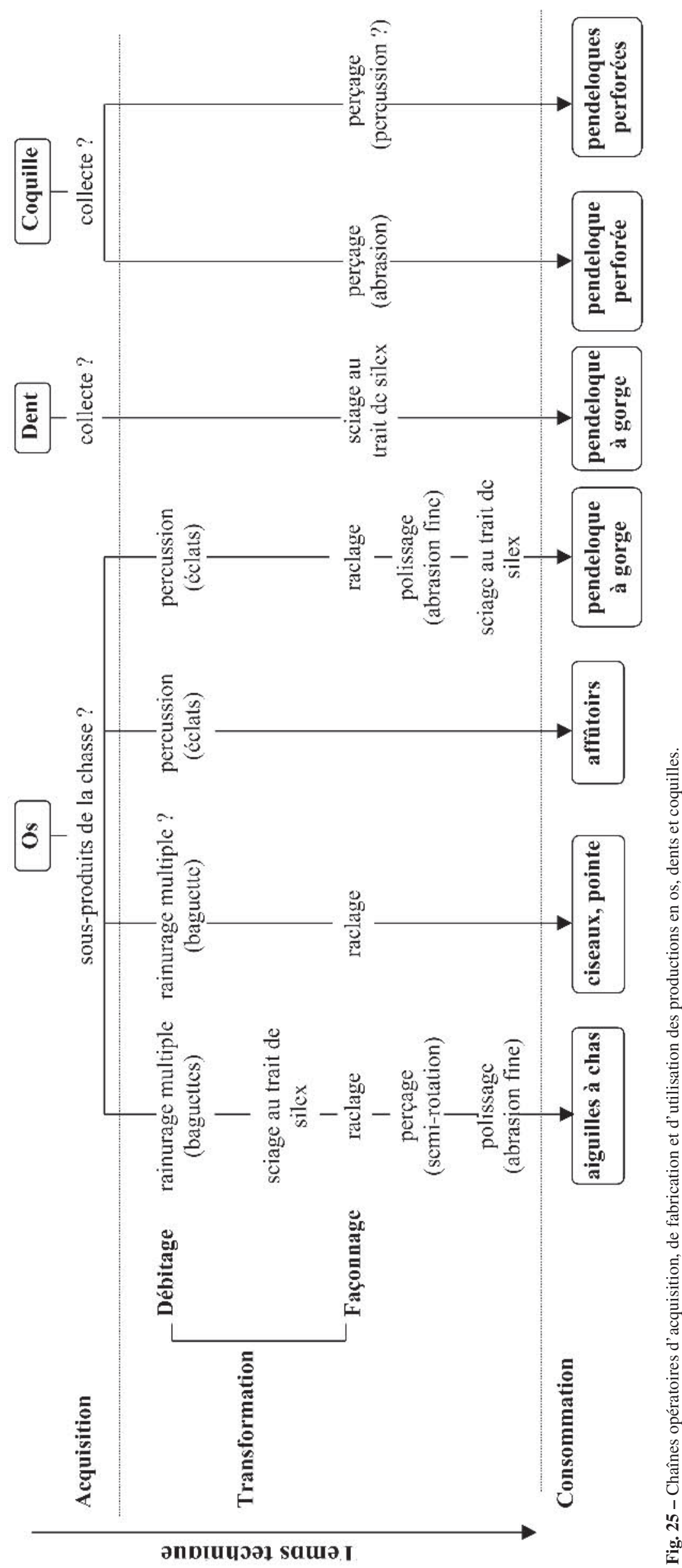




\begin{tabular}{|c|c|c|c|c|c|c|c|}
\hline & & \multirow{3}{*}{$\begin{array}{c}\text { Les Scilles } \\
\text { niveau B }\end{array}$} & \multirow{2}{*}{\multicolumn{4}{|c|}{ Les Harpons }} & \multirow{4}{*}{$\begin{array}{c}\text { Les Bœufs } \\
1\end{array}$} \\
\hline & & & & & & & \\
\hline & & & niveau $A$ & niveau $B$ & niveau C & niveau D & \\
\hline \multirow{11}{*}{ Os } & aiguille à chas & 9 & «plusieurs» & «plusieurs» & & & \\
\hline & lissoir & & «assez nombreuX» & "quelques fgts.» & & & \\
\hline & poinçon & & «plusieurs» & & «quelques» & & "quelques" \\
\hline & spatule & & & & 2 & & \\
\hline & affûtoir & 7 & & & & & \\
\hline & cuiller & & & 1 & & & \\
\hline & ciseau & 2 & & & & & \\
\hline & sagaie & & & & & & \\
\hline & gravure & & 4 & 2 & 2 & 1 & 2 \\
\hline & sculpture & & & & & & 1 \\
\hline & pendeloque & 1 & 1 & & & & \\
\hline Ivoire & pendeloque & & & & & & 1 \\
\hline Dent & pendeloque & 2 & 3 & 3 & 2 & & \\
\hline Coquille & pendeloque & 6 & «plusieurs» & «plusieurs» & «plusieurs" & & 1 \\
\hline
\end{tabular}

Tabl. 12 - Objets sur os, dent, ivoire et coquilles des grottes des Scilles, des Harpons et des Bœufs (fouilles Saint-Périer).

collections, repérages récents d'objets passés inaperçus à l'époque) pour interpréter les corpus à disposition.

\section{DIAGNOSTIC ARCHÉOZOOLOGIQUE DES VESTIGES OSSEUX (C. L. et F. D.)}

L'ensemble osseux tel qu'il nous a été confié pour étude renfermait plusieurs pièces dont la surface montrait des stigmates techniques évidents. Nous avons exclu ces pièces de notre corpus, considérant qu'elles relevaient d'abord de l'étude des systèmes de production des industries en os et bois de Cervidé. Elles sont d'ailleurs présentées dans les chapitres correspondants (cf. supra).

L'examen que nous avons conduit porte sur 125 éléments (ossements, bois de Cervidé, dents). Il est évident que la faiblesse de cet effectif en limite la portée analytique. À défaut d'interprétations, nous proposerons donc un diagnostic archéozoologique de la faune de la grotte des Scilles.

Cette restriction est d'autant plus nécessaire que la série a indéniablement fait l'objet d'un tri. Si les SaintPérier ont pu récolter tous les vestiges osseux lors de la fouille, ils n'ont conservé que ceux qu'ils jugeaient dignes d'intérêt: les fragments pouvant faire l'objet d'une détermination taxinomique ainsi que ceux qui présentaient des traces liées à une intervention anthropique. Les restes indéterminables sont presque absents et les seuls fragments de diaphyses présents portent tous des stigmates rappelant ceux des «retouchoirs». Par ailleurs, selon Saint-Périer (1926, p. 20), le niveau B contenait de nombreux fragments de «galets éclatés par le feu» : l'absence de tout élément carbonisé ou portant des traces de brûlure dans l'accumulation osseuse renforce donc l'hypothèse d'un ramassage sélectif. Nous pouvons cependant évaluer la représentativité de la série, au moins selon certains critères. Dans sa publication de 1926, Saint-Périer propose une liste des espèces découvertes dans le niveau $\mathrm{B}$, qu'il

\begin{tabular}{|l|r|r|}
\hline \multicolumn{1}{|c|}{ Espèce } & NR & \% NRD \\
\hline Renne & 40 & 40,8 \\
Bovinés & 21 & 21,4 \\
Chamois & 14 & 14,3 \\
Cheval & 9 & 9,2 \\
Cerf & 3 & 3,1 \\
Saïga & 2 & 2,0 \\
\hline Total Ongulés déterminés & 89 & 90,8 \\
\hline Renard & 7 & 7,1 \\
Loup & 2 & 2,0 \\
\hline Total Carnivores déterminés & 9 & 9,2 \\
\hline Grands Ongulés & 12 & \\
Moyens Ongulés & 8 & \\
Grands Carnivores & 2 & \\
Petits Carnivores & 1 & \\
Non déterminés & 4 & \\
\cline { 1 - 2 } Nombre de restes total & $\mathbf{1 2 5}$ & \\
\hline
\end{tabular}

Tabl. 13 - Distribution taxinomique des vestiges osseux (nombre de restes et \% du nombre de restes déterminés).

complète par quelques indications sur la nature des vestiges. Il nous a paru intéressant de reproduire ces informations afin de les comparer avec nos propres observations (tabl. 13). Saint-Périer (1926, p. 20-21) mentionne ainsi la présence de :

- Cheval (Equus caballus) avec des «os des membres brisés et [des] dents »;

- Bovinés (Bos sp.) avec des «os du carpe et [des] dents »;

- Renne (Rangifer tarandus) qui «est l'animal dont les débris sont les plus abondants» avec des «os des membres, [des] bois [et des] dents»;

- Cerf (Cervus elaphus) avec «une portion de mandibule et une phalange»;

- Chevreuil (Capreolus capreolus) avec «un calcaneum et une extrémité de radius»;

- Ovinés (Ovis sp.) avec «une extrémité inférieure de métacarpien ou de métatarsien dont il ne subsiste que les deux trochlées, sans qu'il soit possible de préciser davantage à cause de la fragmentation de la pièce» (détermination M. Boule); 
- Chamois (Rupicapra rupicapra) «presque aussi abondant que le renne» avec des «os des membres, [des] dents [et des] chevilles osseuses »;

- Antilope saïga (Saiga tatarica) : «un métacarpien complet : le seul os non brisé par l'Homme, dans ce gisement, a été rapporté par M. Boule à cet animal, dont on sait la rareté dans les Pyrénées »;

- Loup (Canis lupus) avec «une canine, une molaire et une incisive»;

- Renard (Vulpes vulpes) avec des «os des membres et dents »;

- Lion des cavernes (Panthera spelaea) avec «une carnassière inférieure et une deuxième molaire inférieure ».

Ces informations, bien qu'imprécises, sont néanmoins précieuses, car elles s'accordent à quelques détails près avec nos propres déterminations. Retenons ainsi que nos décomptes placent les Bovinés, non pas le Chamois, en seconde place des espèces les mieux représentées et nous n'avons pas identifié de Chevreuil, mais un reste supplémentaire d'Antilope saïga et de Cerf élaphe. Ces détails mis à part, l'ensemble osseux conservé au MAN correspond à celui décrit par SaintPérier en 1926.

Saint-Périer mentionne par ailleurs «l'absence des oiseaux et des poissons, assez abondants dans d'autres grottes de Lespugue». Le fait qu'il ait recherché ces vestiges suppose la mise en œuvre d'une fouille relativement minutieuse.

Pour résumer, l'ensemble osseux conservé au MAN correspond à celui que Saint-Périer décrit dans sa publication de 1926. Néanmoins, l'absence de certains éléments - fragments osseux peu caractéristiques d'un point de vue taxinomique ou dépourvus de traces anthropiques - conforte l'hypothèse d'un ramassage sélectif des ossements privilégiant les éléments les plus remarquables.

\section{Préambule taphonomique}

De manière générale, la conservation de la matière osseuse est médiocre (tabl. 14). La plupart des ossements $\left(77,9 \%{ }^{5}\right)$ sont exfoliés et les pièces les plus altérées présentent des plages d'érosion qui ont creusé la matière, devenue blanchâtre et très friable. Plus de la moitié des vestiges montrent également des craquelures $(54,4 \%)$. Des imprégnations noirâtres (manganèse ?), relativement fréquentes, touchent de nombreuses pièces, parfois de façon envahissante. Elles

\begin{tabular}{|l|c|}
\hline \multicolumn{1}{|c|}{ Altération } & \% observé \\
\hline Exfoliation & 77,9 \\
\hline Craquelure & 54,4 \\
\hline Radicelle & 32,4 \\
\hline Morsure & 7,4 \\
\hline Trace de silex & 26,5 \\
\hline
\end{tabular}

Tabl. 14 - Altérations taphonomiques observées sur les ossements (*dents et bois exclus). constituent alors une gêne évidente lors de la lecture des surfaces osseuses, en masquant certaines portions. Les traces de dissolution, observées sous forme de cupules de percolation, sont parfois présentes, rarement envahissantes.

Ces stigmates dits «d'origine abiotique » sont directement liés aux conditions de formation du site : climat, caractéristiques édaphiques de la structure d'accueil... Leur décryptage individuel est complexe; retenons ici que ces phénomènes abiotiques sont les principaux responsables de la dégradation des ossements. Des empreintes de radicelles sont par ailleurs présentes sur un tiers des vestiges $(32,4 \%)$.

En dépit de ces nombreuses altérations, plus de $23 \%$ des ossements montrent des traces de découpe de boucherie, ce qui conforte l'origine anthropique de l'accumulation. En effet, les grands Carnivores - autres prédateurs possibles des Ongulés retrouvés dans la grotte - sont très peu représentés au sein de l'ensemble osseux. De fait, la présence de l'Hyène, non mentionnée dans l'inventaire de Saint-Périer, reste incertaine et le Loup est attesté par deux vestiges seulement, des dents... peut-être même apportées par les hommes, à l'instar des deux restes dentaires de Lion aménagés en éléments de parure. Le Carnivore le mieux représenté avec sept restes est le Renard, que l'on sait par ailleurs fréquenter les grottes dans lesquelles il aménage son terrier. La présence de ses ossements parmi les vestiges archéologiques pourrait donc être fortuite («intrusive»). Les cinq traces de morsures relevées lors de l'examen taphonomique pourraient lui être attribuées. Mais elles conforteraient alors son intervention secondaire, sur une accumulation osseuse déjà constituée. En effet, les grands Ongulés sur lesquelles ces traces ont été observées constituent des proies bien trop imposantes pour qu'il ait pu les chasser, puis les tirer jusque dans la grotte. Notons enfin qu'aucun de ses ossements ne porte de traces de découpe au silex.

L'accumulation osseuse mise au jour dans ce niveau archéologique de la grotte des Scilles correspond donc probablement aux vestiges des activités alimentaires des groupes paléolithiques qui, à l'époque, occupaient les lieux.

\section{Approche archéozoologique}

\section{Liste de faune et tableau de chasse}

L'ensemble osseux se compose de 125 vestiges : 98 ont été attribués à une espèce précise, 23 à une classe de taille et quatre seulement sont restés sans aucune attribution.

Les Ongulés sont, de loin, les mieux représentés avec 109 restes dont 89 sont déterminés au rang de l'espèce. Le Renne réunit 40 vestiges, c'est - comme le mentionnait déjà Saint-Périer - le taxon le mieux représenté. Il est suivi par les Bovinés, puis le Chamois. Pour ce dernier, nos observations diffèrent de celles de Saint-Périer (1926, p. 20) qui évoquait un «animal presque aussi abondant que le renne». L'absence de 
données détaillées (décomptes et déterminations précises) ne nous permet pas d'expliquer cette divergence : perte de matériel ou désaccord taxinomique? Le Cerf et l'Antilope saïga closent la liste. Cette dernière espèce mérite cependant quelques mots, car elle reste rare dans la région des Pyrénées. Saint-Périer (1926, p. 21) se demande d'ailleurs si «l'os [il n'avait identifié qu'un seul vestige] n'a point été apporté dans la grotte adhérant encore à une peau de Saïga destinée à servir de vêtement ou de parure».

L'ordre des Carnivores rassemble 12 ossements. Le Renard, avec sept restes, est le mieux représenté.

\section{Nombre d'individus}

L'estimation du nombre minimum d'individus (NMI) représentés pour chaque espèce modifie légèrement l'aperçu obtenu d'après le nombre de restes, puisque les Bovinés prennent la tête du cortège avec quatre individus. Le Renne suit avec trois sujets alors que le Cheval et le Chamois en alignent deux chacun.

Cet ajustement nous incite à pondérer la remarque de Saint-Périer (1926, p. 21) concernant «l'abondance des formes froides (renne et chamois)» dans l'ensemble de la grotte des Scilles.

\section{Âge, sexe et saisonnalité}

Nous ne disposons d'aucun indice permettant d'estimer le sexe des individus présents dans l'accumulation. De même, l'absence de restes de dents lactéales nous prive d'indications de saisonnalité. En revanche, l'examen des restes dentaires (usure des surfaces occlusales) nous a fourni quelques indications concernant l'âge des individus (NMIc : nombre minimum d'individu de combinaison). En l'absence de séries dentaires, les indications restent imprécises :

- Bovinés : quatre adultes dont un sujet plus jeune;

- Renne : trois adultes dont un sujet plus âgé;

- Cheval : deux adultes dont un individu plus jeune;

- Chamois : un adulte et un juvénile.

\section{Distribution anatomique des vestiges}

L'effectif enregistré pour chaque espèce est trop faible pour appuyer une comparaison détaillée de la représentation anatomique. Néanmoins, les trois principaux taxons - le Renne, les Bovinés et le Chamois répondent à quelques détails près au même schéma que nous proposons de décrire brièvement (tabl. 15). Le regroupement des vestiges en régions anatomiques en souligne par ailleurs les principales caractéristiques. Ainsi, la région du squelette axial (côtes et vertèbres) comme celle des ceintures (scapula et coxal) sont fortement déficitaires pour les trois espèces alors que la tête est, à l'exception du Chamois, celle qui est la mieux représentée. Les éléments des «bas de pattes» sont plus nombreux (toutes proportions gardées) que les os longs, sauf pour les Bovinés.
Ce schéma anatomique est difficile à apprécier dans la mesure où nous ne pouvons pas écarter l'hypothèse d'un tri des ossements lors de la fouille. En effet, les éléments les plus fragiles - côtes, vertèbres, coxaux, scapulas - souvent peu diagnostiques d'un point de vue spécifique, sont très largement sous-représentés. Leur déficit peut donc sembler suspect. Toutefois, il pourrait aussi signaler le dépeçage des carcasses en «gros quartiers » sur le lieu de capture, puis un transport des unités les plus riches seulement vers le campement. Cela dit, il faut noter que la présence de dents et des «bas de pattes » tend à infirmer l'hypothèse d'un transport sélectif à la faveur des unités anatomiques les plus riches. En revanche, la rareté des fragments de diaphyses, déjà mentionnée, alors que selon les termes mêmes de Saint-Périer le métacarpien de Saïga est «le seul os non brisé par l'homme», conforte l'idée d'un ramassage sélectif des vestiges lors de la fouille.

Ces quelques remarques appellent à la prudence et il semble préférable de se garder de toute interprétation de l'accumulation en termes de modalités de transport et d'exploitation des carcasses.

\section{Synthèse}

Il semble délicat de proposer une quelconque interprétation archéozoologique de cet ensemble osseux qui, rappelons-le, ne représente probablement qu'un échantillon des vestiges osseux abandonnés par les Magdaléniens. En lieu et place d'interprétation, il semble donc plus raisonnable de pointer les informations que nous avons pu recueillir :

- la discrétion des carnivores, et plus particulièrement des grands prédateurs, conforte l'origine anthropique de l'accumulation osseuse;

- les groupes préhistoriques qui ont séjourné aux abords du site ont pratiqué une chasse diversifiée. La

\begin{tabular}{|l|c|c|c|}
\hline \multicolumn{1}{|c|}{ Élément anatomique } & Renne & Bovinés & Chamois \\
\hline Crâne & 1 & 2 & 1 \\
Mandibules & 28 & 12 & 2 \\
Dents isolées & 29 & 14 & 4 \\
\hline Total tête & & 1 & \\
\hline Scapula & & 1 & \\
\hline Total ceintures & 3 & & 1 \\
\hline Humérus & & 1 & 1 \\
Radius & & 2 & 2 \\
Ulna & & 2 & 4 \\
Fémur & 3 & 5 & \\
Tibia & 1 & & 3 \\
\hline Total os longs & 3 & & 2 \\
\hline Métacarpes & 2 & 1 & 6 \\
Métatarses & 1 & & $\mathbf{1 4}$ \\
Métapodes & 1 & & \\
Carpiens & & & \\
Tarsiens & & & \\
Phalange 1 & $\mathbf{4 0}$ & $\mathbf{2 1}$ & \\
\hline Total bas de pattes & & & \\
\hline Total & & & \\
\hline
\end{tabular}

Tabl. 15 - Distribution anatomique des restes de Renne, de Bovinés et de Chamois (nombre de restes). 
présence des Bovinés, du Renne, du Cheval, mais aussi du Chamois montre que les chasseurs ont profité de la localisation de la grotte, implantée entre milieu escarpé et plaine;

- ils n'ont apparemment exercé aucune sélection lors de la capture de leur gibier;

- les modalités de transport des carcasses sont difficiles à apprécier à cause du ramassage sélectif des vestiges lors de la fouille. En revanche, les traces de découpe et la fragmentation apparemment systématique des os longs indiquent le prélèvement de la viande et de la moelle;

- la présence de plusieurs extrémités articulaires semble indiquer qu'elles n'étaient pas utilisées dans les activités alimentaires (confection de «bouillons gras ») ni domestiques (combustibles);

- en l'absence d'indications relatives à la saison de capture des gibiers, il semble délicat de se prononcer sur la nature de l'occupation. Cependant, le nombre d'individus chassés et le poids de viande qu'ils représentent nous incitent à écarter l'hypothèse d'une «halte de chasse» au profit d'un séjour de plus longue durée... à moins qu'il ne s'agisse d'une succession d'épisodes plus brefs ! Les informations dont nous disposons ne nous permettent pas de conclure.

\section{LA LAMPE EN GRÈS \\ DE LA GROTTE DES SCILLES (S. A. de B.)}

La grotte des Scilles a livré une lampe en grès trouvée lors des fouilles de Saint-Périer en 1923-1924. Elle a été publiée dès cette époque (Saint-Périer, 1926), mais elle a disparu par la suite, vraisemblablement dérobée entre le décès de la comtesse de Saint-Périer en 1978 et l'arrivée de la collection au MAN en 1980. Elle a été mentionnée par plusieurs auteurs dans différents inventaires de lampes (Bastin et Chassaing, 1940; Glory, 1961; Viré, 1934). Je n'ai moi-même pas pu l'examiner lors de la préparation de ma thèse sur l'éclairage au Paléolithique car elle ne figurait pas avec le matériel conservé au MAN, et je me suis contentée de reprendre les informations fournies par Saint-Périer (Beaune, 1987a, p. 208). Ce n'est que plusieurs années plus tard que cette lampe a été «redécouverte». Elle se trouvait dans une collection privée jusqu'à ce que le musée en fasse l'acquisition en salle des ventes à la fin des années 1980 ( ${ }^{\circ}$ d'inventaire MAN 86775) avec un certain nombre d'autres pièces. J'ai pu l'examiner en 1990 et l'ai brièvement publiée à deux reprises (Beaune, 2003 et 2004).

Saint-Périer donne quelques indications concernant les circonstances de sa découverte : ses deux fragments ont été retrouvés dans le niveau B, la «base» en 1923 et la «partie terminale» en 1924 (Saint-Périer, 1926, p. 30). Il est curieux que les deux fragments aient été retrouvés lors de campagnes de fouille différentes puisque Saint-Périer précise bien que la lampe gisait à environ $1,5 \mathrm{~m}$ du surplomb, en avant de la grotte, et qu'il ne manquait que «quelques fragments de ses bords, qui, effrités, n'ont pu être recueillis» (Saint-
Périer, 1926, p. 30). On peut conclure de cette description que le bris de la lampe s'est sans doute produit par tassement des terres, longtemps après son abandon ou sa perte par les Magdaléniens.

La lampe a été reconstituée et recollée dès sa découverte (fig. 26). Elle est façonnée dans un galet de grès rouge tendre à grain très fin légèrement micacé. SaintPérier attribue à ce grès une origine corrézienne plutôt que pyrénéenne, à cause de sa ressemblance avec le grès rouge permien de la région de Brive (ibid., p. 30), mais des analyses pétrographiques seraient nécessaires pour vérifier l'origine géologique de cette matière première.

La lampe mesure $20 \mathrm{~cm}$ de long sur $10,8 \mathrm{~cm}$ dans sa plus grande largeur, son épaisseur n'excédant pas $3,5 \mathrm{~cm}$ à la naissance du manche et $2 \mathrm{~cm}$ au niveau de la cuvette. Celle-ci, très régulière et bordée d'une margelle bien plane, a un diamètre de $10,1 \mathrm{~cm}$ pour une profondeur de $2,2 \mathrm{~cm}$. La lampe, entièrement façonnée, porte des traces de piquetage encore visibles par endroits, en particulier sur son revers et sur l'avers du manche. Elle a été entièrement régularisée par polissage et des stries circulaires, peut-être laissées par un abrasif intermédiaire tel que du sable, sont visibles sur les versants de la cuvette. Le manche triangulaire, de $8,5 \mathrm{~cm}$ de longueur, présente quelques traits profondément incisés, assez larges et à section en U, qui pourraient représenter un décor non figuratif. SaintPérier y voyait la figuration possible d'une main schématisée, «le bord cubital étant indiqué par un trait qui se prolonge jusqu'à l'extrémité de l'auriculaire; les autres doigts (?) seraient figurés par des traits divergents et indépendants entre eux, le pouce étant en hyperextension; le bord radial manque» (ibid., p. 32). Cette vision de ces quelques traits rayonnants paraît cependant largement interprétative.

Saint-Périer mentionnait des traces d'action du feu très nettes dans la cuvette : «La cavité et ses bords, jusqu'à un centimètre environ au-delà de la limite de la cupule, montrent une couleur noire, qui tranche nettement sur la teinte rougeâtre du manche et qui résulte du dépôt de noir de fumée dû à la combustion des matières dont la lampe était alimentée » (ibid., p. 30). Ces traces ne sont malheureusement pas aussi nettes que le prétendait Saint-Périer, mais il est possible que la lampe ait subi un nettoyage intensif pendant les années où elle a séjourné dans une collection privée. Quoi qu'il en soit, il reste encore des traces charbonneuses suffisamment visibles dans la cuvette pour qu'on puisse affirmer que cet objet a bien servi de lampe.

Lors de mon étude d'ensemble des lampes, j'ai pu inventorier un peu plus de 300 objets ayant vraisemblablement ou certainement servi de luminaire sur les quelque 550 documents examinés à l'époque dans les musées, collections privées et dépôts de fouille. Or seuls $10 \%$ d'entre elles - soit une trentaine - étaient munis d'un manche façonné bien individualisé. A.-H. Bastin et J. Chassaing avaient en 1940 dressé une typologie morphologique des lampes et isolé deux types différents de lampes munies d'un manche : à manche triangulaire (type la Mouthe) et à manche «en 

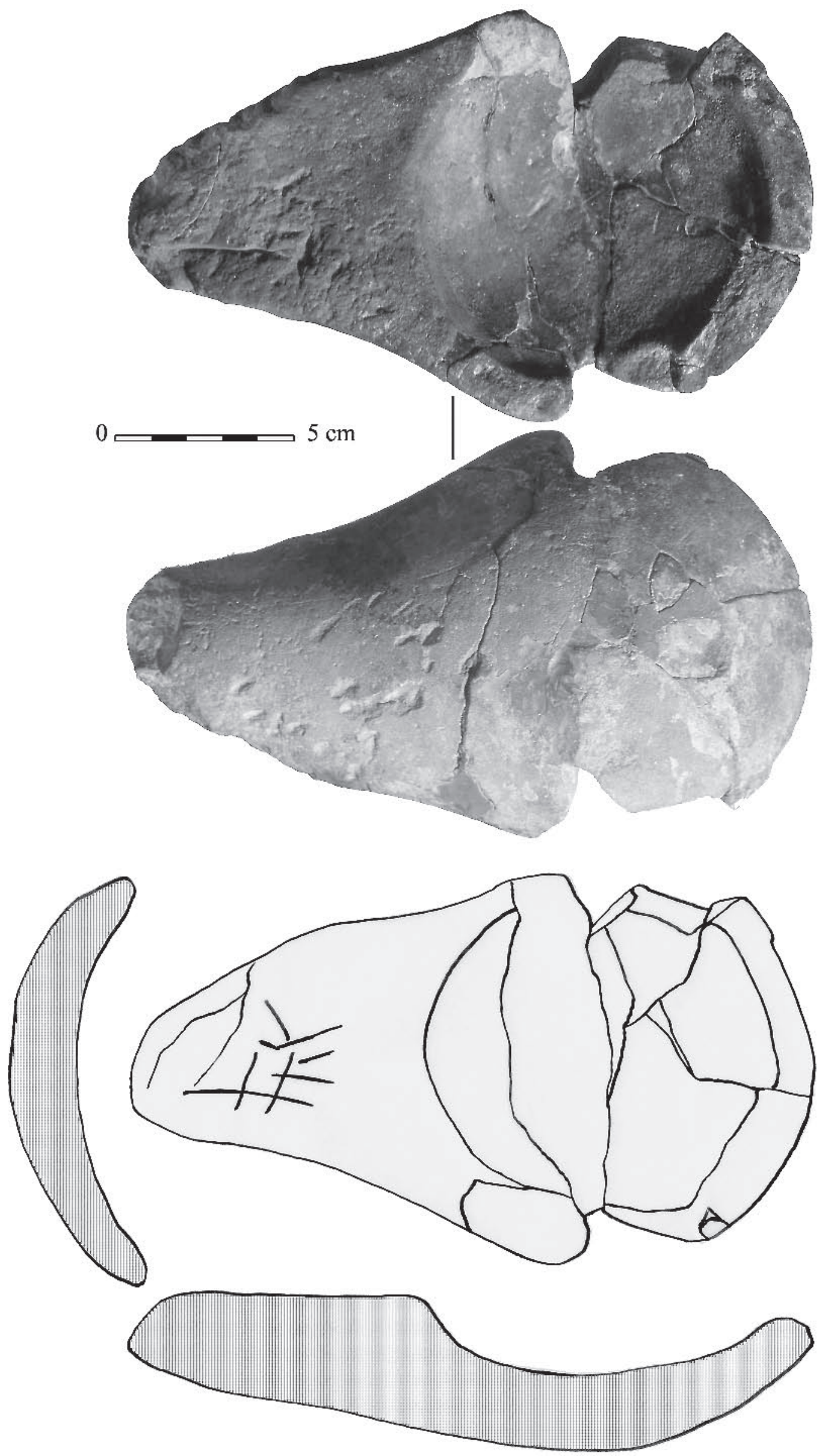

Fig. 26 - Lampe en grès ( $n^{\circ}$ MAN 86775) (clichés et dessin : S. A. de Beaune). 
raquette» (type Lascaux). La faible quantité de lampes de ce type et leur évidente similitude fonctionnelle m'incitent à abandonner une telle typologie, uniquement fondée sur la forme des manches. La moitié d'entre elles sont en grès et dix sont en calcaire. Or, la grande majorité des lampes à circuit fermé, c'est-à-dire celles où le combustible restait dans la cuvette pendant toute la durée de leur utilisation, et qui sont dénuées de manche sont en calcaire. Le choix du grès pour les lampes entièrement façonnées et munies d'un manche peut s'expliquer par plusieurs raisons. D'abord, le calcaire, très abondant dans les régions karstiques comme le Sud-Ouest de la France, présente souvent une forme déjà concave qui nécessite peu ou pas d'aménagement; il était donc préférentiellement ramassé pour servir de récipient ou de petite lampe domestique courante; le grès ne présente pas forcément de concavité sur sa surface mais il est en revanche beaucoup plus facile à sculpter que le calcaire lorsqu'il s'agit d'un grès tendre; il suffit alors de l'attaquer par raclage et abrasion (Beaune, 1993). Une fois polie, sa surface présente un bel aspect régulier et doux au toucher. Ensuite, le grès conduit davantage la chaleur que le calcaire, ce qui implique qu'il était judicieux de prévoir un manche pour les lampes en grès, pour éviter de se brûler en la prenant dans la main.

Il est inutile de présenter ici un inventaire complet des trente lampes façonnées munies d'un manche, disponible ailleurs (Beaune, 1987a). Parmi les spécimens les mieux conservés, on peut se contenter de citer les deux lampes en grès trouvées à Solvieux (Dordogne) par James Sackett (Beaune et al., 1986) et bien sûr le fameux «brûloir» de Lascaux (Glory, 1961). Deux autres lampes en grès intactes, munies d'un manche, provenaient de l'abri du Bois du Roc (Charente); mais l'une avait disparu dès 1926, puisque Saint-Périer n'a pu la retrouver à l'époque, et l'autre, dont le dessin indique qu'elle portait également des traits gravés sur son long manche, a inopinément disparu vers 1973 après avoir été prêtée par la Faculté des sciences de Poitiers pour une exposition (Beaune, 1987a, p. 161-163).

Qu'elles soient munies d'un manche ou non, les lampes portant un décor sont rares puisqu'on n'en connaît actuellement que trente-cinq, soit un peu moins de $12 \%$ de l'ensemble des lampes; or onze d'entre elles ont un manche façonné et dans huit des onze cas, il s'agit d'un décor constitué de «signes» abstraits gravés sur le manche (Beaune, 1987a, fig. 42, p. 88).

J'ai montré ailleurs que les lampes du Paléolithique supérieur pouvaient être classées en deux grands types fonctionnels différents : les lampes à circuit fermé et celles à circuit ouvert. J'ai dit plus haut ce qu'était une lampe à circuit fermé; les lampes à circuit ouvert sont celles dont la graisse combustible était évacuée au fur et à mesure de sa fonte. Les premières pouvaient être de simples godets creusés d'une cuvette plus ou moins bien aménagée, ou bien de beaux luminaires entièrement sculptés et polis, comme la lampe des Scilles. Les secondes pouvaient être des godets avec une ouverture sur un bord de la margelle, des plaquettes planoconcaves ou des plaquettes entièrement planes.
Or la répartition de ces différents types de lampes semble indiquer une possible spécialisation (Beaune, 1987b). Les godets naturels ou plus ou moins façonnés sont plus abondants dans les abris-sous-roche, et donc dans les sites d'habitat, que dans les grottes ornées, ce qui s'accorde avec un statut d'ustensile domestique courant. Les lampes façonnées munies d'un manche et parfois décorées sont rares, mais se trouvent plus souvent dans des abris ou grottes peu profondes ayant servi d'habitat - malgré l'exception remarquable du «brûloir» retrouvé dans le Puits de Lascaux. Cela incite à penser que, si ces lampes avaient une signification particulière et étaient réservées à un usage privilégié, on ne les abandonnait pas dans les grottes et on les conservait soigneusement dans les habitats. Enfin, les plaquettes et godets asymétriques à cuvette ouverte sont rares - encore que ce type de luminaire d'aspect fruste a pu être négligé lors des fouilles anciennes mais plus fréquemment retrouvés dans les grottes profondes; ce qui suggère un usage occasionnel de luminaires de fortune que l'on abandonnait volontiers sur place, une fois leur mission remplie.

Pour autant que les médiocres indications stratigraphiques des découvertes anciennes permettent d'en juger, toutes les lampes sculptées et munies d'un manche datent du Magdalénien, moyen ou supérieur pour la plupart, inférieur pour quelques-unes comme celles de Lascaux et de Solvieux. Elles proviennent toutes du Sud-Ouest de la France (Charente, Dordogne et Pyrénées), à l'exception d'un seul exemplaire trouvé sur le site du Saut du Perron dans la Loire.

Leur rareté, le soin avec lequel elles ont été façonnées, la fréquence d'un décor gravé, suggèrent que ces objets avaient peut-être une signification et une fonction particulières. Il est en effet remarquable de constater que, si les Magdaléniens dominaient parfaitement les techniques de taille des roches dures selon le principe de la fracture conchoïdale, ils réservaient les autres techniques de travail de la pierre, telles que la sculpture et le polissage, à la réalisation d'objets communément rattachés au domaine de l'art - statuettes, pendeloques - et on ne connaît pas, pour le Paléolithique supérieur, d'objets utilitaires sculptés dans de la pierre. Cela fait une raison supplémentaire de penser que ces objets n'étaient pas anodins et dépassaient le cadre des préoccupations quotidiennes. L'hypothèse formulée par A. Glory (1961) de l'utilisation de «ramilles aromatiques » dans de telles lampes ne peut être confirmée dans l'état actuel de nos connaissances, les analyses physico-chimiques du contenu des lampes étant encore trop rares. Si ces lampes ne jouaient sûrement pas un rôle quotidien, étant donné leur rareté, on ne peut pour autant conclure à leur usage de «brûloir à fumigation » ou de «brûle-parfum» comme le fit A. Glory.

\section{L'ART MOBILIER (P. C., C. B. et J.-M. P.)}

Nous considérons comme pièces d'art mobilier tous les éléments portant des aménagements de surface qui ne peuvent être rapportés à une fonction utilitaire. À l'exception de la lampe en grès, ces vestiges sont au 
nombre de quatre : deux en bois de Cervidé et deux en pierre.

\section{Art mobilier sur support osseux}

La première pièce est un objet appointé de section circulaire, sur baguette en bois de Cervidé (108 x 8 x $7 \mathrm{~mm}$ ) (fig. 27, $\mathrm{n}^{\circ} 1$ ). Cette pièce avait été présentée par Saint-Périer (1926, p. 25-26) comme une pointe de projectile à biseau simple. Il est vrai que son extrémité la plus fine présente un pan de fracture pouvant évoquer un impact, ou du moins une rupture par flexion. En revanche, l'extrémité opposée ne présente aucun aménagement indiquant sans ambiguïté un dispositif d'emmanchement : de section biconvexe, de contour dissymétrique (déjetée vers le bord gauche), décorée sur les deux bords, cette extrémité ne peut être assimilée à la partie proximale d'une pointe à biseau simple. Nous avons donc classé cet objet parmi les pièces typologiquement indéterminées, notamment parce que nous ne pouvions exclure la possibilité qu'il s'agisse d'un outil appointé (poinçon ?) et non d'une armature. Il est décoré de multiples incisions obliques couvrant les bords et la face supérieure.
La seconde pièce est un outil intermédiaire entier, de section planoconvexe, sur baguette en bois de Renne de gros module (119 x 17 x $11 \mathrm{~mm})$ (fig. 27, $\mathrm{n}^{\circ} 2 \mathrm{a}$ ). Sa face supérieure porte un décor dont Breuil avait fait le relevé (Saint-Périer, 1926, fig. 8) (ici fig. 27, n² 2b) et que Saint-Périer interprétait comme «une tête d'herbivore, vue de face, dont on distingue les oreilles allongées, les yeux, indiqués par un point, le contour de la face, alors que le museau est indistinct. Deux traits parallèles gravés sous la tête schématisent peut-être les membres antérieurs. L'altération de la matière ne permet pas une identification précise de l'espèce. Il peut s'agir d'une femelle de cervidé ou d'un équidé » (SaintPérier, 1926, p. 29). La face supérieure de cette pièce est en effet très dégradée et son examen au musée de Montmaurin a montré que le relevé Breuil amalgamait, de façon peu lisible, les tracés anthropiques et les marques d'altération taphonomique. Nous avons donc effectué un nouveau relevé des tracés anthropiques, s'appuyant sur une observation à l'œil nu en lumière rasante complétée par des macrophotographies. Compte tenu du très mauvais état de surface de l'objet, nous nous sommes limités à un relevé minimaliste ne conservant que les traits gravés absolument sûrs (fig. 27, $\left.\mathrm{n}^{\circ} 2 \mathrm{c}\right)$.

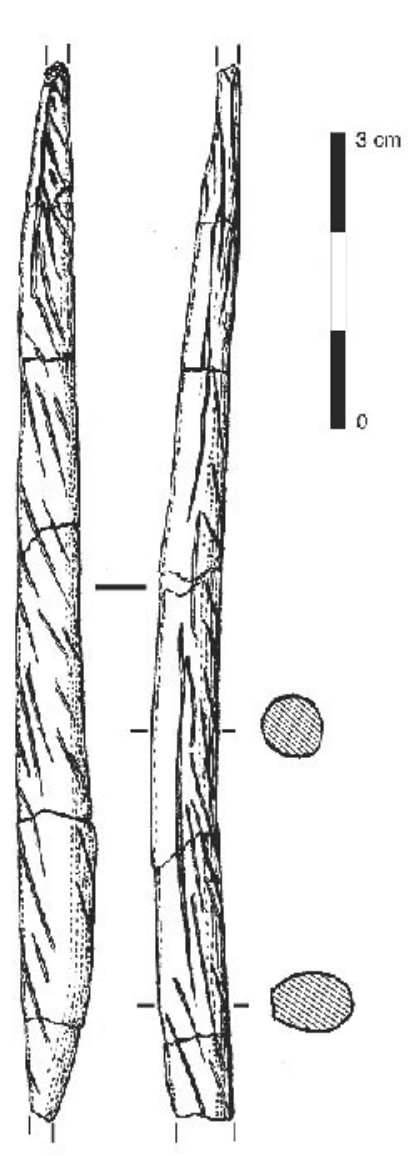

1

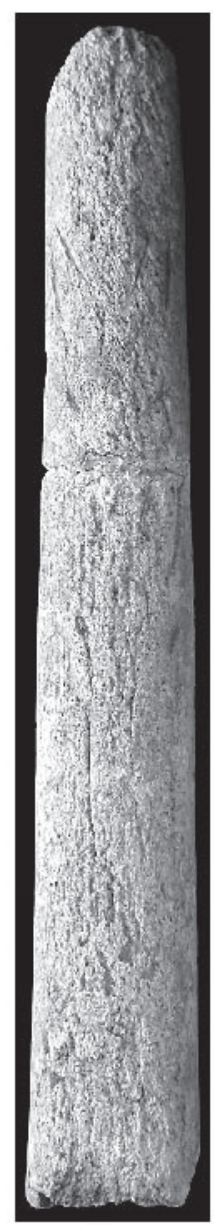

$2 \mathrm{a}$

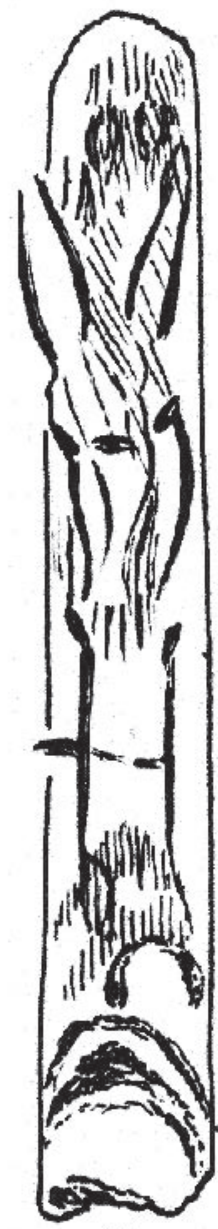

$2 b$
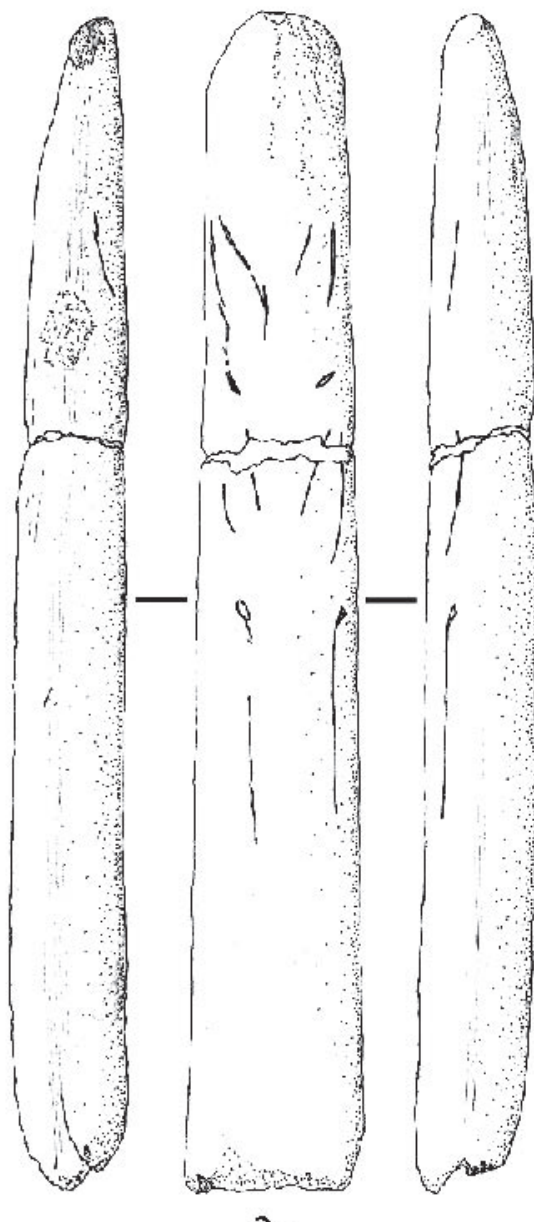

2c

Fig. 27 - Art mobilier sur support osseux. $\mathrm{N}^{\circ} 1$ : objet appointé décoré (dessin D. Molez); $\mathrm{n}^{\circ} 2$ : outil intermédiaire décoré (a : photographie montrant l'état de surface de l'objet; $b$ : relevé Breuil, d'après Saint-Périer, 1926; $c$ : dessin et relevé C. Bellier). 
Le tiers supérieur de la zone décorée peut éventuellement s'accorder avec l'interprétation de Saint-Périer : les deux oreilles apparaissent assez nettement, ainsi que les yeux, marqués chacun par une incision oblique, courte et profonde. Ce motif (oreilles-yeux) est répété dans le tiers central de l'objet, en dessous du motif précédent qu'il prolonge peut-être : en effet, le bord interne des oreilles de la tête inférieure suggère le contour du museau de la tête supérieure, mais est-ce intentionnel? Le tiers inférieur se réduit à deux incisions longitudinales d'interprétation hasardeuse.

Cette figuration de face ne trouve guère de parallèles dans le matériel publié des niveaux du Magdalénien inférieur. Tout au plus peut-on la rapprocher de têtes de cervidés schématiques superposées, représentées de profil sur des sagaies à base en biseau unifacial lancéolé de la grotte du Placard, attribuées par Breuil au Magdalénien I et II (Breuil, 1937, fig. $17, \mathrm{n}^{\text {os }} 7$ et 8 ).

En revanche, elle se rapproche de plusieurs exemples du Magdalénien moyen et surtout du Magdalénien supérieur, à l'exclusion du Magdalénien à navettes, dans lequel nous n'avons trouvé aucune figuration comparable.

En ce qui concerne le Magdalénien moyen, une des pièces les plus proches provient du niveau IXa de Las Caldas : il s'agit d'une lame osseuse crantée qui présente un avant-train d'équidé vu de face, dont l'allure générale est assez proche de la représentation des Scilles (Corchon, 1995, fig. 4). Selon nous, il pourrait tout aussi bien s'agir d'une représentation de cervidé. Au-dessus des oreilles, un motif en $\mathrm{V}$ doublé pourrait en quelque sorte «dupliquer» les oreilles de l'animal représenté. Le même site livre d'autres représentations préférentielles de face, mais en bas relief, comme le bouquetin sur propulseur probable, à rapprocher du propulseur au bouquetin du Mas d'Azil.

Les parallèles les plus abondants appartiennent au Magdalénien supérieur : bison (MAN 48596), cheval? (MAN 47323) et bouquetin (MAN 48575) de Gourdan; bouquetin (MAN 48220) de Lortet; capridé (MAN 289) et cervidé (MAN 47946) du Mas d'Azil (Chollot, 1964, p. 68, 94, 102, 173, 254, 367). Des représentations frontales de têtes animales schématiques superposées figurent également sur des baguettes demirondes de Teyjat (Breuil, 1937, fig. 29, n ${ }^{\text {os }} 5$ et 7), sans oublier la tête d'ours de face sur bâton percé de Massat (ibid., fig. 37, $\mathrm{n}^{\circ} 2$ ).

Sans vouloir établir un catalogue exhaustif de ce type de représentation, nous ne pouvons passer sous silence les représentations schématiques gravées de bouquetins en position frontale des niveaux du Magdalénien supérieur et final des sites d'El Pendo, La Paloma, Cueto de la Miña, Urtiaga, Morin, Aitzbitarte IV, Sofoxó, El Valle, Torre et Ekain, qui trouvent de lointains antécédents, moins faciles à interpréter, dans les niveaux du Magdalénien inférieur de Bolinkoba, Santimamine, Ermittia, El Cierro et Altamira (Utrilla, 1990, p. 95 et fig. 5).

Pour conclure, le décor de la baguette des Scilles s'inscrit clairement dans la «culture» magdalénienne, mais il s'agit en quelque sorte des prémices d'un type de représentation qui trouvera son apogée beaucoup plus tard.

\section{Art mobilier sur support lithique}

Les deux pièces suivantes n'ont pas été publiées par Saint-Périer.

Un petit fragment de roche gréseuse ( $27 \times 20 \times 10 \mathrm{~mm})$ (fig. $28, \mathrm{n}^{\circ} 1$ ), de contour grossièrement triangulaire et de section ovalaire, présente quatre profondes incisions longitudinales d'origine anthropique (trois sur une face, une sur l'autre). Ces incisions soulignent les bords et dégagent deux zones en relief sur l'une des faces. Ce fragment ne semble pas provenir d'un polissoir à aiguilles (Beaune, 1997) et ne se raccorde pas à la lampe en grès trouvée dans le même gisement; son interprétation demeure incertaine.

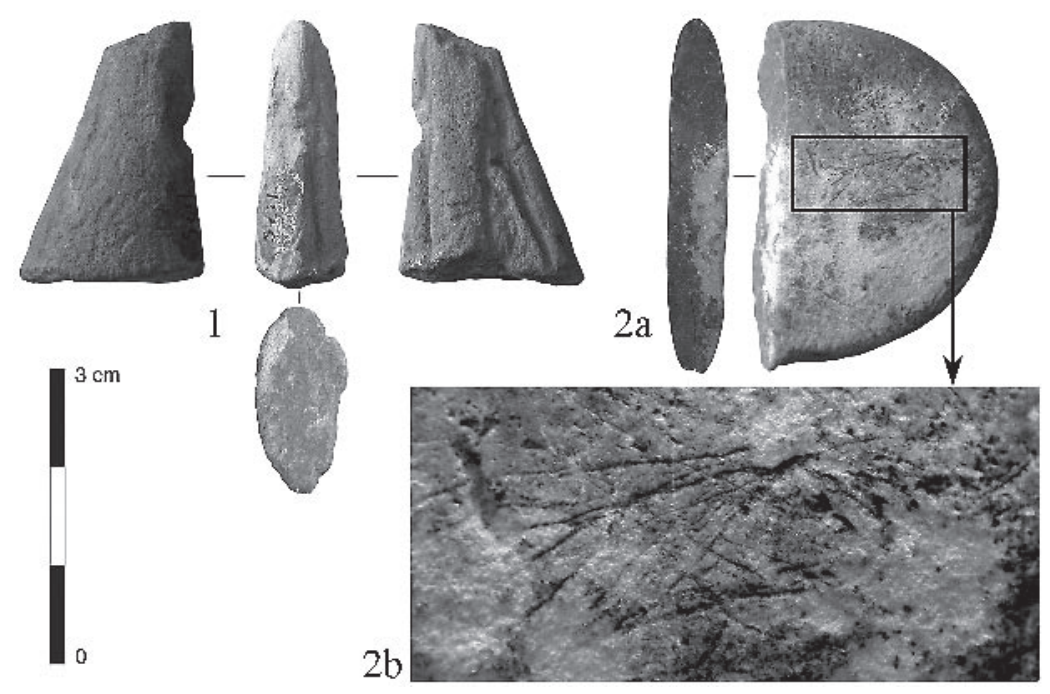

Fig. 28 - Art mobilier sur support lithique. $N^{\circ} 1$ : fragment de grès sculpté; $n^{\circ} 2$ : galet gravé (a: vue générale; $b$ : détail du motif gravé, X 3). 
Un galet de contour demi-circulaire ( $37 \times 26 \times 6 \mathrm{~mm})$ (fig. 28, $\mathrm{n}^{\circ}$ 2) présente, sur une des faces, une série de traits de gravure entrecroisés. Cette face est malheureusement très altérée et la faible portion préservée ne permet pas une lecture précise du motif gravé.

\section{RÉSULTATS D'ANALYSE DE DATATIONS}

PAR LE RADIOCARBONE (C. S. et R. B.)

\section{L'importance des datations à la grotte des Scilles}

Le Sud-Ouest de la France, et en particulier les zones du Périgord et des Pyrénées, est une région clé pour le Magdalénien. Pourtant, la datation directe d'objets typologiquement attribués à diverses phases du Magdalénien n'a que très rarement été entreprise pour cette région. La méthode du radiocarbone par spectrométrie de masse par accélérateur (SMA) nous permet d'entreprendre une telle démarche, étant donné la quantité très réduite de matière que nécessite cette technique. Les périodes précises pendant lesquelles s'est déroulée l'occupation magdalénienne du versant nord des Pyrénées ont été débattues depuis longtemps. Se basant sur les données qui étaient à sa disposition jusqu'à la fin des années 1980, J. Clottes (1989) indiqua qu'à part quelques rares traces du Badegoulien, il n'y avait aucune indication d'une occupation magdalénienne dans cette région jusqu'à celle du Magdalénien moyen (à partir de 14500 BP).

L'attribution magdalénienne du matériel de la grotte des Scilles n'a jamais été remise en cause. Par contre la phase précise du Magdalénien à laquelle appartient cette série est encore sujette à controverse. Saint-Périer (1926, p. 40) l'a reliée à ce qui était dénommé à l'époque le «Magdalénien ancien». Elle a ensuite été attribuée au Magdalénien moyen ancien (1500014500 BP) par R. Simonnet (1973), puis au plein Magdalénien moyen (ca. 14500-13000 BP) par J. Clottes (1989), chacun s'appuyant sur les données alors disponibles. En particulier, la pointe de LussacAngles, dont cette série comprend deux exemplaires, est un type d'objet qui a depuis longtemps été considéré comme étant lié au Magdalénien moyen et surtout au Magdalénien moyen ancien (ca. 15000-14000 BP), voire comme un marqueur chronologique de cette période. Pourtant, aucune pointe de ce genre n'a été datée directement sur aucun site. Sans datation directe, nous ne pouvons pas connaître avec certitude à quel moment de telles pointes sont apparues pour la première fois, ni la durée de leur existence. Leur valeur en tant qu'indicateur chronologique reste donc à démontrer.

Par contre, une nouvelle analyse technologique de l'industrie lithique de la couche B, telle que décrite ici, montre de fortes affinités avec des séries du Magdalénien inférieur (ca. 17000-15000 BP) de régions avoisinantes. Étant donné l'apparente contradiction des données concernant l'âge de cette série, il devint évident que seule la datation radiométrique directe de pièces caractéristiques pourrait aider à la résolution de cette question. La présence d'artefacts organiques dans cette série ouvre donc la voie à l'utilisation de la méthode de datation par le radiocarbone par SMA, dont l'analyse est décrite, plus loin, dans cette section.

\section{Protocole pour la sélection des échantillons}

Saint-Périer a identifié trois niveaux archéologiques dans la grotte des Scilles : le niveau A, le niveau B et une structure dénommée «four polynésien» entre les deux. Des restes de faune ont été trouvés dans tous ces niveaux et structures, mais aucune indication stratigraphique n'a été notée sur ces restes. Il est fort probable, par contre, que la plupart (si ce n'est tous) des restes de faune actuellement disponibles proviennent de la couche B (cf. supra). La présente étude porte sur la couche B, qui est le niveau le plus riche. Il était donc crucial que les échantillons datés ne proviennent pas de la couche $\mathrm{A}$ ou du «four polynésien». Par ailleurs, même si des restes de Carnivores sont très rares sur ce site (et qu'il y a peu de traces de Carnivores sur les restes d'Ongulés), il reste tout de même possible quoique très peu probable - que certains ongulés aient été transportés sur ce site par un agent accumulateur non anthropique.

Étant donné les problématiques soulevées ci-dessus, nous n'avons cherché à dater que des artefacts organiques travaillés (plutôt que des fragments d'ongulés non modifiés) et en particulier ceux perçus comme étant chronologiquement caractéristiques. Ceci permettra d'établir un lien aussi fiable que possible entre objet daté et occupation humaine de la couche B, ainsi que de contribuer à la résolution de certaines questions et problématiques sur l'occupation magdalénienne dans les Pyrénées.

Nous avons choisi de dater trois vestiges organiques en bois de Renne de la couche B. En particulier, il nous est apparu important de dater directement une pointe de Lussac-Angles (fig. 17, $n^{\circ} 2$ ). Pour les autres échantillons, nous avons sélectionné deux des plus fréquents type d'artefacts de cette couche, soit un élément appointé sur baguette (fig. 19, n 7) (un type de déchet présent en 22 exemplaires dans la série) et un outil intermédiaire (dont la série comprend sept exemplaires). Dater ces objets est important non seulement pour ce site en particulier, mais aussi comme point d'ancrage pour d'autres sites ayant ces types d'artefacts. Ceci pourrait aussi aider à placer dans un cadre chronologique absolu certains éléments typologiques qui sont souvent utilisés comme «marqueurs » du Magdalénien et à tester leur fiabilité en tant qu'indices chronologiques.

\section{Description des artefacts choisis pour une analyse radiocarbone}

Les détails des artefacts en bois de Renne sélectionnés pour une analyse par le radiocarbone sont présentés dans le tabl. 16. Une description plus complète de ces objets ainsi que leur analyse technotypologique se 
trouvent ci-dessus dans la section intitulée «l'industrie en bois de Cervidé».

Les artefacts ont été choisis en tenant compte de paramètres de différentes natures $(e . g$. protocole technique de datation, critères archéologiques et muséologiques). Ils ont été sélectionnés parmi la série d'artefacts en bois de Cervidé qui se trouve au MAN. Les trois objets ont été photographiés et dessinés avant de les traiter. Chacun porte une indication de provenance en encre de marquage, soit «grotte des Scilles» ou «Scilles».

La sélection de ces trois artefacts a été faite afin de nous permettre de trancher entre trois hypothèses :

- 1) Que l'occupation humaine de la couche B se déroula exclusivement pendant le Magdalénien moyen $(15000$ à $13000 \mathrm{BP})$ - Cette hypothèse tiendrait si les trois artefacts datés donnaient des dates correspondant à cette période. Si tel était le cas, les pointes de Lussac-Angles seraient effectivement des vestiges du Magdalénien moyen, mais sans pour autant exclure la possibilité que leur fabrication ait commencé plus tôt et/ou se soit poursuivie ensuite. Étant donné que le lithique n'est pas daté directement de façon absolue, les ressemblances de la série lithique de la couche B avec celles de séries du Magdalénien inférieur de régions avoisinantes seraient soit le résultat d'une continuité ou convergence technologique entre le Magdalénien inférieur et le Magdalénien moyen ce qui serait inattendu étant donné la rupture assez nette entre ces périodes (Langlais, sous presse; mais voir aussi Langlais, 2007b qui évoque certains paramètres pouvant démontrer une continuité) - soit une indication que la couche $\mathrm{B}$ regroupait une industrie lithique du Magdalénien inférieur avec une industrie en bois de Cervidé du Magdalénien moyen;

- 2) Que l'occupation humaine de la couche B se déroula exclusivement pendant le Magdalénien inférieur ( 17000 à $15000 \mathrm{BP}$ ) -Cette hypothèse tiendrait si les trois artefacts datés donnaient des dates correspondant à cette période. Si ceci était le cas, l'industrie en bois de Cervidé daterait de la même période que celle qui est fortement évoquée par la technologie lithique. Ceci remettrait en question certaines suppositions concernant l'analyse typologique et surtout le lien entre typologie et chronologie. Ceci nous inciterait à devoir réévaluer nos hypothèses concernant l'occupation de cette région au Magdalénien ainsi que nos idées sur les prémices et développement de ce dernier. D'une part, les pointes de Lussac-Angles ne pourraient plus être considérées comme appartenant exclusivement au Magdalénien moyen, ni nécessairement un indice de cette période. D'autre part, l'idée que le versant nord des Pyrénées fut vide de toute occupation humaine au début du Magdalénien serait certainement une hypothèse à revoir. Les liens entre cette région et les régions avoisinantes pendant cette période, ainsi que le rôle de cette région en ce qui a trait au développement du Magdalénien, pourraient donc être envisagés;

- 3) Que la couche B regroupe plusieurs occupations humaines - Cette hypothèse pourrait se justifier si les trois artefacts donnaient des dates fiables mais statistiquement différentes. Selon les résultats, ceci remettrait sans doute en cause certaines suppositions chronotypologiques concernant la période magdalénienne.

\section{Analyse radiocarbone}

\section{Traitement des échantillons}

Les trois artefacts en bois de Cervidé ont été analysés au IsoTrace Accelerator Mass Spectrometry Laboratory de l'université de Toronto, Canada, en utilisant une version modifiée de la méthode dite de Longin (1971) d'extraction du collagène. Étant donné que les vestiges en bois de Cervidé travaillés peuvent être nécessaires pour entreprendre de nouvelles analyses et que ce sont des pièces provenant d'un musée (qui seront peut-être mises en exposition), nous avons cherché à ne prélever qu'une quantité de matière aussi réduite que possible et de prélever à un endroit aussi peu visible que possible, sur chaque pièce. De plus, nous avons évité les parties décorées, la colle et l'encre de marquage. Les artefacts n'avaient été recouverts ni d'agents de conservation ni de consolidant; aucun moulage n'avait été fait de ces pièces.

\section{- Prétraitement physique}

Les artefacts ont été forés pour extraire les copeaux et la poudre de bois de Renne avec des mèches ayant un diamètre de $5 \mathrm{~mm}$ ou de $10 \mathrm{~mm}$, choisies selon la largeur, l'épaisseur et la longueur de l'artefact. La surface du vestige où s'est déroulé le forage a d'abord été nettoyée avec la mèche appropriée. Les copeaux et la poudre qui ont été dégagés n'ont pas été conservés. La mèche fut nettoyée et utilisée pour forer à basse vitesse l'artefact pour en extraire des copeaux de bois de Renne. Nous avons utilisé des mèches en acier enduit de titane permettant ainsi de réduire la friction et donc le surchauffement dû au processus de forage. Ceci

\begin{tabular}{|c|c|c|c|c|c|c|}
\hline $\begin{array}{c}\text { Numéro } \\
\text { IsoTrace }\end{array}$ & Type d'artefact & Masse $\mathbf{( g )}$ & $\begin{array}{c}\text { Longueur } \\
\mathbf{( m m )}\end{array}$ & $\begin{array}{c}\text { Masse de bois } \\
\text { de Renne utilisée } \\
\text { (mg) }\end{array}$ & $\begin{array}{c}\text { Taux de } \\
\text { collagène } \\
\text { (\%) }\end{array}$ & $\begin{array}{c}\text { Age }{ }^{\mathbf{1 4}} \mathbf{C} \text { non calibré exprimé } \\
\text { en années BP } \mathbf{( m o y e n n e} \\
\text { pondérée de deux cibles) }\end{array}$ \\
\hline TO-13554 & pointe de Lussac-Angles & 1,8 & 40,6 & 327 & 4,8 & de la combustion : voir texte \\
\hline TO-13555 & élément appointé sur baguette & 4,2 & 47,6 & 515 & 1,3 & $16180 \pm 140$ \\
\hline TO-13557 & outil intermédiaire & 20,2 & 141,8 & 581 & 0 & pas de collagène \\
\hline
\end{tabular}

Tabl. 16 - Les échantillons soumis à une analyse radiocarbone. Tous sont en bois de Renne et proviennent de la couche B. 
a été fait dans le but de minimiser l'éventuelle destruction du collagène datable. Les copeaux ont été pesés (les masses précises sont indiquées dans le tableau 16) et ont été placés dans un contenant pour la phase d'extraction du collagène.

\section{- Prétraitement chimique et extraction du colla- gène}

Les copeaux de bois de Renne ont été rapidement déminéralisés dans de l'acide $(1.0 \mathrm{~N} \mathrm{HCl})$ à basse température $\left(4\right.$ à $6{ }^{\circ} \mathrm{C}$, pour minimiser la perte de collagène). Le résidu a été dessalé et rincé jusqu'à $\mathrm{pH}$ neutre pour supprimer tous les contaminants solubles dans l'acide. Le collagène brut a ensuite été extrait à l'aide d'un traitement alcalin froid afin d'éliminer tous les polluants solubles dans la base. Quant aux éventuels polluants insolubles, le collagène brut a été gélatinisé dans de l'eau chaude acidifiée. À chaque étape, la séparation entre le surnageant et les résidus insolubles s'est faite par ultra-centrifugation réfrigérée (25000 g).

Le laboratoire IsoTrace se distingue par son utilisation d'une ultra-centrifugeuse (accélération 10 à 100 fois plus élevée que les centrifugeuses standards et 1000 fois plus que les manuelles). Cette force de centrifugation particulièrement élevée permet une excellente séparation entre le surnageant et les résidus insolubles. Les éventuelles contaminations qui auraient pu être présentes dans l'échantillon peuvent ainsi être éliminées de manière plus minutieuse. L'utilisation d'une ultra-centrifugeuse est une des meilleures méthodes d'élimination de polluants. Elle est particulièrement importante après l'étape de gélatinisation, lorsque l'épaisse gélatine doit être bien séparée des éventuels contaminants insolubles. Une force considérable s'avère nécessaire à la séparation complète de ces deux fractions.

Après lyophilisation, le collagène purifié a été pesé et le taux a été calculé à partir de la proportion de la masse totale du collagène extrait à la masse totale de copeaux/poudre de bois de Renne.

\section{- Combustion, graphitisation et mesure}

La combustion de la gélatine a été faite en présence d'oxyde de cuivre et d'un petit fil d'argent dans une ampoule Vicor qui a été scellée sous vide. L'ampoule a été progressivement et lentement chauffée jusqu'à ce que la température atteigne $800{ }^{\circ} \mathrm{C}$. Cette température a été maintenue pendant quatre heures afin d'assurer une combustion complète. Pendant les quatre heures qui suivirent, la température fut baissée progressivement et doucement jusqu'à ce qu'elle atteigne la température ambiante. Le dioxyde de carbone $\left(\mathrm{CO}_{2}\right)$ a été converti à de l'acétylène via la synthèse de $\mathrm{Li}_{2} \mathrm{C}_{2}$. Par décharge de courant électrique alternatif au sein de l'acétylène, deux cibles de graphite ont été produites pour chaque échantillon (Beukens, 1990; Beukens et al., 1986; Beukens et Lee, 1981).

La norme suivie au laboratoire IsoTrace consiste d'une part à préparer deux cibles de graphite par échantillon analysées séparément à différents moments, chacune avec des standards précis. Si les deux analyses sont en accord statistique, la moyenne pondérée des deux analyses est utilisée comme résultat final. Chaque cible est analysée à 16 endroits différents pour les trois isotopes de carbone avant de passer à la mesure de la prochaine cible dans la roue. Une fois que toutes les cibles ont été analysées une première fois, ces mesures sont répétées au moins dix fois, fournissant donc au moins 320 mesures par échantillon (Beukens, 1994). Les rapports ${ }^{13} \mathrm{C} /{ }^{12} \mathrm{C}$ mesurés ont été utilisés pour corriger le fractionnement isotopique naturel $\left(\delta^{13} \mathrm{C}\right)$, ainsi que celui lié à la dispersion dans la source d'ionisation (Beukens et al., 1986).

La préparation de deux cibles par échantillon, le grand nombre de mesures prises par cible et l'utilisation d'une ultra-centrifugeuse sont des normes particulières et uniques au laboratoire IsoTrace. Ces démarches ont été adoptées afin d'améliorer la justesse, la validité et la précision des dates obtenues.

\section{Résultats}

Les résultats obtenus sur les trois échantillons de la grotte des Scilles sont présentés dans le tabl. 16. Sur les trois, seul l'élément appointé sur baguette (TO13555) a pu être daté. L'échantillon TO-13557 (outil intermédiaire) n'avait plus de collagène, tandis que le $\mathrm{CO}_{2}$ de l'échantillon TO-13554 (pointe de LussacAngles) a été perdu lorsque l'une des extrémités de l'ampoule Vicor a éclaté pendant la période de refroidissement, suite à la combustion. L'âge radiocarbone non calibré exprimé en années radiocarbone BP (before Present) de TO-13555 (en utilisant la valeur Libby de la demi-vie du ${ }^{14} \mathrm{C}$ ), est de $16180 \pm 140$ BP. L'élément appointé sur baguette en bois de Renne se rattache donc au Magdalénien inférieur. Calibrant cette date en utilisant la courbe de calibration INTCAL04 (Reimer et al., 2004), on obtient une date calibrée de 19400 cal. BP, une intervalle de $1 \sigma(68,3 \%)$ de 19475 cal. BP à 19185 cal. BP et une intervalle de $2 \sigma$ $(95,5 \%)$ de 19555 cal. BP à 19030 cal. BP. Le taux de collagène de l'échantillon était au-dessus de la valeur de $1 \%$ considérée comme taux minimal pour une datation fiable (Hedges, 1992; Weber et al., 2005).

L'analyse radiocarbone présentée ici contribue donc à avancer les connaissances et à mieux élucider les débats concernant l'occupation magdalénienne du versant nord des Pyrénées. La date obtenue est la toute première indication directe que cette occupation fut en fait plus ancienne que cela avait été supposé. Cette région fut donc peuplée dès le Magdalénien inférieur, plutôt qu'uniquement à partir de $14500 \mathrm{BP}$. Nous pouvons donc conclure que l'hypothèse 1 n'est pas valide. En revanche l'ampleur de cette présence ne pourra être mieux cernée qu'en poursuivant et en multipliant le nombre d'analyses des séries de cette région ainsi que le nombre de dates. À cette étape de l'analyse il n'est pas encore possible de distinguer entre l'hypothèse 2 et l'hypothèse 3 ci-dessus. Donc la possibilité que la couche B de la grotte des Scilles contienne aussi une composante du Magdalénien moyen n'est pas exclue. 
Reste que, d'après l'état actuel de nos connaissances et résultats, les deux pointes de Lussac-Angles des Scilles se trouvent en correspondance avec un artefact qui date de $16180 \pm 140 \mathrm{BP}$.

\section{CONCLUSIONS}

La collection Saint-Périer de la grotte des Scilles livre un ensemble d'éléments permettant d'une part d'attribuer cette occupation à une phase précise du Magdalénien, et d'autre part d'appréhender les territoires et les comportements techno-économiques et symboliques mis en œuvre par ces groupes jusqu'ici non documentés sur le versant nord-pyrénéen.

À la grotte des Scilles, le débitage destiné à l'obtention de supports de lamelles et microlamelles à dos marginal est caractéristique du Magdalénien inférieur tel qu'il a été défini dans le Nord de l'Espagne et en Aquitaine (fig. 29), comme par exemple à Erralla V (Altuna et al., 1985 ; Cazals, 2000), à Saint-Germainla-Rivière c.3-4 (Lenoir et al., 1991; Cazals, 2005 ; Langlais, 2007b et 2008), au Petit Cloup Barrat c.4 (Castel et al., 2006; Chauvière et al., 2008), à Gandil c.20-25 (Ladier, 2000; Langlais et al., 2007), à Fontgrasse (Bazile, 2006; Langlais, 2007a) ou à Montlleó (Mangado et al., 2005; Langlais, 2007a). Des travaux récents ont mis en évidence un Magdalénien inférieur dans la Vienne au Taillis des Coteaux n.III (Primault et al., 2007), dans l'Yonne à Thèmes (Brou et Le BrunRicalens, 2005) mais également dans la vallée de l'Èbre (Utrilla, 2006; Utrilla et Montes, 2007). La date obtenue aux Scilles s'intègre parfaitement dans le train de datations du Magdalénien inférieur, entre 17000 et 15000 BP, soit autour de 20000-18000 cal. BP (fig. 30).

Il existe pour l'instant peu de séries d'industrie osseuses clairement attribuées au Magdalénien inférieur ayant fait l'objet d'une étude typotechnologique détaillée. Les comparaisons sont donc délicates. Pour la série de la grotte des Scilles, on peut cependant souligner quatre points :

- la production de baguettes en bois de Renne exclusivement par double rainurage ne correspond pas à ce que l'on connaît aujourd'hui des industries osseuses badegouliennes (à l'abri Fritsch : Allain et al., 1974; Rigaud, 2004; au Cuzoul de Vers : Pétillon et Averbouh, à paraître; à Lassac : Pétillon et Sacchi, à paraître). En revanche, cela rappelle tout à fait le Magdalénien;

- aucun des «marqueurs» habituels du Magdalénien moyen des Pyrénées n'est documenté : ni rondelle percée, ni contour découpé, ni baguette demi-ronde (ces dernières sont pourtant présentes dans toutes les grottes de Lespugue ayant livré des niveaux attribués

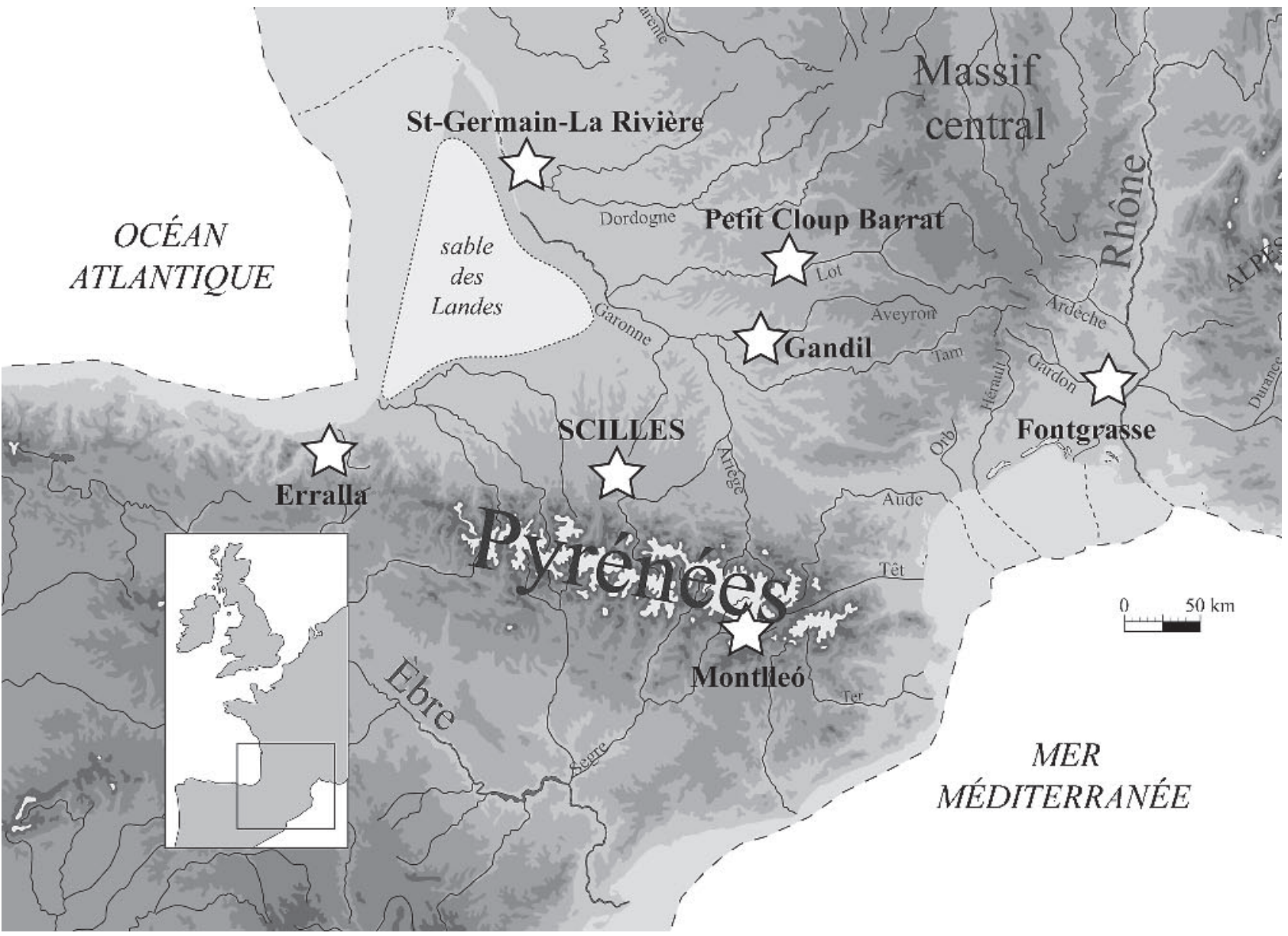

Fig. 29 - Localisation de la grotte des Scilles et des sites mentionnés dans le texte. 


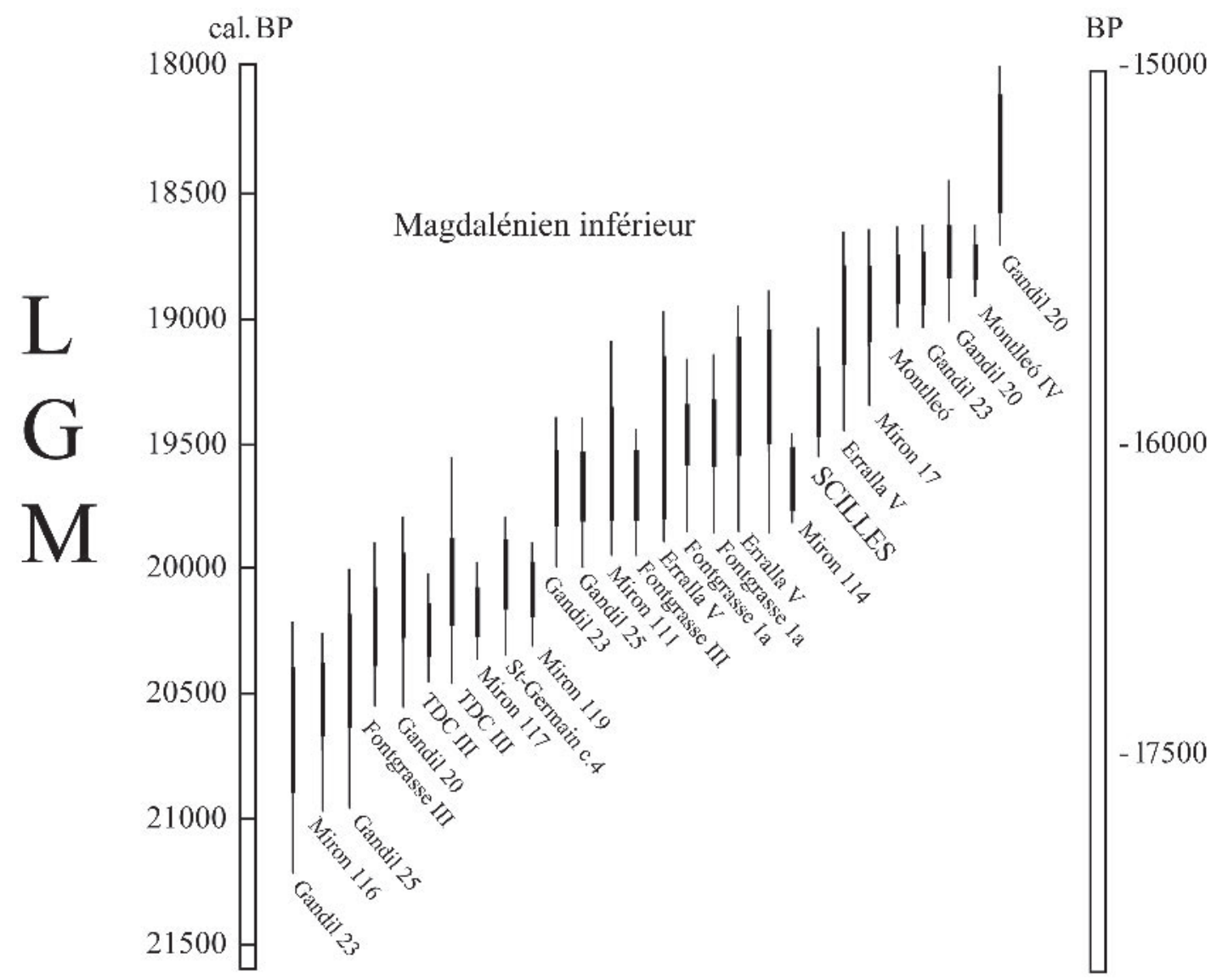

Fig. 30 - Les dates ${ }^{14} \mathrm{C}$ du Magdalénien inférieur (Gandil : Ladier, 2000 et comm. pers.; Mirón : Straus et Gonzalez Morales, 2005; Fontgrasse : Bazile, 2006; Taillis des Coteaux : Primault et al., 2007; Saint-Germain : Lenoir et al., 1991; Erralla : Altuna et al., 1985; Montlleó : Fullola, 2001; Mangado et al., 2005).

au Magdalénien moyen) (Saint-Périer, 1912, 1920 et 1927), ni pointe à biseau simple en dehors des deux pointes de Lussac-Angles (cf. infra);

- dans le domaine de l'outillage et de la parure en matières osseuses, l'association de pièces «communes » (aiguilles, coquilles percées...) et de pièces exceptionnelles (molaires de Lion aménagées) rend les comparaisons difficiles. Les outils intermédiaires présentent plusieurs particularités (certains sont en os, un est décoré...) qui pourraient trouver des parallèles ailleurs, mais on manque là encore de points de comparaison;

- dans le domaine des armatures osseuses, plusieurs traits s'accordent bien avec ce qui a été entrevu pour le Magdalénien inférieur du Sud-Ouest de la France (Pétillon, études en cours) : domination des pointes à base pleine, rareté des décors et aménagements de surface, présence de pointes à trois rainures longitudinales (Langlais, 2007a);

- la question de la datation des pointes de LussacAngles - traditionnels marqueurs de l'avènement du Magdalénien moyen et documentées par deux pièces à la grotte des Scilles - ouvre un autre débat autour de l'ancienneté de ces pièces. Rappelons que certaines sont présentes dans le Magdalénien inférieur cantabrique, comme à Mirón c.116 (Straus et Gonzales, 2005).
Le Magdalénien inférieur était jusqu'à présent inconnu dans les Pyrénées : en dehors de quelques indices de Badegoulien, les hypothèses d'un hiatus et d'un développement tardif du Magdalénien classique (moyen et supérieur) dans cette région étaient privilégiées (Clottes, 1989) ${ }^{6}$. Aux prémices des contreforts pyrénéens, la grotte des Scilles offre donc aujourd'hui un nouveau jalon du peuplement humain de la fin du Dernier Maximum glaciaire et conduit à s'interroger sur le territoire culturel du Magdalénien inférieur. Les matières premières lithiques de la grotte des Scilles témoignent de contacts avec l'Aquitaine, comme cela avait été vu par R. Simonnet ou P. Foucher dans d'autres gisements du Magdalénien et du Solutréen de la vallée de la Save. C'est également vers le nord (Périgord et Charente, notamment) que convergent les comparaisons concernant la lampe en grès ${ }^{7}$. L'origine des coquilles percées, plutôt côté atlantique, ne contredit pas la tendance générale. De plus, même s'il est tout à fait plausible que l'unique métapode de Saïga provienne d'un animal chassé dans les environs du site, cet Ongulé reste très rare dans les Pyrénées (Delpech, 1983; Costamagno, 2001). Poursuivant la remarque de Saint-Périer selon laquelle cet os est «le seul os non brisé par l'homme pour récupérer la moelle» (1926, p. 20-21), on peut rappeler que les métapodes de Saïga 
sont fréquemment utilisés comme matrices d'aiguilles (à Jaurias : Cousté, 1963; à Saint-Germain-la-Rivière c.3 : Costamagno, 1999). Dans ce cas, on peut se demander si cet os n'a pas été introduit sur le site comme bloc de matière première. Si l'on considère la biogéographie de cette espèce à l'époque, cet élément témoignerait également de contacts avec l'Aquitaine.

En définitive, si ce site s'avère somme toute classique à l'échelle du Sud-Ouest français, voire européen, il apparaît original dans son domaine pyrénéen ${ }^{8}$ et alimente ainsi la question du premier peuplement magdalénien au cours de la fin du LGM dans cette région.

Remerciements : Pour nous avoir donné accès aux collections étudiées ici, les auteurs tiennent à remercier Catherine Schwab et Marie-Sylvie Larguèze, du MAN, Thérèse Miro du musée de Montmaurin et Marie-Laure Pellan du musée de Saint-Gaudens. Tous nos remerciements également à Robert Simonnet pour ses conseils et discussions, à Marc Jarry pour nous avoir transmis les versions originales de ses dessins et à Danièle Molez pour la réalisation des dessins inédits. Nous remercions en particulier Catherine Schwab, conservateur des collections paléolithiques du MAN, de nous avoir accordé la permission de dater des vestiges d'industrie osseuse. Ceci témoigne de son ouverture d'esprit ainsi que de sa perspicacité à reconnaître l'importance primordiale de choisir des échantillons appropriés aux problématiques envisagées. Les analyses de datation ont été réalisées avec le concours de la fondation des Treilles et du Conseil de recherche en sciences naturelles et en génie du Canada (CRSNG; subvention AIM, «Accès aux installations majeures »). Nous leur en sommes très reconnaissants.

\section{NOTES}

(1) Cet article devait initialement faire l'objet d'une publication dans Antiquités nationales; mais du fait des contraintes éditoriales de cette revue, nous avons opté pour une version abrégée (Pétillon et al., 2008) et proposé à la SPF le texte exhaustif comprenant la partie inédite sur l'art mobilier.

(2) Sept pièces conservées à Saint-Gaudens et publiées par M. Allard et M. Jarry (1993, fig. 10, n 63, et 6 pièces inventoriées p. 69) n'ont pas été retrouvées.

(3) Pour la description de l'industrie en bois de Cervidé, le vocabulaire utilisé est celui qui a été développé par A. Averbouh (2000) et N. Provenzano (2004).

(4) Au sens défini récemment par A. Rigaud (Rigaud, 2007).

(5) Restes dentaires, bois de Cervidé et chevilles osseuses exclus.

(6) «Il reste bien un vide, qui ne pourra être comblé que par la fouille de couches bien datées, dont l'étude reposera sur des analyses précises et des dates qui permettront de les situer avec certitude, dans le "trou" que nous constatons actuellement [...]» (Clottes, 1989, p. 285).

(7) Sur les onze lampes paléolithiques «à manche façonné présentant un décor gravé», huit proviennent de Dordogne et deux de Charente, la dernière étant celle de la grotte des Scilles (Beaune, 1987a). De manière générale, les lampes à manche façonné, décorées ou non, proviennent très majoritairement de Charente et du nord de l'Aquitaine : sur 30 exemplaires recensés, deux seulement se situent dans les Pyrénées, dont celle des Scilles (Beaune, 1987a, p. 85).

(8) Saint-Périer (1926) établissait un parallèle entre l'industrie osseuse de la grotte des Scilles et celle du site pyrénéen de Montconfort (SaintMartory, Haute-Garonne). Après examen du matériel au Muséum d'histoire naturelle de Toulouse (J.-M. P.), il s'avère que l'industrie osseuse de Montconfort se rapporte plus vraisemblablement au Magdalénien moyen.

\section{RÉFÉRENCES BIBLIOGRAPHIQUES}

ALLAIN J., FRITSCH R., RIGAUD A., TROTIGNON F. (1974) - Le débitage du bois de Renne dans les niveaux à raclettes du Badegoulien de l'abri Fritsch et sa signification, in $\mathrm{H}$. Camps-Fabrer dir., Premier colloque international sur l'industrie de l'os dans la Préhistoire, abbaye de Sénanque, avril 1974, CNRS/université de Provence, Aixen-Provence, p. 67-71.

ALLARD M., JARRY M. (1993) - Collection R. et S. de Saint-Périer à Saint-Gaudens (Haute-Garonne), Préhistoire ariégeoise, t. 48, p. 4783.

ALTUNA J., BALDEONA., MARIEZKURRENA K. dir. (1985) - Cazadores magdalenienses en la cueva de Erralla (Cestona, Pais Vasco), Munibe, t. 37, 206 p.

AVERBOUH A. (2000) - Technologie de la matière osseuse travaillée et implications palethnologiques, thèse de doctorat, université Paris IPanthéon-Sorbonne, 2 vol., 500 p.

BARGE-MAHIEU H., TABORIN Y. (1991) - Fiche générale des dents percées, in H. Camps-Fabrer dir., Fiches typologiques de l'industrie osseuse préhistorique, cahier IV : objets de parure, publications de l'université de Provence, Aix-en-Provence, p. 29-36.

BARRAGUÉ E., BARRAGUÉ J., JARRY M., FOUCHER P., SIMONNET R. (2001) - Le silex du flysch de Montgaillard et son exploitation par l'homme préhistorique à Hibarette (Hautes-Pyrénées), Paléo, t. 13, p. $29-51$.

BASTIN A.-H., CHASSAING J. (1940) - Découverte d'une lampe paléolithique à Domme (Dordogne), Bulletin de la Société préhistorique française, t. XXXVII, n 10-12, p. 219-229.

BAZILE F. (2006) - Datations du site de Fontgrasse (Vers-Pont du Gard, Gard). Implications sur la phase ancienne du Magdalénien en France méditerranéenne, Bulletin de la Société préhistorique française, t. $103, \mathrm{n}^{\circ} 3$, p. $597-602$.

BEAUNE S. A. de (1987a) - Lampes et godets au Paléolithique, suppl. à Gallia préhistoire, $\mathrm{n}^{\circ} 23, \mathrm{CNRS}$, Paris, $278 \mathrm{p}$.

BEAUNE S. A. de (1987b) - Palaeolithic lamps and their specialization. A hypothesis, Current anthropology, vol. 28, 4, p. 569-577.

BEAUNE S. A. de (1993) - Approche expérimentale de techniques paléolithiques de façonnage de roches peu aptes à la taille, Paléo, t. 5, p. $155-177$

BEAUNE S. A. de (1997) - Les galets utilisés au Paléolithique supérieur, suppl. à Gallia Préhistoire, n³ 32, CNRS, Paris, 298 p.

BEAUNE S. A. de (2003) - De la domestication du feu aux premières lampes, in L. Chrzanovski dir., Nouveautés lychnologiques/Lychnological news, Lychnoservices, Hauterive, p. 13-20.

BEAUNE S. A. de (2004) - La technologie des hommes préhistoriques, Dossiers d'archéologie, t. 296, p. 26-36.

BEAUNE S. A. de, ROUSSOT A., SACKETT J. (1986) - Les lampes de Solvieux (Dordogne), L'Anthropologie, t. 90, 1, p. 107-119.

BERTRAND A. (1999) - Les armatures de sagaies magdaléniennes en matière dure animale dans les Pyrénées, BAR international series, 773, Archaeopress, Oxford, 139 p.

BEUKENS R.P. (1990) - High-precision intercomparison at IsoTrace, Radiocarbon, vol. 32, 3, p. 335-339.

BEUKENS R.P. (1994) - Procedures and precision in 14C AMS, Nuclear Instruments and Methods in Physics Research, vol. B92, p. 182-187. 
BEUKENS R.P., LEE H.L. (1981) - The production of small carbon samples by R.F. dissociation of acetylene, Symposium on accelerator mass spectrometry. Proceedings, Argonne national laboratory-physics division, Argonne, p. 416-425.

BEUKENS R.P., GURFINKEL D.M., LEE H.W. (1986) - Progress at the IsoTrace radiocarbon facility, Radiocarbon, vol. 28, 2A, p. 229 236.

BON F., CHAUVAUD D., DARTIGUEPEYROU S., GARDÈRE P., MENSAN R. (1996) - La caractérisation du silex de Chalosse, Antiquités nationales, t. 28, p. 33-38.

BOUCHUD J. (1974) - L'origine anatomique des matériaux osseux utilisés dans les industries préhistoriques, in H. Camps-Fabrer dir., Premier colloque international sur l'industrie de l'os dans la Préhistoire, abbaye de Sénanque, avril 1974, CNRS/université de Provence, Aix-en-Provence, p. 21-26.

BREUIL H. (1937) - Les subdivisions du Paléolithique supérieur et leur signification, Congrès international d'anthropologie et d'archéologie préhistoriques. C.R. de la XIV session, Genève 1912, $2^{e}$ édition, complétée et retouchée, office des éditions universitaires, Paris, 78 p.

BROU L., LE BRUN-RICALENS F. (2005) - Productions lamellaires et technocomplexes paléolithiques. Incidences : le Paléolithique supérieur revisité, in F. Le Brun-Ricalens dir., Productions lamellaires attribuées à l'Aurignacien, chaînes opératoires et perspectives technoculturelles, ArchéoLogiques, 1, MNHA, Luxembourg, p. 489-498.

CASTEL J.-C., CHAUVIÈRE F.-X., LHOMME X., CAMUS H (2006) - Un nouveau gisement du Paléolithique supérieur récent : le Petit Cloup Barrat (Cabrerets, Lot, France), Bulletin de la Société préhistorique française, t. $103, \mathrm{n}^{\circ} 2$, p. 263-273.

CAZALS N. (2000) - Constantes et variations des traits techniques et économiques entre le Magdalénien «inférieur» et "moyen» : analyse des productions lithiques du Nord de la péninsule Ibérique, thèse de doctorat, université de Paris I-Panthéon-Sorbonne.

CAZALS N. (2005) - Le début du Magdalénien de part et d'autre des Pyrénées. Quelques réflexions au travers des techniques de taille et des modes d'exploitation des ressources, in J. Jaubert et M. Barbaza dir., Territoires, déplacements, mobilité, échanges durant la Préhistoire, éd. du CTHS, Paris, p. 295-309.

CHADELLE J.-P., GENESTE J.-M., PLISSON H. (1991) - Processus fonctionnels de formation des assemblages technologiques dans les sites du Paléolithique supérieur. Les pointes de projectiles lithiques du Solutréen de la grotte de Combe-Saunière (Dordogne, France), 25 ans d'études technologiques en préhistoire, APDCA, Juan-les-Pins, p. 275-287.

CHAUVIÈRE F.-X., RIGAUD A. (2005) - Les «sagaies» à «base raccourcie» ou les avatars de la typologie : du technique au «non fonctionnel» dans le Magdalénien à navettes de la Garenne (SaintMarcel, Indre), in V. Dujardin dir., Industrie osseuse et parures du Solutréen au Magdalénien en Europe, Mémoire n 34 , Société préhistorique française, Paris, p. 233-242.

CHAUVIÈRE F.-X., CASTEL J.-C., L'HOMME X., CAMUS H., LANGLAIS M., DAULNY L., DEFOIS B., DUCASSE S., MORALA A., RENARD C., TURQ A. (2008) - Ein neuer Fundort aus dem späten Jungpaläolithikum in Südwestfrankreich: Le Petit Cloup Barrat (Cabrerets, Lot), Quartär, t. 55, p. 159-163.

CHOLLOT M. (1964) - Musée des Antiquités nationales, collection Piette, art mobilier préhistorique, Musées nationaux, Paris, 477 p.

CLOTTES J. (1989) - Le Magdalénien des Pyrénées, in J.-P. Rigaud dir., Le Magdalénien en Europe. La structuration du Magdalénien, ERAUL, t. 38, service de Préhistoire, université de Liège, Liège, p. 281-360.

CORCHÓN RODRIGUEZ M.S. (1995) - La Cueva de Las Caldas (Priorio, Oviedo). III. Resultados preliminares de las excavaciones (campañas 1991-1994), Excavaciones arqueológicas en Asturias, 1991-94, p. $45-60$

COSTAMAGNO S. (1999) - Stratégies de chasse et fonction des sites au Magdalénien dans le Sud de la France, thèse de doctorat, université Bordeaux 1, 495 p.
COSTAMAGNO S. (2001) - Exploitation de l'Antilope saïga au Magdalénien en Aquitaine, Paléo, t. 13, p. 111-128.

COUSTÉ R. (1963) - Gisement magdalénien des grottes de Jaurias à Saint-Quentin-de-Baron (Gironde), Bordeaux.

DELPECH F. (1983) - Les faunes du Paléolithique supérieur dans le Sud-Ouest de la France, Cahiers du Quaternaire, ${ }^{\circ}$ 6, CNRS, Paris, $453 \mathrm{p}$.

DELPORTE H., MONS L. (1988) - Fiche sagaie à biseau simple (unifacial), in $\mathrm{H}$. Camps-Fabrer dir., Fiches typologiques de l'industrie osseuse préhistorique, cahier I: sagaies, université de Provence, Aix-en-Provence, fiche 3, $17 \mathrm{p}$.

DUCASSE S., LANGLAIS M. (2007) - Entre Badegoulien et Magdalénien inférieur, nos cœurs balancent... Approche critique des industries lithiques du Sud de la France et du Nord-Est espagnol entre 19000 et 16500 BP, Bulletin de la Société préhistorique française, t. 104, $\mathrm{n}^{\circ} 4$, p. $771-785$

FERUGLIO V. (1992) - Fiche baguettes demi-rondes, in H. CampsFabrer dir., Fiches typologiques de l'industrie osseuse préhistorique, cahier $V$ : bâtons percés, baguettes, CEDARC, Treignes, p. 71-83.

FERUGLIO V. (2003) - Les baguettes demi-rondes, in J. Clottes et H. Delporte dir., La grotte de la Vache (Ariège), I : les occupations du Magdalénien, éd. du CTHS/RMN, Paris, p. 275-284.

FERUGLIO V., BUISSON D. (1999) - Accolements de pièces à section demi-ronde, in M. Julien, A. Averbouh et D. Ramseyer dir., Préhistoire d'os, recueil d'études sur l'industrie osseuse préhistorique offert à Henriette Camps-Fabrer, publications de l'université de Provence, Aix-en-Provence, p. 143-149.

FOUCHER P. (2007) - Les territoires solutréens des Pyrénées-Cantabres, d'après les armatures foliacées et la circulation des matières premières, in N. Cazals, J. González Urquijo et X. Terradas dir., Frontières naturelles et frontières culturelles dans les Pyrénées préhistoriques/ Fronteras naturales y fronteras culturales en los Pirineos prehistóricos, PubliCan, ediciones de la universidad de Cantabria, Santander, p. 279-299.

FULLOLA J.M. (2001) - Recherches sur le Paléolithique supérieur dans le Nord-Est ibérique : la Catalogne (1996-2000), Le Paléolithique supérieur européen. Bilan quinquennal 1996-2001, XIVE congrès IUSPP, commission VIII, Liège, 2001, ERAUL, t. 97, p. 141-148.

GLORY A. (1961) - Le brûloir de Lascaux, Bulletin de la Société d'études et de recherches préhistoriques et Institut pratique de Préhistoire, Les Eyzies, t. 10, p. 92-97.

GOUTAS N. (2004) - Caractérisation et évolution du Gravettien en France par l'analyse techno-économique des industries en matières osseuses, thèse de doctorat, université Paris I-Panthéon-Sorbonne, 2 vol., $680 \mathrm{p}$

HEDGES R.E.M. (1992) - Sample treatment strategies in radiocarbon dating, in R.E. Taylor, A. Long et R.S. Kra dir., Radiocarbon after four decades: an interdisciplinary perspective, Springer-Verlag, New York, p. 165-183.

LACOMBE S. (1998) - Préhistoire des groupes culturels au Tardiglaciaire dans les Pyrénées centrales. Apports de la technologie lithique, thèse de doctorat, université de Toulouse II-Le Mirail, $385 \mathrm{p}$.

LACOMBE S. (2005) - Territoires d'approvisionnement en matières premières lithiques au Tardiglaciaire. Remarques à propos de quelques ensembles pyrénéens, in J. Jaubert et M. Barbaza dir., Territoires, déplacements, mobilité, échanges durant la Préhistoire, éd. du CTHS, Paris, p. 329-353.

LADIER E. (2000) - Le Magdalénien ancien à lamelles à dos de l'abri Gandil à Bruniquel (Tarn-et-Garonne) : étude préliminaire de l'industrie de la C.20, in G. Pion dir., Le Paléolithique supérieur récent: nouvelles données sur le peuplement et l'environnement, Mémoire $\mathrm{n}^{\circ} 28$, Société préhistorique française, Paris, p. 191-200.

LANGLAIS M. (2007a) - Dynamiques culturelles des sociétés magdaléniennes dans leurs cadres environnementaux. Enquête sur 7000 ans d'évolution de leurs équipements lithiques, thèse de doctorat, université de Toulouse II-Le Mirail et université de Barcelone, 550 p. 
LANGLAIS M. (2007b) - Des identités qui se cherchent... Apports des industries lithiques à la question de l'origine du Magdalénien moyen dans le Sud-Ouest européen, Bulletin de la Société préhistorique française, t. $104, \mathrm{n}^{\circ} 4$, p. $759-770$.

LANGLAIS M. (2008) - Chronologie et territoires au Magdalénien entre le Rhône et l'Èbre : l'exemple des armatures lithiques, in J.-M. Pétillon, M.-H. Dias-Meirinho, P. Cattelain, M. Honegger, C. Normand et N. Valdeyron dir., Recherches sur les armatures de projectiles du Paléolithique supérieur au Néolithique, Palethnologie, 1, p. 220-249, www.palethnologie.org/revue.php?numero $=1 \&$ partie $=1$

LANGLAIS M. (sous presse) - La pluralité des productions microlamellaires du Magdalénien inférieur entre le Rhône et l'Èbre (1750015000 BP), in N. Teyssandier, P. Bodu, M.-I. Cattin, L. Klaric et L. Slimak dir., Les productions lamellaires au Paléolithique moyen et supérieur, une perspective diachronique, $X V^{e}$ congrès de l'IUSPP. colloque 86, Lisbonne, septembre 2006, BAR.

LANGLAIS M., LADIER E., CHALARD P., JARRY M., LACRAMPECUYAUBÈRE F. (2007) - Aux origines du Magdalénien quercinois les industries de la séquence inférieure de l'abri Gandil (Bruniquel, Tarn-et-Garonne), Paléo, t. 19, p. 341-366.

LE BRUN-RICALENS F. (2005) - Chronique d'une reconnaissance attendue. Outils «carénés », outils «nucléiformes » : nucléus à lamelles. Bilan après un siècle de recherches typologiques, technologiques et tracéologiques, in F. Le Brun-Ricalens dir., Productions lamellaires attribuées à l'Aurignacien, chaînes opératoires et perspectives technoculturelles, ArchéoLogiques, 1, MNHA, Luxembourg, p. 23-72.

LEGRAND A. (2000) - Vers une identification technologique et fonctionnelle des outils biseautés en matière osseuse. Le site magdalénien de la Garenne Saint-Marcel (Indre), mémoire de DEA, université Paris I-Panthéon-Sorbonne, 2 vol., 51 p. + annexes.

LENOIR M., MARMIER F., TRÉCOLLE G. (1991) - Données nouvelles sur les industries de Saint-Germain-la-Rivière (Gironde), 25 ans d'études technologiques en Préhistoire, $X I^{\text {es }}$ rencontres internationales d'Archéologie et d'Histoire d'Antibes, éd. APDCA, Juan-les-Pins, p. 245-254.

LIOLIOS D. (1999) - Variabilité et caractéristiques du travail des matières osseuses au début de l'Aurignacien, thèse de doctorat, université de Paris X-Nanterre, $352 \mathrm{p}$.

LONGIN R. (1971) - New method of collagen extraction for radiocarbon dating, Nature, vol. 230, p. 241-242.

MANGADO J., MERCADAL O, FULLOLA J M., ESTÈVE X, LANGLAIS M., NADAL J., ESTRADA A., SANCHEZ E., LACRUZ S. GRIMAO J. (2005) - Montlleó (Prats i Sansor, La Cerdanya). El primer jaciment magdalenía a l'aire lliure en altitud al cor dels pirineus, in N. Ferreira dir., O Paleolitico, Actas do IV Congresso de Arqueologia Peninsular, Promontoria monografica, universidade do Algarbe, Faro, p. 471-480.

MERLET J.-C. (2005) - Le Badegoulien et le Magdalénien ancien dans le bassin de l'Adour : un état de la question, Archéologie des Pyrénées occidentales et des Landes, t. 24, p. 103-118.

MÉROC L. (1947) - Le silex dans le bassin sous-pyrénéen de la Garonne et son emploi par l'homme préhistorique, Bulletin de la Société archéologique du Midi de la France, t. 5, p. 234-250.

MORALA A. (1984) - Périgordien et Aurignacien en Haut-Agenais. Étude d'ensembles lithiques, Archives d'écologie préhistorique, $\mathrm{n}^{\circ} 7$, EHESS, Toulouse, $140 \mathrm{p}$.

NORMAND C. (1986) - Inventaire des gîtes à silex de la Chalosse (1984-1985), Bulletin de la Société de Borda, t. 402, p. 132-140.

PATOU-MATHIS M. dir. (2002) - Fiches de la commission de nomenclature sur l'industrie de l'os préhistorique, cahier $X$ : retouchoirs, compresseurs, percuteurs... Os à impressions et éraillures, Société préhistorique française, Paris, $136 \mathrm{p}$.

PELEGRIN J., O'FARRELL M. (2005) - Les lamelles retouchées ou utilisées de Castanet, in F. Le Brun-Ricalens dir., Productions lamellaires attribuées à l'Aurignacien, chaînes opératoires et perspectives technoculturelles, ArchéoLogiques, 1, MNHA, Luxembourg, p. 103121.
PÉTILLON J.-M. (2004) - Lecture critique de la stratigraphie magdalénienne de la grande salle d'Isturitz (Pyrénées-Atlantiques), Antiquités nationales, t. 36, p. 105-131.

PÉTILLON J.-M. (2006) - Des Magdaléniens en armes. Technologie des armatures de projectile en bois de Cervidé du Magdalénien supérieur de la grotte d'Isturitz (Pyrénées-Atlantiques), Artefacts, 10 CEDARC, Treignes, $302 \mathrm{p}$.

PÉTILLON J.-M., AVERBOUH A. (à paraître) - Le travail du bois de Renne dans les couches badegouliennes, in J. Clottes, J.-P. Giraud et P. Chalard dir., Diversités et identités des groupes solutréens et badegouliens en Quercy. L'exemple de l'abri du Cuzoul de Vers (Lot), ERAUL, Service de préhistoire, université de Liège, Liège.

PÉTILLON J.-M., SACCHI D. (à paraître) - L'industrie osseuse, in D. Sacchi, J.-L. Brulé et S. Ducasse dir., La station badegoulienne de Lassac à Sallèles-Cabardès (Aude). Le locus 1, GAEP, Carcassonne.

PÉTILLON J.-M., LANGLAIS M., BEAUNE S. A. de, CHAUVIÈRE F.-X., LETOURNEUX C., SZMIDT C., BEUKENS R., DAVID F. (2008) - Le Magdalénien de la grotte des Scilles (Lespugue, Haute-Garonne), premiers résultats de l'étude pluridisciplinaire de la collection Saint-Périer, Antiquités nationales, t. 39, p. 57-71.

PEYRONY D. (1950) - L'industrie de la grotte de Lascaux, Bulletin de la Société préhistorique française, t. XLVII, n 3-4, p. 135-137.

PINÇON G. (1988) - Fiche sagaie de Lussac-Angles, in H. Camps-Fabrer dir., Fiches typologiques de l'industrie osseuse préhistorique, cahier I : sagaies, université de Provence, Aix-en-Provence, fiche 3bis, 7 p.

PRIMAULT J., BROU L., GABILLEAU J., LANGLAIS M. et coll. (2007) - La grotte du Taillis des Coteaux à Antigny (Vienne) : intérêts d'une séquence originale à la structuration des premiers temps du Magdalénien, Bulletin de la Société préhistorique française, t. 104, $\mathrm{n}^{\circ} 4$, p. 743-758.

PROVENZANO N. (2004) - Fiche Terminologie du travail des matières osseuses, du Paléolithique aux Âges des métaux, in D. Ramseyer dir., Industrie de l'os préhistorique, cahier XI : matières et techniques, Société préhistorique française, Paris, p. 29-37.

REIMER P., BAILLIE M.G.L., BARD É., BAYLISS A., BECK J.W., BERTRAND C.J.H., BLACKWELL P.G., BUCK C.E., BURR G.S., CUTLER K.B., DAMON P.E., EDWARDS R.L., FAIRBANKS R.G., FRIEDRICH M., GUILDERSON T.P., HOGG A.G., HUGHEN K.A., KROMER B., MCCORMAC G., MANNING S., BRONK RAMSEY C., REIMER R.W., REMMELE S., SOUTHON J.R., STUIVER M., TALAMO S., TAYLOR F.W., VAN DER PLICHT J., WEYHENMEYER C.E. (2004) - INTCAL04 Terrestrial radiocarbon age calibration, 0-26 cal kyr BP, Radiocarbon, vol. 46, 3, p. 1029 1058

RIGAUD A. (2004) - Fiche transformation du bois de Renne au Badegoulien. L'exemple de l'abri Fritsch (Indre, France), in D. Ramseyer dir., Industrie de l'os préhistorique, cahier XI : matières et techniques, Société préhistorique française, Paris, p. 75-78.

RIGAUD A. (2006) - Étude technologique des baguettes demi-rondes de Labastide (Hautes-Pyrénées), Archéologie des Pyrénées occidentales et des Landes, t. 25, p. 229-246.

RIGAUD A. (2007) - Retouchoirs sur éclats diaphysaires ou «affûtoirs » de Labastide (Hautes-Pyrénées). Du barbarisme scientifique à la rigueur artisanale au travers de l'expérimentation, Archéologie des Pyrénées occidentales et des Landes, t. 26, p. 193-200.

SAINT-PÉRIER R. de (1912) - La grotte des Bœufs à Lespugue (HauteGaronne). Magdalénien, Bulletin de la Société préhistorique française, t. IX, p. 3-22.

SAINT-PÉRIER R. de (1920) - La grotte des Harpons à Lespugue (Haute-Garonne), L'Anthropologie, t. 30, n 3-4, p. 209-234.

SAINT-PÉRIER R. de (1924) - Les fouilles de 1923 dans la grotte des Rideaux à Lespugue (Haute-Garonne), L'Anthropologie, t. 34, $\mathrm{n}^{\circ} 1-2$, p. 1-15.

SAINT-PÉRIER R. de (1926) - La grotte des Scilles à Lespugue (HauteGaronne), L'Anthropologie, t. 36, p. 15-40. 
SAINT-PÉRIER R. de (1927) - La Grotte de Gouërris à Lespugue, L'Anthropologie, t. 37, p. 233-276.

SÉRONIE-VIVIEN M., SÉRONIE-VIVIEN M.-R. (1987) - Les silex du Mésozö̈que nord-aquitain. Approche géologique de l'étude des silex pour servir à la recherche préhistorique, suppl. au t. $15 \mathrm{du}$ Bulletin de la Société linnéenne de Bordeaux, Bordeaux, 136 p.

SÉRONIE-VIVIEN M., SÉRONIE-VIVIEN M.-R., FOUCHER P. (2006) L'économie du silex au Paléolithique supérieur dans le bassin d'Aquitaine. Le cas des silex à lepidorbitoïdes des Pyrénées centrales. Caractérisation et implications méthodologiques, Paléo, t. 18, p. 193-216.

SIMONNET R. (1973) - Le Paléolithique supérieur entre l'Hers et la Garonne, Préhistoire et Protohistoire des Pyrénées françaises, Musée pyrénéen, Lourdes, p. 39-44.

SIMONNET R. (1976) - Les gisements préhistoriques des gorges de la Save dans le massif de Lespugue-Montmaurin, in J. Clottes dir. UISPP, XI $I^{e}$ congrès, livret-guide de l'excursion A5, Pyrénées, éd. UISPP, Nice, p. 117-122.

SIMONNET R. (1981) - Carte des gîtes à silex des pré-Pyrénées, $L a$ Préhistoire en Quercy dans le contexte de Midi-Pyrénées, Congrès préhistorique de France, compte rendu de la $21^{e}$ session, Quercy, Montauban-Cahors, 3-9 septembre 1979, Société préhistorique française, Paris, p. 308-323.

SIMONNET R. (1996) - Approvisionnement en silex au Paléolithique supérieur : déplacements et caractéristiques physionomiques des paysages, l'exemple des Pyrénées centrales, in H. Delporte et J. Clottes dir., Pyrénées préhistoriques, arts et sociétés, éd. du CTHS, Paris, p. $117-128$.

SIMONNET R. (1998) - Le silex et la fin du Paléolithique supérieur dans le bassin de Tarascon-sur-Ariège, Préhistoire ariégeoise, t. 53, p. $181-222$.

SIMONNET R. (1999) - De la géologie à la Préhistoire. Le silex des pré-Pyrénées. Résultats et réflexions sur les perspectives et les limites de l'étude des matières premières lithiques, Paléo, t. 11, p. 71-88.

SIMONNET R. (2007a) - Le silex «grains de mil». Localisation des gîtes, in N. Cazals, J. González Urquijo et X. Terradas dir., Frontières naturelles et frontières culturelles dans les Pyrénées préhistoriques/ Fronteras naturales y fronteras culturales en los Pirineos prehistóricos, PubliCan, ediciones de la universidad de Cantabria, Santander, p. $101-102$

SIMONNET R. (2007b) - Du silex des Pyrénées centrales aux Magdaléniens à Labastide, in N. Cazals, J. González Urquijo et X. Terradas dir., Frontières naturelles et frontières culturelles dans les Pyrénées préhistoriques/Fronteras naturales y fronteras culturales en los Pirineos prehistóricos, PubliCan, ediciones de la universidad de Cantabria, Santander, p. 93-100.

STRAUS L.G., GONZALEZ MORALES M. (2005) - El Magdaleniense de la Cueva del Miron (Ramales de la Victoria, Cantabria, Espana): observaciones preliminares, in N. Ferreira dir., O Paleolitico, Actas do IV Congresso de Arqueologia Peninsular, Promontoria monografica, universidade do Algarve, Faro, p. 49-62.

TABORIN Y. (1993) - La parure en coquillage au Paléolithique, suppl. à Gallia préhistoire, n 29 , éd. du CNRS, Paris, 538 p.

TABORIN Y. (1995) - La parure préhistorique, Archéologia, t. 312, p. $69-70$.

TABORIN Y. (2004) - Langage sans parole. La parure aux temps préhistoriques, La Maison des roches, Paris, 216 p.

TABORIN Y., THIÉBAULT S. (1994) - Scilles (grotte des), in A. LeroiGourhan dir., Dictionnaire de la Préhistoire, PUF, Paris, p. 996.

TURQ A. (2000) - Paléolithique inférieur et moyen entre Dordogne et Lot, suppl. à Paléo, n 2, éd. SAMRA, Les Eyzies, 456 p.

UTRILLA P. (1990) - Bases objectives de la chronologie de l'art mobilier paléolithique sur la côte cantabrique, in J. Clottes dir., L'Art des objets au Paléolithique, 1 : l'art mobilier et son contexte, Actes de colloques de la Direction du patrimoine, 8, Direction du patrimoine, Paris, p. 87-99.
UTRILLA P (2006) - Evolución histórica de las sociedades cantábricas durante el Tardiglacial: El Magdaleniense inicial, inferior y medio (16500-13000 BP), in M.A. Fano dir., Las Sociedades del Paleolítico en la Región Cantábrica. De los orígenes del poblamiento en el Pleistoceno medio al inicio del Neolítico en el V milenio, Diputación Foral de Bizkaia, Bilbao, p. 245-276.

UTRILLA P., MONTES L. (2007) - La période 19000-14000 BP dans le bassin de l'Èbre, Bulletin de la Société préhistorique française, t. $104, n^{\circ} 4$, p. $797-807$.

VIALOU D. (2004) - Lespugue, in D. Vialou dir., La Préhistoire. Histoire et dictionnaire, coll. Bouquins, éd. Robert Laffont, Paris, p. 851852.

VIRÉ A. (1934) - Les lampes du quaternaire moyen et leur bibliographie, Bulletin de la Société préhistorique française, t. XXXI, p. 517520

WEBER A., McKENZIE H.G., BEUKENS R.P., GORIUNOVA O.I. (2005) - Evaluation of radiocarbon dates from the Middle Holocene hunter-gatherer cemetery Khuzhir-Nuge XIV, Lake Baikal, Siberia, Journal of archaeological Science, vol. 32, p. 1481-1500.

Mathieu LANGLAIS

CNRS, UMR 5199 PACEA

Université Bordeaux 1

Avenue des facultés, B18 33405 Talence Cedex m.langlais@ipgq.u-bordeaux1.fr

Jean-Marc PÉTILLON

CNRS, UMR 5608 TRACES

Maison de la recherche 5, allées A. Machado 31058 Toulouse petillon@univ-tlse2.fr

Sophie A. de BEAUNE Université Jean Moulin-Lyon III UMR 7041 ArScAn

Maison René Ginouvès 21, allée de l'Université 92023 Nanterre Cedex sophie.de-beaune@mae.u-paris10.fr

Pierre CATTELAIN

Université libre de Bruxelles/ CEDARC Musée du Malgré-Tout Écomusée du Viroin - ASBL Dire 81 , rue de la Gare 5670 Treignes, Belgique pierre.cattelain@ulb.ac.be

François-Xavier CHAUVIÈRE Institut de préhistoire et des sciences de l'Antiquité, université de Neuchâtel Université Jean Moulin-Lyon III Office et musée d'Archéologie Laténium, espace Paul Vouga CH-2068 Hauterive, Suisse francois-xavier.chauviere@unine.ch 
Claire LETOURNEUX

Max-Planck Institute for Evolutionary Anthropology

Department of Human Evolution

Deutscher Platz, 6, D-04103 Leipzig claire.letourneux@eva.mpg.de

Carolyn SZMIDT

IsoTrace Accelerator Mass Spectrometry Laboratory, University of Toronto 60, St. George Street, Toronto, Ontario, M5S 1A7 Canada Et Archaeology Centre, University of Toronto 19, Russell Street, Toronto, Ontario, M5S 2S2 Canada c.szmidt@utoronto.ca
Claire BELLIER

CEDARC Musée du Malgré-Tout 28, rue de la Gare, 5670 Treignes, Belgique claire.bellier@skynet.be

Roelf BEUKENS

IsoTrace Accelerator Mass Spectrometry

Laboratory, University of Toronto 60, St. George Street, Toronto, Ontario M5S 1A7 Canada

Francine DAVID CNRS, UMR 7041 ArScAn Maison René Ginouvès 21, allée de l'Université, 92023 Nanterre Cedex francine.david@mae.u-paris10.fr 